Florida International University

FIU Digital Commons

$6-29-2020$

\title{
Isolating Critical Components of a Pediatric Obesity Intervention: Does it Really Take a Village?
}

Jennifer Coto

Florida International University, jhern451@fiu.edu

Follow this and additional works at: https://digitalcommons.fiu.edu/etd

Part of the Health Psychology Commons

\section{Recommended Citation}

Coto, Jennifer, "Isolating Critical Components of a Pediatric Obesity Intervention: Does it Really Take a Village?" (2020). FIU Electronic Theses and Dissertations. 4480.

https://digitalcommons.fiu.edu/etd/4480

This work is brought to you for free and open access by the University Graduate School at FIU Digital Commons. It has been accepted for inclusion in FIU Electronic Theses and Dissertations by an authorized administrator of FIU Digital Commons. For more information, please contact dcc@fiu.edu. 


\title{
FLORIDA INTERNATIONAL UNIVERSITY
}

Miami, Florida

\section{ISOLATING CRITICAL COMPONENTS OF A PEDIATRIC OBESITY INTERVENTION: DOES IT REALLY TAKE A VILLAGE?}

\author{
A dissertation submitted in partial fulfillment of \\ the requirements for the degree of \\ DOCTOR OF PHILOSOPHY \\ in \\ PSYCHOLOGY \\ by \\ Jennifer Coto
}

2020 
To: Dean Michael R. Heithaus

College of Arts, Sciences and Education

This dissertation, written by Jennifer Coto, and entitled Isolating Critical Components of a Pediatric Obesity Intervention: Does it Really Take a Village?, having been approved in respect to style and intellectual content, is referred to you for judgment.

We have read this dissertation and recommend that it be approved.

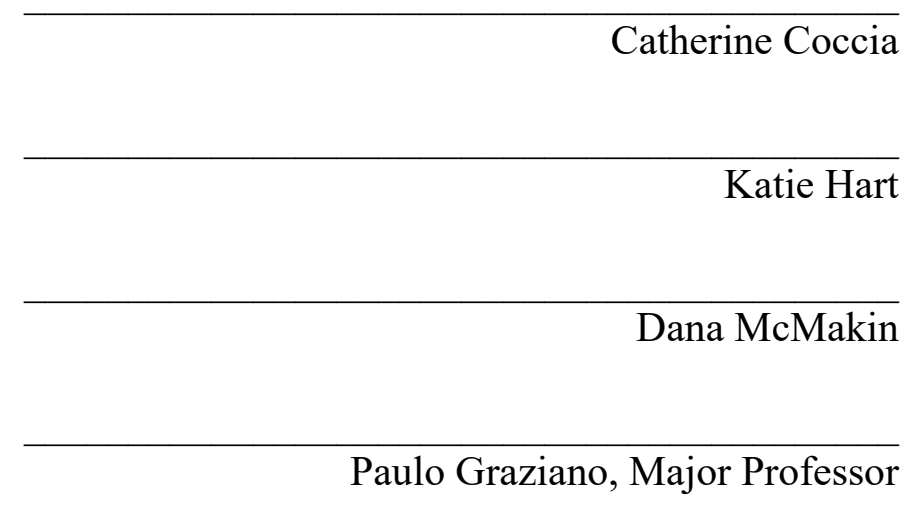

Date of Defense: June 29, 2020

The dissertation of Jennifer Coto is approved.

Dean Michael R. Heithaus College of Arts, Sciences and Education

Andrés G. Gil Vice President for Research and Economic Development and Dean of the University Graduate School

Florida International University, 2020 
(C) Copyright 2020 by Jennifer Coto

All rights reserved. 


\section{DEDICATION}

To my loving husband, amazing daughters, and wonderful family for all their unconditional love and support. 


\section{ACKNOWLEDGMENTS}

First, I would like to thank my mother and father for always encouraging and supporting me in every way possible. Next, my brother, for being an amazing role model and best friend. Most importantly, my husband, David, thank you for always being my rock and teammate. I could not have done any of this without you. To my intelligent, beautiful, and spirited daughters, Mackenzie and Madison, thank you for being my ongoing inspiration. I can't wait to see how you will both change the world. Also, to my mentor, Dr. Paulo Graziano, who believed in me and always pushed me for excellence. Thank you for being an amazing mentor and allowing me to be part of your lab family. Thank you to my committee members, Drs. Coccia, Hart, and McMakin for their invaluable feedback and support. I would also like to acknowledge the families who participated in my studies, the Town of Miami Lakes for their support, and my fellow lab mates for all their help and advice. 


\title{
ABSTRACT OF THE DISSERTATION \\ ISOLATING CRITICAL COMPONENTS OF A PEDIATRIC OBESITY \\ INTERVENTION: DOES IT REALLY TAKE A VILLAGE?
}

\author{
by \\ Jennifer Coto \\ Florida International University, 2020 \\ Miami, Florida \\ Professor Paulo Graziano, Major Professor
}

The current work examined healthy lifestyle interventions in different settings and their associated child and parent outcomes. Specifically, the first study examined, via a randomized trial, the efficacy of the Healthy Lifestyle Summer Camp and Parenting program (HLSC+HLPP) compared to the Health Lifestyle Summer Camp (HLSC) on improving child and parent health outcomes as well as mechanistic outcomes. Various anthropometric, fitness, nutrition, home environment, and parenting outcomes were collected for both children and their parent pre- and post-intervention. Results indicated that both HLSC+HLPP and HLSC were feasible and acceptable. There were no statistically significant differences between groups, however, both groups did demonstrate improvement. Specifically, there was a decrease in child Body Mass Index (BMI) z-score and increase in child fitness and parental monitoring after the intervention for both groups. Moreover, there were improvements in nutrition in HLSC+HLPP and improvements in physical activity and parenting stress in HLSC. These findings highlight the feasibility, acceptability, and improvement of child health outcomes after both the HLSC+HLPP and HLSC. Future research should examine group differences during a 
follow-up period. Utilizing an open trial, the second study examined the feasibility, acceptability, and initial promise of implementing the Healthy Lifestyle Parenting Program (HLPP) within a community setting. Measures were identical to that of Study One. Findings indicated that the HLPP was feasible and highly acceptable among participating families. Improvements were found in child nutrition knowledge and family frequency of sedentary activity. Additionally, $50 \%$ of children showed clinically significant changes in BMI z-score. These findings highlight that a parent-based obesity intervention implemented in a community setting may contribute to positive health changes in children. However, given recruitment and retention difficulties noted, finding convenient ways for families to participate is of utmost importance. 


\section{TABLE OF CONTENTS}

CHAPTER

PAGE

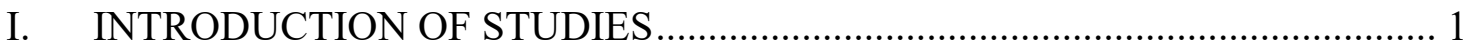

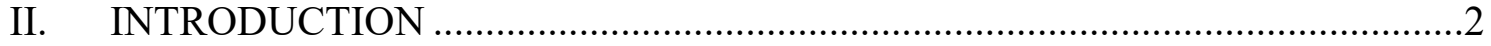

Prevalence and Public Health Impact of Obesity .................................................2

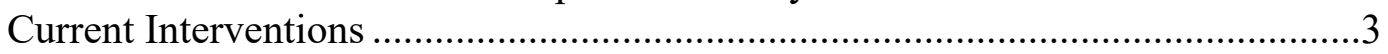

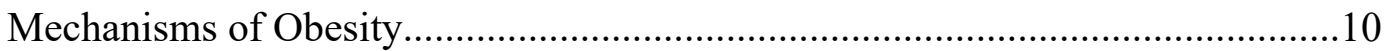

Study 1: The Current Study ............................................................................16

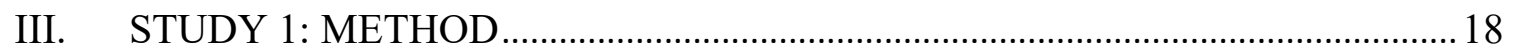

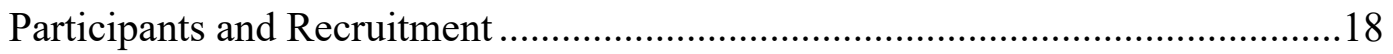

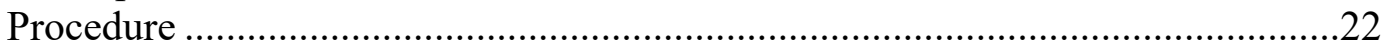

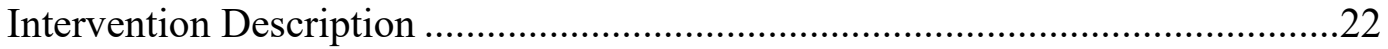

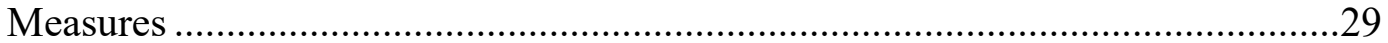

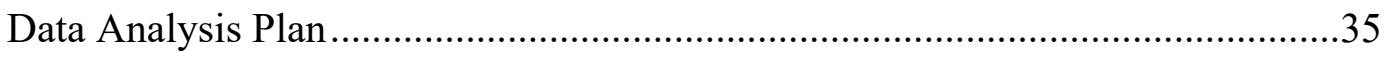

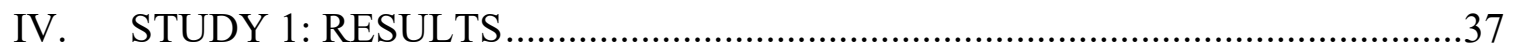

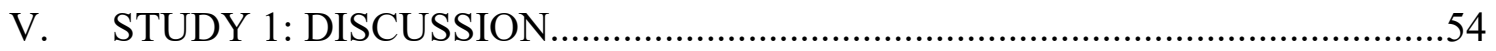

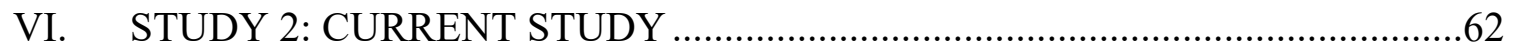

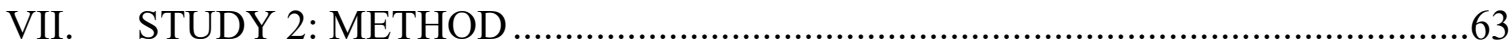

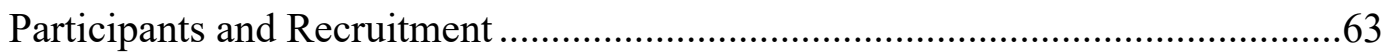

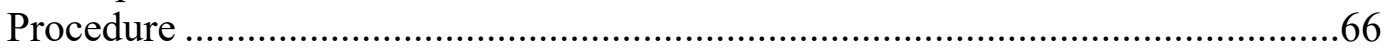

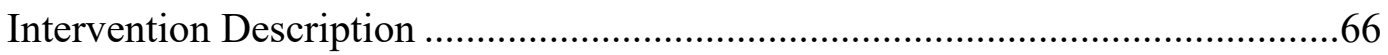

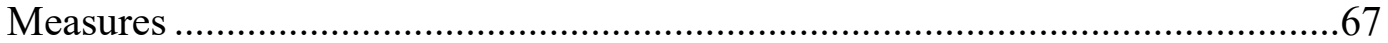

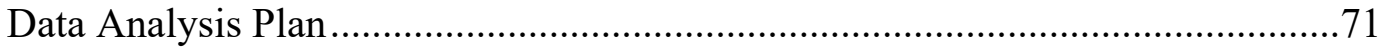

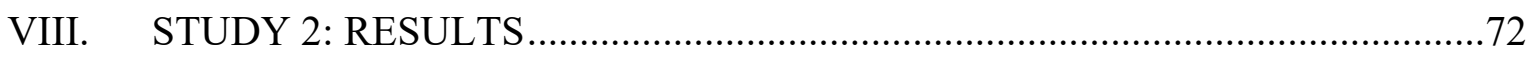

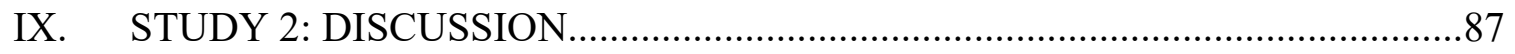

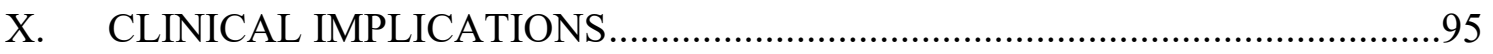

LIST OF REFERENCES ....................................................................................99

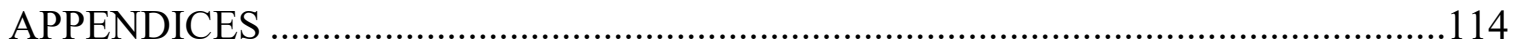

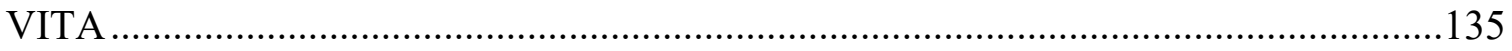




\section{LIST OF TABLES}

TABLES

PAGE

1. Study One: Participant Demographic Variables ........................................... 21

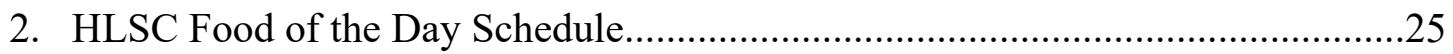

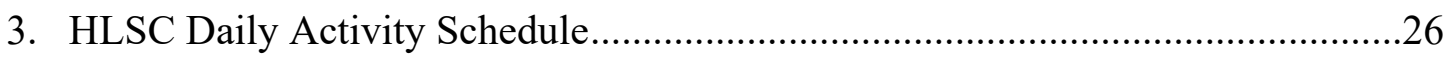

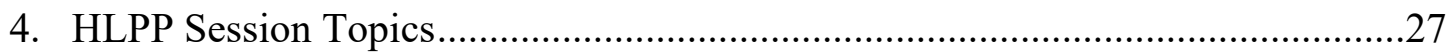

5. Study One: Correlations: Demographics and Health Outcomes............................38

6. Study One: Correlations: Demographics and Nutrition Outcomes.......................39

7. Study One: Correlations: Demographics, Physical Activity, and Home Environment Outcomes ...........................................................................4

8. Study One: Correlations: Demographics and Parenting Outcomes......................42

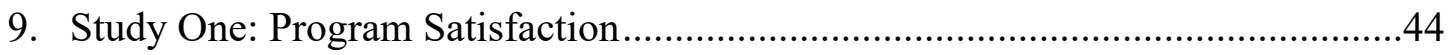

10. Study One: Results: Main Health Outcomes .................................................46

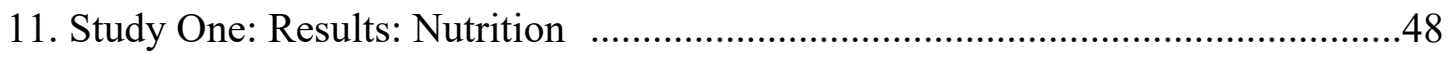

12. Study One: Results: Physical Activity, Home Environment, Parenting ................52

13. Study Two: Participant Demographic Variables .............................................65

14. Study Two: Correlations: Demographics and Health Outcomes .........................73

15. Study Two: Correlations: Demographics and Nutrition Outcomes.......................74

16. Study Two: Correlations: Demographics, Physical Activity, and Home

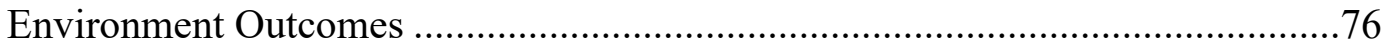

17. Study Two: Correlations: Demographics and Parenting Outcomes ..................... 77

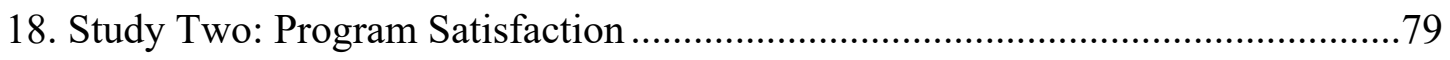

19. Study Two: Results Main Health Outcomes.................................................... 81

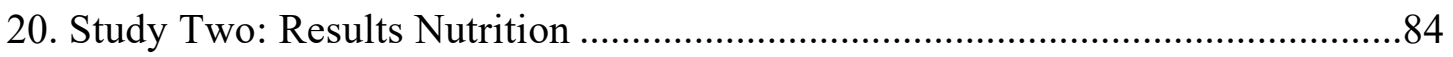

21. Study Two: Results Physical Activity, Home Environment, Parenting ................86 


\section{LIST OF FIGURES}

FIGURES

PAGE

1. Study One and Two CONSORT Flow Diagram............................................ 20

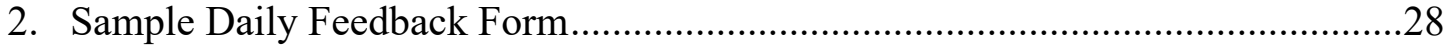

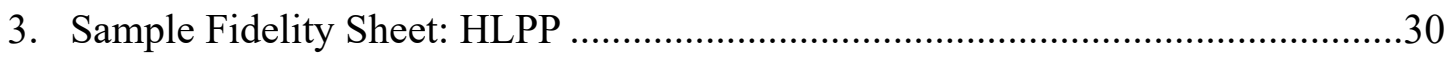

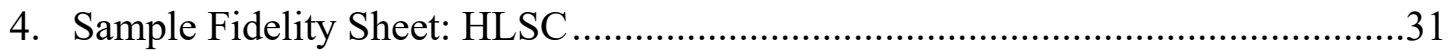

5. Study Two: Clinically Significant Change: Child BMI z-score and Parent BMI ..82 


\section{INTRODUCTION OF STUDIES}

The current dissertation project consisted of two studies focusing on healthy lifestyle interventions in different settings and the improvement of child and parent outcomes following the interventions.

The first study used a randomized trial design to examine the efficacy of the Healthy Lifestyle Summer Camp and Parenting program (HLSC+PP) compared to the Health Lifestyle Summer Camp (HLSC) on improving child and parent health outcomes as well as mechanistic outcomes (e.g., family home environment, family healthy habits, parenting strategies, and feeding practices).

Utilizing an open trial, the second study examined the feasibility, acceptability, and initial promise of implementing the Healthy Lifestyle Parenting Program (HLPP) within a community setting. 


\section{INTRODUCTION}

Prevalence and Public Health Impact of Obesity

Pediatric obesity represents a significant public health concern, with

epidemiological research indicating that $31.8 \%$ of children between the ages of two and 19 years are overweight (Body mass index $[\mathrm{BMI}]$ between the $85^{\text {th }}$ and $95^{\text {th }}$ percentile) or obese (BMI $\geq 95^{\text {th }}$ percentile age and sex; Ogden et al., 2014). Rates of pediatric obesity are especially high among children from underrepresented racial and ethnic minority backgrounds, with recent estimates as high as $38.9 \%$ (Ogden et al., 2014). Hispanic children between the ages of 6-and-11-years old are particularly affected with the prevalence rates of overweight and obesity at $46.2 \%$ compared to $29.4 \%$ for non-Hispanic white children (Ogden et al., 2014). Furthermore, previous research has noted that obese Hispanic children have more metabolic problems (e.g., insulin resistance, elevated liver enzymes) compared to obese white children (Goran et al., 2002; Schwimmer et al., 2005).

In addition to its considerable increase in prevalence over the past decade (Ogden et al., 2012), pediatric obesity is associated with a variety of health problems, including increased risk for metabolic syndrome, cardiovascular disease, skeletal abnormalities, pulmonary problems, and psychosocial difficulties (Daniels, 2006; Stradmeijer et al., 2000). Furthermore, children who are obese are more likely to require health services in comparison to children who are at a healthy weight (Cuttler et al., 2008). As a result, annual direct costs of pediatric obesity are estimated at $\$ 13.37$ billion nationally (Biener et al.,2017), and costs are predicted to increase due to the high stability of pediatric obesity into adulthood (Whitaker et al., 1997; Deshmukh-Taskar et al., 2006; Ward et al., 2017). 
In an effort to help reduce the rates of obesity among children, numerous interventions have been created including parent-, child-, and family-based approaches. Previous work has identified parents as a mechanism of change, suggesting that parental involvement in a pediatric obesity treatment is key in producing lasting changes in the child (Hesketh \& Campbell, 2010; Resnicow et al., 2015). The Familial Approach to the Treatment of Childhood Obesity: Conceptual Model (Golan and Weizman, 2001) posits that changes in child weight status are achieved by parental cognitive and behavioral change (e.g., enhancing knowledge about nutrition, increasing parenting self-efficacy) as well as environmental change (e.g., creating opportunities for physical activities).

\section{Current Interventions}

Parent-based Interventions. Parent-based obesity interventions target the parent as the agent of change for intervening on their child's health outcomes. The interventions can be group-based or individual, involve different treatment content (e.g., nutrition and physical activity education, behavioral management strategies), range in length (nine weeks-four years), and include varying ages (3-17 years of age; Niemeier et al., 2012; Skouteris et al., 2011). While parent-based obesity interventions are available for both children and adolescents, the focus of the current study is on elementary school age children, given the potential greater role of parents in this age group. For a review of parent-based interventions that includes older children, please see Niemeier et al., 2012.

Parent-based obesity interventions have demonstrated positive health outcomes for children (Hingle et al., 2010; Mazzeo et al., 2014). Specifically, the High 5 for Preschool Kids (H5-KIDS) program showed improvements in child fruit and vegetable intake when the parents improved their own fruit and vegetable intake (Haire-Joshu et al., 2008). Also, a 
motivational interviewing intervention conducted over two years by primary care providers and registered dietitians aimed at parents of children ages two-to-eight years who were overweight, demonstrated a statistically significant BMI percentile reduction in children in the intervention group compared to usual care (Resnicow et al., 2015). Similarly, Golan, Kaufman, \& Shahar (2006), found that a 12-session parent-based intervention led to greater improvements in child BMI compared to the combined parent and child group. However, the aforementioned parent and child intervention did not include components specific for children and therefore it is questionable whether this could be classified as a true parent and child intervention. Additionally, a 10-week parenting intervention for parents of children four-to-six years of age demonstrated that a parent-only treatment had a greater reduction in BMI z-score than their standard family treatment (parent and child attended two individual visits with a pediatrician and two visits with a pediatric nurse over the course of 12 months; Ek et al., 2019). Also, Janicke et al. (2008) demonstrated similar improvements in children 8-to-14-years of age at 10-month follow-up after a 16-week obesity intervention in both a parent-only intervention and family-based intervention compared to a control group.

Furthermore, a systematic review of obesity interventions during the preschool period concluded that modifying parental variables might be beneficial in obesity prevention (Skouteris et al., 2011). Similarly, a systematic review of parent-only pediatric obesity interventions in children aged 5-11 years concluded that parent-only interventions are an effective treatment option when compared with a wait list control (Loveman et al., 2015). However, these reviews both noted methodological limitations in the studies, including insufficient follow-up analyses, and called for properly designed longitudinal 
studies. Further limitations of parent-based interventions include timely intervention length, small sample sizes, and poor attrition (Niemeier et al., 2012; Ek et al., 2019; Loveman et al., 2015). Thus, there is still a considerable amount of research to be conducted to clarify the role of parents in reducing pediatric obesity. A reasonable alternative would be to focus on the child in an obesity intervention.

\section{Child-based Interventions}

Camp Interventions. On the opposite continuum of parent-based interventions are child-based interventions, which can occur in numerous settings (e.g., camp, school, afterschool) and can include a combination of treatment components. Specifically, in weight loss camp interventions, the curriculums may vary, yet most include some components of a dietary intervention, increased physical activity, and cognitive behavioral treatment (Gately et al., 2005; Walker et al., 2003; Barton et al., 2004). Camp interventions tend to focus on older children (Kirschenbaum, 2010) and range in intervention length (two-eight weeks; Gateley et al., 2005). Studies have shown promising results, with reductions in BMI and improvements in dietary behaviors (Gately et al., 2000; Walker et al., 2003; Quinlan et al., 2009). For example, following an 8-week residential summer camp which focused on increasing physical activity, calorie restriction, and health education, there was a significant reduction in BMI and weight loss that was maintained at four-month follow-up in a sample of 12-year-olds (Gately et al., 2000). Likewise, a four-week weight loss camp showed reductions in BMI and improvements in self-esteem and global self-worth in a sample of 13-year-olds (Walker et al., 2003). The residential camp also restricted calories based on the child's basal metabolic rate and encouraged parents to visit for a weekend to experience the camp firsthand (Walker et al., 2003). Additionally, the Forever-Fit Summer Camp 
(FFSC), a six-week day camp for 8-to-12-year old children, found significant improvements at the end of the intervention in BMI, waist circumference, and fitness (Mikati et al., 2020). Furthermore, previous research has demonstrated significantly greater reductions in BMI z-score in 11-to-15-year old children who participated in an eight-week camp versus a four-week camp (Huelsing et al., 2010).

Overall, weight loss camps have demonstrated improvements in the health outcomes of children and adolescents (Huelsing et al., 2010; Mikati, et al., 2020). Despite the favorable physical and socioemotional improvements, weight loss camps typically do not include comprehensive parent components which as mentioned, might be beneficial in pediatric obesity interventions. For example, one study allowed parents to visit the camp for a weekend and provided informational packets, however, they did not intervene directly with the parents (Walker et al., 2003). Additionally, weight loss camps can be expensive and not easily accessible to the general public (Kirschenbaum, 2010).

After-school Programs. Over ten million children participate in afterschool programs in the United States (Alliance, 2014), making the afterschool setting an advantageous location for obesity interventions. Furthermore, afterschool programs are an ideal setting for obesity interventions given the already intact resources, such as facilities, organizational structure, and rapport with families.

Multiple studies have shown positive changes in child health behaviors following after-school obesity interventions (Davis et al., 2011; Annesi \& Vaughn, 2011; Howe et al., 2011; Glabska et al., 2019). Specifically, in a sample of eight-year-old children, the Medical College of Georgia FitKid Project showed reductions in percentage of body fat and a greater relative reduction in heart rate response to a step test in those who participated 
in the eight-month program versus a control group (Yin et al., 2005). Shorter length interventions have also been successful. For example, nine-year-old participants in a 12 week gardening, nutrition, and cooking program (LA Sprouts) showed reductions in BMI and diastolic blood pressure as well as increases in dietary fiber intake compared to the control group (Davis et al., 2011). Additionally, a pilot program focused on 8-to-17-year old children in a Boys and Girls Club afterschool program demonstrated significant pre-topost improvements in self-efficacy and motivation for physical activity, and attendance was correlated with decreased BMI z-scores (Wieland et al., 2020). Similar results were found in an after-school program targeting 6-to-17-year old girls, Aggie Play, where girls in the intervention group demonstrated improvements in fitness as well as physical activity selfefficacy compared to the control group (Post \& Palacios, 2019). Furthermore, the Go-GirlGo (GGG) intervention demonstrated within-subject improvements in minutes of moderate-to-vigorous activity in elementary school girls after a 12-week program (Huberty et al., 2014).

Regardless of the encouraging results, after-school programs still face many challenges. For example, lack of parental involvement and transportation home, as well as insufficient funding for additional staff, which hinders the inclusion of all children. Additionally, there are methodological limitations in the after-school obesity program literature, such as, not tracking session attendance (Huberty et al., 2014), lack of a control group (Wieland et al., 2020), and non-randomized trials (Davis et al., 2011; Huberty et al., 2014).

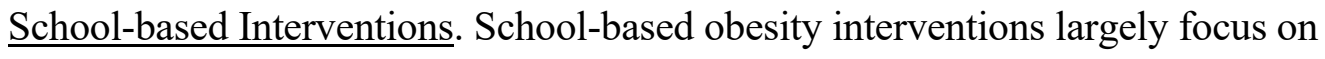
prevention, targeting all students. The emphasis of school-based interventions is typically 
on intervening at the child level, and usually do not include significant parent components (Coleman et al., 2005; Sahota et al., 2001). The length of interventions ranges from one week to four years, and grade levels span the full range from kindergarten through Highschool (Katz et al., 2005; Kropski et al., 2008).

The literature on the efficacy of school-based programs is mixed. Robinson (1999) found reductions in child BMI after a school-based intervention focused on minimizing screen time. Similarly, using the Coordinated Approach to Child Health program (CATCH; Luepker et al., 1996), Coleman et al. (2005) found that children in the intervention schools had healthier weights at the end of the program compared to children in the control schools. Additionally, the Motivating Adolescents with Technology to CHOOSE Health (MATCH) program targeted middle school children and demonstrated that four years postintervention, students participating in MATCH had significantly lower BMI z-scores as well as lower self-reported intake of unhealthy foods (e.g., sweetened beverages and snacks) compared to the control group (Lazorick et al., 2016).

Conversely, another study found that there were no reductions in child BMI after a year-long school-based intervention that included school action plans designed to promote healthy behaviors (Sahota et al., 2001). Likewise, the Lunchpower intervention provided to $3^{\text {rd }}-5^{\text {th }}$ graders (Donnelly et al., 1996) which included healthy changes to school lunches, nutrition education and improvements in physical education over a two-year period, did not demonstrate significant improvements in anthropometric or metabolic measures. Additionally, the West Midlands ActiVe lifestyle and healthy Eating in School children (WAVES) intervention targeted 5-to-6-year old children and their families in a yearlong 
school-based intervention, and did not find any group differences on anthropometric, dietary, or physical activity outcomes compared to the control group (Adab et al., 2018).

Given some of these mixed results, it may be the case that the lack of improvements in child health outcomes following a school-based intervention is related to the absence of parental involvement. In fact, the literature suggests that including both children and parents improves treatment outcomes (Wrotniak et al., 2004; Epstein et al., 1990; Yackobovitch-Gavan et al., 2018).

Family-based Interventions. Family-based interventions for pediatric obesity focus on a variety of elements, including parental support, family functioning, improving eating patterns in the child and parent, and the home environment (Ebbeling et al., 2009). Children and adolescents (2-15 years) and their parents comprise family-based interventions which can last in duration from four weeks to two years (Sung Chang et al., 2013). Treatment can be provided in family groups where both parents and children are present or concurrent parent and child groups (Sung Chang et al., 2013)

There is a strong evidence base for the efficacy of family-based interventions (Epstein et al., 2007; Collins et al., 2011; Berry et al., 2014; Yackobovitch-Gavan et al., 2018). Specifically, the Summer Healthy-Lifestyle Intervention Program (HIP), which consists of the Healthy Lifestyle Summer Camp and Parenting program (HLSC+HLPP), was effective in improving and maintaining both child and mothers' healthy-habits and children's nutritional knowledge and fitness via a combined summer camp and parenting group intervention in a sample of four-eight-year old children (Graziano et al., 2017). Despite the demonstrated efficacy of this program, there was not a control group included in the sample and therefore only within-subjects analyses were conducted. Furthermore, a 
family-based obesity intervention, Healthy Dads Healthy Kids, focused on fathers and children ages 4-to-12- years of age, demonstrated improvements in paternal BMI, child BMI z-score and several other health outcomes (Morgan et al., 2019). Similarly, the Parenting Eating and Activity for Child Health study (PEACH), a program which includes a parent group as well as a child group for children 5-to-11 years, showed improvements in BMI z-score, eating behaviors and physical activity after the intervention (Moores et al., 2018). Yet, neither Healthy Dads Healthy Kids nor PEACH included a comparison group and therefore results can be the result of regression to the mean. Additionally, the Special Turku Coronary Risk Factor Intervention Project (STRIP) documented improvements in dietary intake and cardiometabolic risk factors in children compared to a control group (Niinikoski et al., 2007). However, the comparison group did not include a parent-only group and therefore they were unable to tease apart which components of the intervention (e.g., parent-focused or child-focused) contributed to the improvements in health outcomes.

Thus, the literature has identified that family-based interventions can be effective in improving child health outcomes. Yet, there is a significant gap in identifying which components specifically are responsible for the improvements in child health, especially within underserved populations. Aside from who the treatment targets, there are many factors that contribute to pediatric obesity, which may play a role in the effectiveness of an obesity intervention.

\section{Mechanisms of Obesity}

Nutrition

Dietary Intake. Consumption of high-calorie foods (Doak et al., 2006) and lack of consumption of fruits and vegetables are related to childhood obesity (Lin \& Morrison, 
2002). Additionally, sugar-sweetened beverage consumption and increased consumption of snacks are associated with increased body mass index in children (Moreno \& Rodriguez, 2007; Ludwig et al., 2001; Zizza et al., 2001). Most obesity interventions focus on reducing the intake of high-calorie foods and increasing consumption of fruits and vegetables (Graziano et al., 2017; Castro et al., 2013; Epstein et al., 2001). Although making changes in dietary intake is an important component of weight reduction, knowledge of the appropriate foods to consume is imperative to success.

Nutrition knowledge. Nutrition knowledge can be difficult to define as it is a multifaceted construct. For example, assessment of nutrition knowledge can include knowledge of micro or macronutrients, distinguishing the healthfulness of foods, and identifying the parts of a nutrition label (Worsley, 2002). Regardless of how one defines nutrition knowledge, previous research has demonstrated an association between nutrition knowledge and health outcomes.

Increases in nutrition knowledge has been associated with positive dietary changes in young children and adolescents (Fahlman et al., 2008; Baskale \& Bahar, 2011). In a study conducted with middle-school children, a one-month nutrition curriculum was found to be effective compared to a control group at improving nutrition knowledge as well as increasing fruit and vegetable intake and reducing junk food consumption (Fahlman et al., 2008). Similarly, a six-week nutrition education curriculum demonstrated improvements in nutrition knowledge and preferences for fruits and vegetables compared to a control group in a sample of second grade children (Schmitt et al., 2018). Additionally, in a study conducted with preschoolers, nutrition knowledge increased following a year-long nutrition intervention and there was an increase in consumption of healthy snacks, white meat and 
fish, fruits, and green leafy vegetable and root vegetables compared to a control group (Baskale \& Bahar, 2011). Furthermore, children who participate in nutrition education programs show improvements in anthropometric measurements and fitness. Specifically, Lee et al. (2009) showed decreases in fourth graders percent body fat and waist-to-hip ratio following a five-month nutrition education program. Additionally, increases in fitness and decreases in body mass index z-scores were seen in young children after an eight-week summer camp intervention where nutrition education was provided (Graziano et al., 2017). Given the relationship between nutrition knowledge and child health, targeting child nutrition knowledge is an important component of an obesity intervention. However, the literature is unclear how to best target such knowledge, whether thru the child or parent.

Physical Activity/Sedentary Behaviors. Energy expenditure (number of calories burned each day) is a key factor in balancing daily total energy. Sedentary behaviors, such as screen time, have been found to be associated with childhood obesity (Doak et al., 2006; Lobstein et al., 2004; Danner, 2008; Epstein et al., 2008). Specifically, Gortmaker et al. (1996) found that children watching television five or more hours a day were five times more likely to be overweight than children who watched less than two hours of television per day. Additionally, sedentary behavior has been linked to increased exposure to advertising of high-fat foods as well as increased snacking (Coon \& Tucker, 2001; Taveras et al., 2006; Utter et al., 2006). Moreover, reductions in sedentary behavior are associated with increases in physical activity (Epstein et al., 1995). Specifically, in a study conducted with obese children ages 8-12 years old, when time spent in sedentary behavior was reduced, the children reallocated their time to participating in physical activity (Epstein et al., 1995). Additionally, in a study of girls aged 14-to-18 years, those in the intervention 
group reduced time spent in sedentary behaviors and increased physical activity compared to the control group (Staiano et al., 2017). Similarly, a 12-week exercise program showed improvements in physical activity and reductions in sedentary behavior at 6-month followup (Gow et al., 2016). Moreover, a recent review of the effects of screen time on child and adolescent health suggests that higher levels of screen time are associated with multiple poor health outcomes, such as, poor diet, adiposity, and mental health problems (Stiglic \& Viner, 2019). Physical activity and sedentary behavior habits are worsened by an obesogenic environment.

Obesogenic environment. Obesogenic environments are a contributing factor to the childhood obesity epidemic. Low availability of healthy foods and high concentration of fast food restaurants are associated with lower quality diets (Jetter \& Cassady, 2006; Walker et al., 2010). Additionally, larger portion sizes have been associated with greater energy intake (Ello Martin et al., 2005). Furthermore, Hawkes and colleagues (2015) recommend that pediatric obesity prevention programs should include changes to the food and consumer environment, such as, the price of food products and marketing. In terms of physical activity, a lack of safe physical activity environments and lack of accessible parks and recreational areas are associated with childhood obesity (Davison \& Birch, 2001; Gordon-Larsen et al., 2006; Sahoo et al., 2015). Moreover, a review of current obesity interventions suggests that interventions should alter the environment, such as, improving the physical education program in schools (Doak et al., 2006) and incorporate parenting factors (Gerards et al., 2011). 


\section{Parenting}

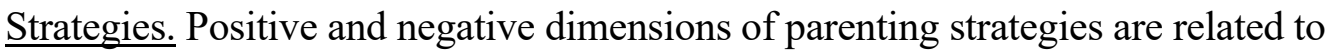
overall parenting styles, of which authoritative (high demand, high warmth) is optimum (Baumringd, 1966). Parenting styles have been associated with multiple child health outcomes (Kremers et al., 2003; Rhee et al., 2006; Gerards et al., 2011). Specifically, in a study examining parenting styles and weight status, children with parents who had an authoritarian parenting style (high demand and low warmth) had the greatest risk of being overweight two years later compared to an authoritative parenting style (Rhee et al., 2006). Additionally, children with parents who were permissive or neglectful also had an increased risk of obesity compared to parents with high demand, sensitivity, and involvement (Rhee et al., 2006). Similarly, in a study of 6-to-12-year old children and their mothers, results demonstrated that children who were obese had more authoritarian and permissive mothers than children who were not obese (Pace et al., 2019). Also, mothers of preschool children with an authoritarian parenting style had children with 4.71 greater odds of being overweight or obese compared to children with mothers with an authoritative parenting style (Yavuz \& Selcuk, 2018). Furthermore, interventions which focus on parenting styles as the mechanism of change (and supplement with physical activity and/or nutrition education) have been found to be effective in improving weight outcomes in children (Gerards et al., 2011). A review of obesity interventions suggests that an authoritative parenting style in particular is an effective parenting strategy that supports healthy weight in children (Gerards et al., 2011). It may be the case that parents who are more sensitive and cognizant of their child's emotional needs foster an independence in children in terms of regulating their own eating. 
Child feeding practices. Pressure to eat (i.e., requesting that the child eat everything on their plate), excessive parental control and restriction (i.e., limiting access to certain foods) of child feeding has been associated with increased consumption of food higher in fat (Vollmer \& Baietto, 2017; Zive et al., 1998; Birch et al., 2003) as well as with child weight (Birch et al., 2003). Furthermore, using high-calorie foods as a reward can contribute to an unhealthy relationship with food. For example, pairing an unhealthy food as a reward for a behavior can lead to a preference for the unhealthy food (Savage et al., 2007). Additionally, in a systematic review, using food as a reward was found to be positively correlated with unhealthy eating in children (Yee et al., 2017). Overall, child feeding practices are associated with poor child health outcomes and can contribute to the learning of unhealthy behaviors. The home environment is an essential location for demonstrating healthy and unhealthy behaviors.

Home environment. Children are twice as likely to be overweight adults if they have a parent that is overweight, regardless of their own weight status (Whitaker et al., 1997). Part of the association between childhood and adult obesity may be due to genetic influences and also shared lifestyles within the home (Hendrei et al., 2011). For instance, overweight mothers are more likely to give their children unhealthy snacks compared to mothers with lower weight status (Sherman et al., 1992). Similarly, previous research has found that mothers who are heavier and have a more emotional and external (eating in response to an outside stimuli) eating style, have a less healthful home environment (Schrempft, et al., 2016). Parental role modeling also plays an important role in childhood obesity. For example, in a study of children five-seven years old, children who had parents that were consuming the recommended amount of fruit and vegetable servings per day 
were ten times more likely to also be consuming the recommended amount of fruits and vegetables per day compared to parents who were not (Coto et al., 2019). Additionally, compared to healthy weight mothers, mothers who are obese have a less healthy home environment and demonstrate less modeling of healthy eating (Haycraft et al., 2017). Furthermore, children might be motivated to eat healthy foods via repeated exposure of healthy foods that their parents are eating (Davison \& Birch, 2001). Moreover, a recent review of Latino family's home environment influences on childhood obesity identified that parental influences, including parent feeding practices and parental modeling, was one of the main factors across the literature contributing to a less healthy home environment and childhood obesity (Ochoa \& Berge, 2017).

\section{Study 1: The Current Study}

As noted above, the literature has acknowledged that family-based interventions can be effective in improving child health outcomes. However, there is a significant gap in the literature due to methodological limitations (e.g., lack of control groups) as well as lack of comparison groups (e.g., parent-only, or child-only- interventions) that would allow us to tease apart which components of the family-based interventions (e.g., parentfocused or child-focused) contribute to the improvements in health outcomes. The Healthy Lifestyle Summer Camp and Parenting program (HLSC+HLPP) is a familybased health intervention that includes child-focused and parent-focused components that can be implemented alone or together (Graziano et al., 2017). Given the aforementioned gaps in the literature and the flexibility of the Healthy Lifestyle Summer Camp and Parenting program (HLSC+HLPP), the purpose of the current study was to examine, via a randomized trial, the efficacy of the Healthy Lifestyle Summer Camp and Parenting 
program (HLSC+HLPP) compared to the Health Lifestyle Summer Camp (HLSC) on improving child and parent health outcomes. Additionally, we examined changes in mechanistic outcomes [e.g., family home environment, family healthy habits (i.e., nutrition, physical activity), parenting strategies, and feeding practices]. In accordance with previous research (Graziano et al., 2017; Huelsing et al., 2010; Kirschenbaum et al., 2007), we expected that families in both interventions would have similar improvements in health outcomes (e.g., BMI and fitness) from pre-treatment to post-treatment assessment. However, at three-month follow-up, we expected that families in HLSC+HLPP would have better maintained their improvements in BMI and fitness compared to families in HLSC, given the documented role of parents in child weight loss (Golan et al., 2006; Graziano et al., 2017). Within the mechanistic outcomes, given the focus on parents in the HLSC+HLPP, we expected that families who completed HLSC+HLPP would experience significantly greater gains on parent-driven outcomes [e.g., family home environment, family healthy habits (i.e., nutrition, physical activity), parenting strategies, and feeding practices] at post-treatment and at three-month follow-up compared to families in HLSC who did not receive the parenting group. 


\section{STUDY 1: METHOD}

\section{Participants and Recruitment}

Following institutional review board approval (IRB-19-0163), recruitment was conducted at local schools during health screenings where graduate students measured children's BMI and provided parents with results and camp brochures. Also, camp brochures were displayed in the waiting rooms of local children's hospitals, pediatrician's offices, and libraries. Additionally, study staff promoted the summer camp at elementary school open houses and community resource fairs. Interested parents called the study center $(n=57)$ and spoke with study staff who described the study and scheduled them for a screening appointment to determine eligibility. Families were eligible if a) the child was between four and nine years of age; b) the child had a BMI $\geq$ the $85^{\text {th }}$ percentile for weight based on the Centers for Disease Control and Prevention age/gender norms; c) the parent spoke and understood English/Spanish; and d) the family was able to participate in an eight-week summer camp and parenting program. Families were excluded if the child had dietary or exercise restrictions, was previously diagnosed with a developmental delay or pervasive developmental disorder, was on medication that may affect weight loss/gain, or was enrolled in another weight control or exercise program. Figure 1 provides a CONSORT Flow diagram detailing participant recruitment and participation.

Thirty children were randomized to either the HLSC+HLPP or HLSC treatments. Six families did not participate in the intervention (reasons for not participating included: moved to another city, no show, planned vacation). The final sample consisted of 24 children $\left(M_{\text {age }}=6.17\right.$ years; $58.3 \%$ male; $87.5 \%$ Hispanic/Latino; $n=2$ diagnosed with Attention-Deficit/Hyperactivity Disorder) classified as overweight $(n=7)$ or obese $(n=$ 
$17)$ and their caregivers $\left(M_{\text {age }}=39.67\right.$ years; $100 \%$ female; $83.3 \%$ Hispanic/Latino; see

Table 1). Mean family annual income was $\$ 36,401.84$. 


\title{
Figure 1. Study One and Two CONSORT Flow Diagram
}

\author{
Recruitment
}

Flyers Distributed $n=1,354$

Social media blasts (CCF listserv, CCF Facebook, Self-Reg database,

Facebook mom groups, Town of Miami Lakes listserv)

Health screener $n=5$; Open house $n=3$; Children's Trust Fair

\section{Study One: HLSC+HLPP}

Assessed for eligibility $(n=57)$

Excluded $n=27$

- Not meeting inclusion criteria $n=8$

- No longer interested $n=5$

- Other reasons: Lives too far $n=5$; lost contact $n=5$; not available during camp dates $n=4$

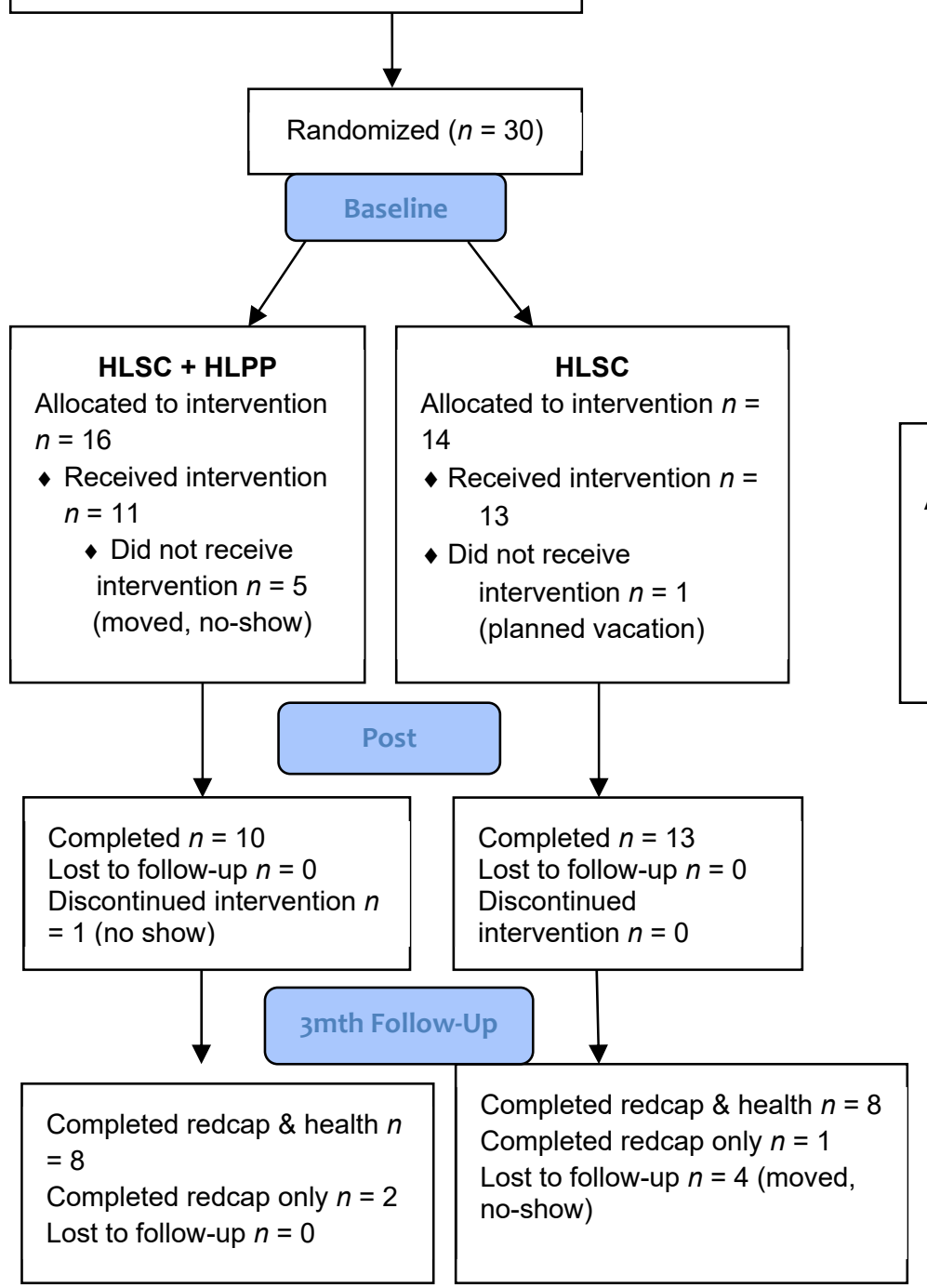

Assessed for eligibility $(n=$ 71)

Excluded $n=53$

- Not meeting inclusion criteria $n=12$

- No longer interested $n=$ 11

- Other reasons: Lives too far $n=3$; lost contact $n$ $=17$; no show to first group $n=4$; not available during group dates/times $n=6$

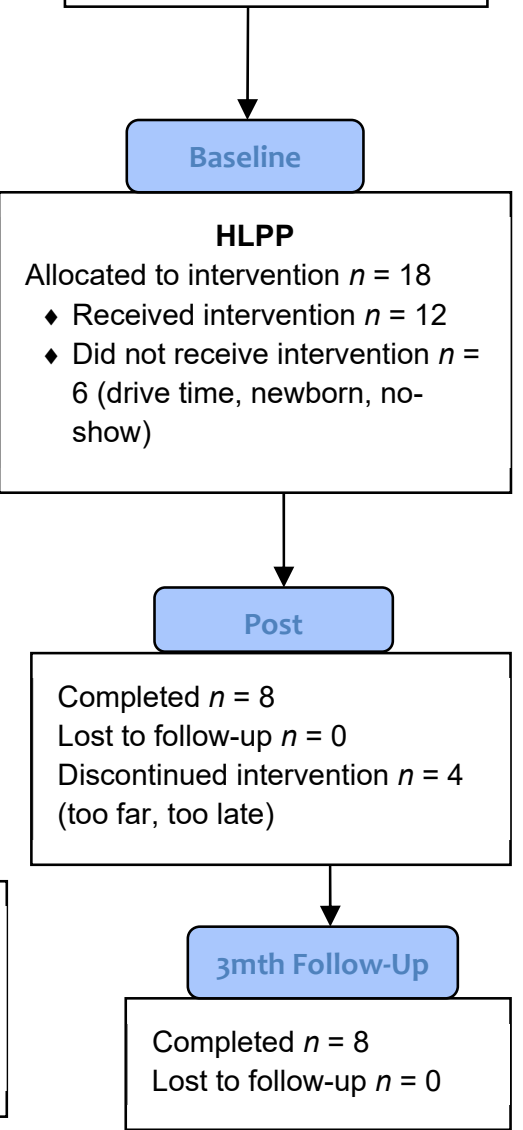




\section{Demographic Variables}

Child gender ( $\%$ male)

$67 \%$

Mean child age (Range)

$6.17(4-9)$

Child ethnicity (\%)

Hispanic/Latino

$87.5 \%$

Diagnosis of a neurodevelopmental disorder (\%)

$8 \%$

Caregiver gender ( $\%$ female)

$100 \%$

Mean caregiver age (Range)

$39.67(29-53)$

Caregiver ethnicity (\%)

Hispanic/Latino

$83.3 \%$

Mean Annual Income (SD)

$\$ 36,401.84(\$ 38,110.06)$

Caregiver Highest educational level completed (\%)

High school graduate

$4.2 \%$

Some college

$16.7 \%$

Associate's degree

$16.7 \%$

Bachelor's degree

$45.8 \%$

Advanced degree (Masters, MBA, MD, JD, PhD)

$16.7 \%$

Caregiver marital status (\%)

Single, never married

$12.5 \%$

Living with a partner

$4.2 \%$

Married

$70.8 \%$

Separated

$4.2 \%$

Divorced

$8.3 \%$ 


\section{Procedure}

Children of families randomized to HLSC attended an eight-week manualized summer camp that promoted children's nutritional knowledge/awareness and physical activity via the use of a behavior modification system (Graziano et al., 2017). The intervention is further described below. Children of families randomized to HLSC+HLPP attended the summer camp and their parents attended nine weekly HLPP sessions, which focused on learning behavioral modification strategies and supporting their child's engagement in healthy nutrition and physical activity habits (Graziano et al., 2017; also described in detail below). Both groups completed all measures at a baseline assessment before the start of treatment, a post-treatment assessment one week after treatment, and a three-month follow-up assessment which is consistent with other obesity interventions (Edwards et al., 2006; Stovitz et al., 2014). Families were compensated with a $\$ 25$ gift card at the completion of each assessment.

\section{Intervention Description}

HLSC. The HLSC is an eight-week manualized summer camp for children who are overweight held daily from 8:00 A.M. to 5:00 P.M. with a ratio of 1:4 staff to children. Undergraduate students with knowledge in nutrition and behavioral modification were the HLSC lead and supporting counselors. All counselors underwent a 10-day training in conjunction with the Summer Treatment Program for PreKindergarteners and had to demonstrate mastery of the manual by scoring at least $80 \%$ on a procedural test (Graziano et al., 2014). Counselors received daily supervision and weekly feedback by a doctoral level trainee and a clinical psychologist. During the physical activity component, children engaged in various exercise periods throughout the 
day including sport skills (e.g., soccer, obstacle course races), dance video games, and step competitions. The nutrition component included education on the MyPlate program (U.S. Department of Agriculture, 2019), the Stop-Light Diet system (Esptein \& Squires, 1988), food groups, and food tastings (see Table 2 for food of the day schedule). The behavior modification program was comprised of a point system adapted from The Summer Treatment Program-Prekindergartners (Graziano et al., 2014) where children received points for trying healthy foods, participating in physical activities, self-control skills, and prosocial behaviors (e.g, encouraging others). Points accumulated were then used for daily and weekly rewards (e.g., fun activities, daily trophies). See Table 3 for a daily activity schedule. Daily parental feedback was also provided where parents received verbal and written feedback on their child's health, behavioral, and academic progress. The camp cost was $\$ 1600$; however, a sliding fee scale was used and the final cost to participants ranged from $\$ 200-\$ 1600(M=\$ 720)$.

HLSC+HLPP. Participants in the HLSC+HLPP group participated in the HLSC described above as well as the HLPP. The HLPP is a nine-session parenting group held weekly lasting 1.5-2 hours. A graduate student with expertise in pediatric obesity was the HLPP therapist. The nutrition component focused on teaching parents about the StopLight Diet System (Esptein \& Squires, 1988) as well as the MyPlate (U.S. Department of Agriculture, 2019) and encouraging the use of these skills at home. Additionally, food monitoring via food logs and a phone application (i.e., MyFitness Pal) was completed by the parent. The physical activity component included education on monitoring and limiting sedentary activities (e.g., minimizing screen time) while promoting physical activities (e.g., going on family walks). Lastly, parents were taught behavior modification 
strategies adapted from Parent Child Interaction Therapy (Eyberg \& Hood, 2003) such as, attending to desired behaviors via labeled praises and differential attention for picky eating. See Table 4 for a summary of session topics. There was also a parental feedback component where parents received daily verbal and written feedback on their child's health, behavioral, and academic progress as well as parent's success in providing daily healthy meals during camp see Figure 2 for a sample daily feedback form. 
Table 2. HLSC Food of The Day Schedule

Week 1 Strawberries, lettuce, oranges, corn, apples

Week 2 Raspberries, carrots, blueberries, multigrain bread, cucumbers

Week 3 Mango, broccoli, kiwi, cauliflower, green beans

Week 4 Grapes, asparagus, watermelon, sweet potato, cherry tomatoes

Week 5 Cherries, edamame, spaghetti squash, hummus/carrots, spinach

Week 6 Squash, honey dew melon, brown rice, cantaloupe, blackberries

Week 7 Pineapple, celery, veggie burger, zucchini, whole wheat pasta

Week 8 Greek yogurt, grapefruit, bananas 
Table 3. HLSC Daily Activity Schedule

\begin{tabular}{|l|l|}
\hline \multicolumn{1}{l}{ Time } & Activity \\
\hline 7:30-8:00 & Arrivals \\
\hline 8:00-8:30 & Morning Meeting/Food of the Day Tasting \\
\hline 8:30-8:45 & Transition/Bathroom break \\
\hline 8:45-9:15 & Exercise Period 1 \\
\hline 9:15-9:25 & Transition/Water break \\
\hline 9:25-9:45 & Snack 1 \\
\hline 9:45-10:05 & Seatwork \\
\hline 10:05-10:50 & Art and Exercise Break \\
\hline 10:50-10:55 & Transition \\
\hline 10:55-11:40 & XBOX Just Dance \\
\hline 11:40-11:45 & Transition \\
\hline 11:45-12:25 & Lunch in Classroom \\
\hline 12:25-12:30 & Transition to Recess/Bathroom Break \\
\hline 12:30-12:50 & Recess \\
\hline 12:50-1:00 & Transition/Water break \\
\hline 1:00-1:30 & Mid-Day Meeting/Food of the Day Tasting \\
\hline 1:30-2:00 & Practicing our Abilities to Control our Emotions (PACE) \\
\hline 2:00-2:30 & Instructional Period \\
\hline 2:30-2:40 & Transition/Bathroom break \\
\hline 2:40-3:30 & Exercise Period 2 \\
\hline $3: 30-3: 40$ & Transition/Water break \\
\hline $3: 40-4: 00$ & Snack 2 \\
\hline $4: 00-4: 30$ & End of Day Meeting/Food of the Day Tasting/Daily Awards \\
\hline $4: 30-4: 35$ & Transition \\
\hline $4: 35-4: 55$ & Recess \\
\hline $4: 55-5: 00$ & Transition \\
\hline $5: 00-5: 30$ & Dismissals \\
\hline
\end{tabular}


Table 4. HLPP Session Topics

\section{Session 1 Orientation}

Session 2 Stoplight System and Strengthening the Parent -Child Relationship

Session 3 My Plate/Goal Setting/Healthy Substitutions and Implementing

Child Directed Interaction Skills

Session 4 Portion Control and Implementing Child Directed Interaction Skills

Session 5 Home Environment/Snack/Breakfast and Social-Emotional Functioning

Session 6 Promoting Your Child's Fitness and Energy Balance

Session 7 Reducing Screen Time/Healthy Beverages and Promoting Positive

Behaviors at Home

Session 8 Eating Out and Promoting Positive Behaviors in Public

Session 9 Progress Assessment and Maintenance 
Figure 2. Sample Daily Feedback Form

\section{(Child Name)'s DRC}

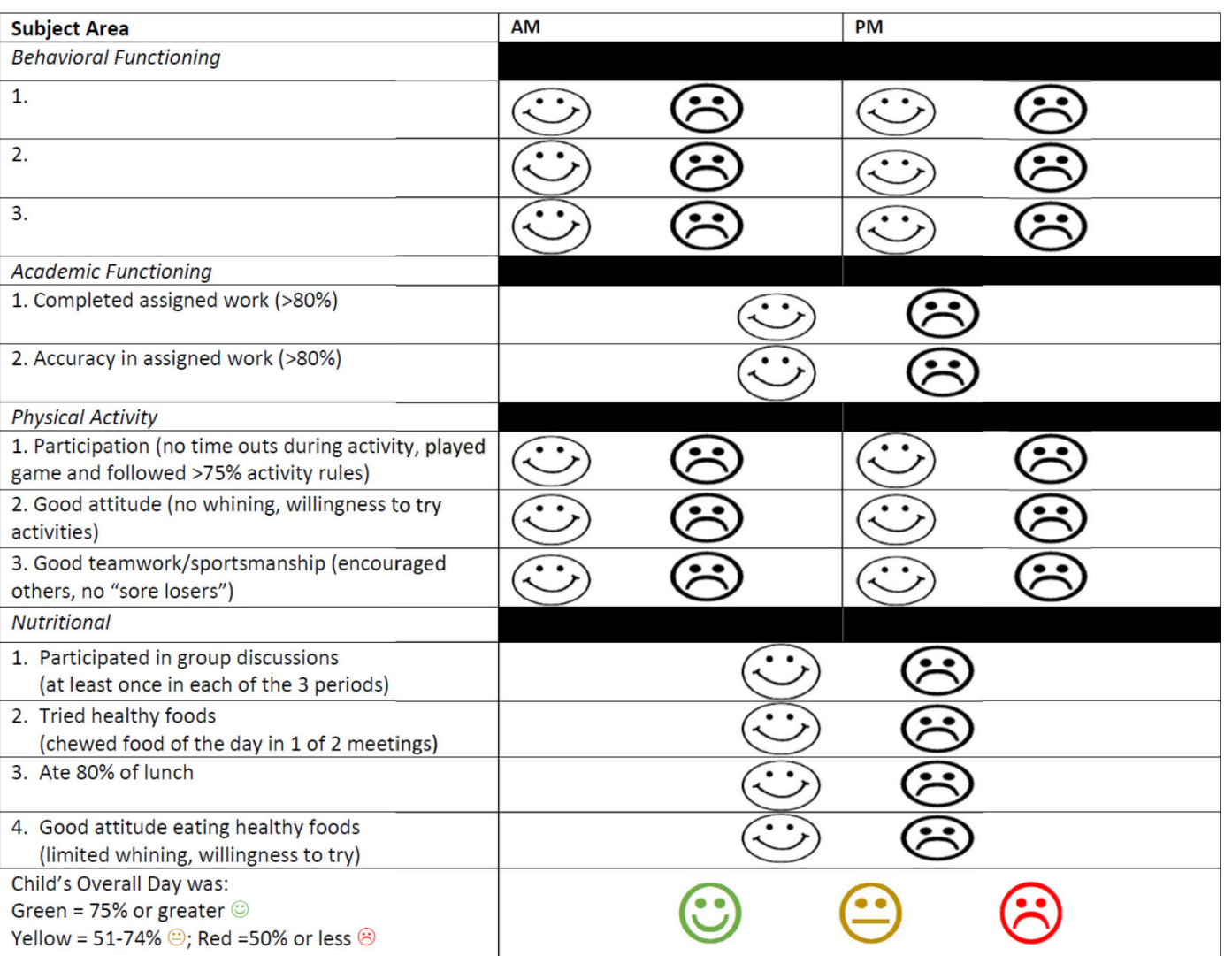

\begin{tabular}{|c|c|c|}
\hline \multirow{2}{*}{\multicolumn{3}{|c|}{$\begin{array}{l}\text { Period } \\
\text { Lunch }\end{array}$}} \\
\hline & & \\
\hline 1. Fruit & & \\
\hline 2. Vegetables & & \\
\hline 3. Grains & & \\
\hline 4. Protein & & \\
\hline 5. Healthy Drink & & \\
\hline 6. Good portion & & \\
\hline Snack & & \\
\hline 1. Healthy & & \\
\hline 2. Good portion & & \\
\hline Parent's Overall Grade was: & & \\
\hline
\end{tabular}

$* * * *$ To be completed by Parent and returned the next day $* * * *$

Child's reward (if applicable) at home was:

Parent signature: 


\section{Measures}

\section{Process Measures}

Attendance, Treatment Satisfaction, and Fidelity. Child attendance was recorded during HLSC via sign-in sheets completed by the parents during drop-off and pickup. Parent attendance at HLPP sessions was also recorded via sign-in sheets completed at the beginning of the sessions. Homework (i.e., food log forms) were collected from parents during each HLPP session. Treatment satisfaction was measured via an adapted standard satisfaction questionnaire developed for behavioral treatments (MTA Cooperative Group, 1999). Parents indicated their degree of satisfaction across a seven-point Likert scale on various topics as well as provided an overall rating of treatment satisfaction. Fidelity was assessed via checklists (see Figure 3 ) completed on $20 \%$ of the recorded HLPP sessions by a research assistant who was blind to group assignment. Fidelity of the HLSC was completed by a doctoral level student using a treatment fidelity checklist (See Figure 4) on a weekly basis for a full camp day and all counselors received weekly feedback. 


\section{Figure 3. Sample Fidelity Sheet: HLPP}

Fidelity Session 1: Orientation

Coder Initials

Date

Group

As you view the tape/observe, place a checkmark under the appropriate column.

\begin{tabular}{|l|l|l|l|}
\hline ITEM NUMBER & Completed & Not Completed & N/A \\
\hline 1. Begin Session & & & \\
\hline 2. Give overview or program & & & \\
\hline 3. Overlap of physical and mental health & & & \\
\hline 4. Benefits of early intervention & & & \\
\hline 5. Topics covered in HIPP & & & \\
\hline 6. Monitoring (hard copy, Myfitness pal) & & & \\
\hline 7. How to involve your child & & & \\
\hline 8. Home activity assignment & & & \\
\hline Fidelity \% (\# of Completed Items/Total \# of Items) & & & \\
\hline
\end{tabular}

How effective was/were the therapist(s) in:

Engaging the parents during the session

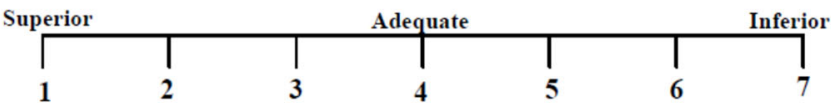

Providing social reinforcement/support to the parents during the session

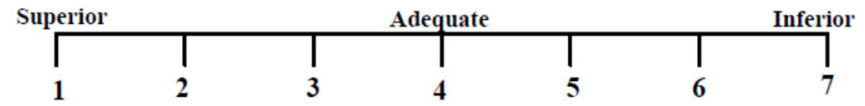

Therapist comments about the session:

Integrity Checker comments about the session: 


\section{Figure 4. Sample Fidelity Sheet: HLSC}

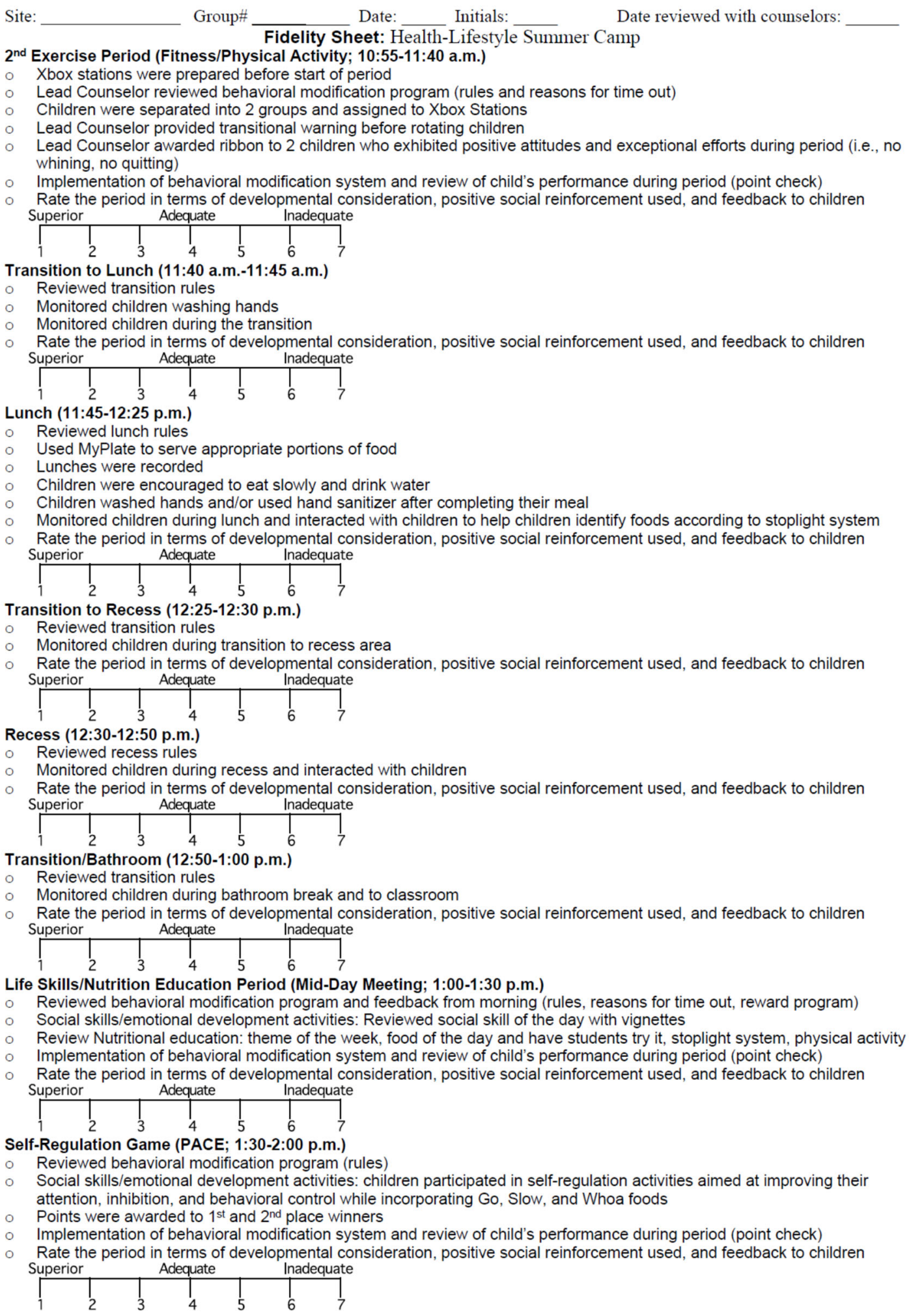




\section{Main Health Outcome Measures}

Child and Parent Anthropometrics. Parent and child height and weight were measured by calibrated stadiometer and portable digital scale following standard anthropometric procedures (Cameron, 1986) by trained personnel in triplicate (using the medium value; Ward \& Anderson, 1998). Body Mass Index (BMI; weight in kg/height in meters squared) was calculated for both parents and children, and child BMI was transformed into z-scores using national norms from the CDC (Kuczmarski et al., 2000).

Child and Parent Fitness. Child physical fitness was assessed via side-to-side jumps which is part of the Karlsruhe Motor Screening (KMS) test battery (Bos et al., 2004). Children are asked to jump with both legs from one side of a strip on the floor to the other as fast as possible for 30 seconds. In accordance with previous research, greater number of side-to-side jumps indicate better physical fitness (Bayer et al., 2009). Parent physical fitness was assessed via heart rate and blood pressure measured in triplicate and averaged. Routine physical activity has been associated with lower blood pressure in adults (Ahmed \& Ndumele, 2014). Child heart rate and blood pressure was also assessed in triplicate and averaged.

\section{Mechanistic Outcome Measures}

Nutrition. Dietary Intake: Child and parent dietary intake was assessed via the Automated Self-Administered 24-hour Dietary Assessment Tool (ASA24-2016; Kirkpatrick et al., 2014). The ASA24-2016 is a valid web-based tool that enables multiple automated self-administered 24-hour recalls and food records (Kirkpatrick et al., 2014; Thompson et al., 2015). The ASA24 uses the validated United States Department of Agriculture's (USDA) Automated Multiple-Pass Method (AMPM; Raper et al., 2004) 
which is the method used in the dietary interview component of the National Health and Nutrition Examination Survey. Parents were asked to recall and describe foods and drinks consumed at each meal during the previous day including portion sizes. Pictures of portion sizes were provided to aid in estimation. Parents also completed the ASA24-2016 for their child's previous day food and drink consumption. Consistent with previous research (Aeberli et al., 2008; Lin et al., 2012; Riera-Crichton \& Tefft, 2014), we examined dietary intake at a macronutrient (e.g., fat grams, calories) level as well as number of total daily fruit and vegetables consumed. Nutritional Awareness and Knowledge. Nutritional awareness and knowledge was assessed via The Dietary Interview Assessment of Nutritional Awareness (DIANA; Graziano, 2015). The DIANA is a 24-item measure of children's nutritional expressive knowledge and health classification. Total scores were calculated for Part A (expressive knowledge; $\alpha=.66$ ) and total relative scores were calculated for Part B (health classification; $\alpha=.73$ ), with higher scores indicating greater nutritional knowledge.

Physical Activity. The Family Healthy Lifestyle Questionnaire (FHLQ; Graziano, in preparation) is a 12-item self-report measure of frequency of family's healthy habits scored on a 7-point Likert scale. Family participation in physical activity was assessed via the following items from the FHLQ (Graziano, in preparation): How much time does your family typically spend watching television or playing videos games per day?, How many minutes a day does your child spend in active play/exercise (faster breathing sweating)?, How many minutes a day do you spend in active play/exercise (faster breathing sweating)?, and How often does your family go outside to play a physical activity (ride a bike, jump rope, soccer, basketball)?. 
Family Home Environment. The Family Nutrition and Physical Activity (FNPA; Ihmelset al., 2009) screening tool was used as a measure of the home environment. The screening tool assesses aspects of the food and physical activity environment inside of the child's home. The FNPA is comprised of 20-items in ten domains: family meals, family eating practices, food choices, beverage choices, restriction/reward, screen time, healthy environment, family physical activity, child physical activity, and family schedule/sleep routine. Reliability and validity are well-established for the FNPA (Peyer \& Welk, 2017; Ihmels et al., 2009). For the purposes of the present study, the total score $(\alpha=.62)$ was used with higher scores indicating a more favorable home environment.

Parenting. Parenting Strategies. The Alabama Parenting Questionnaire (APQ; Shelton et al., 1996) measures five dimensions of parenting: involvement, positive parenting, poor monitoring/supervision, inconsistent discipline, and corporal punishment via 42-items. Items use a 5 -point Likert scale $(1=$ Never to $5=$ Always $)$. The APQ has been found to have good internal consistency across the positive parenting $(\alpha=.80)$ and involvement ( $\alpha=.80)$ scales, good criterion validity in differentiating clinical and nonclinical groups (Shelton et al., 1996). The current study examined the positive parenting factor $(\alpha=.70)$ consisting of the involvement and positive parenting subscales and the negative parenting factor $(\alpha=.79)$ consisting of the following subscales: poor monitoring/supervision, inconsistent discipline and corporal punishment. Parenting Stress. Parents completed the Parenting Stress Index/Short Form (PSI; Abidin, 1995) to assess the source and degree of parenting stress. The PSI contains 36 items rated on a 6-point Likert scale $(1=$ Strongly Disagree to $5=$ Strongly Agree $)$ and yields subscales assessing parental distress, stress related to parent-child interactions, stress related to the child's behavior, and 
a total score. The APQ demonstrates good test-retest reliability (.68-.85), internal consistency (.85-.91) and concurrent validity (Abidin, 1995). Higher scores indicate increased total parenting stress. For the purposes of the current study, we used the total parenting stress score $(\alpha=$.78). Parent Feeding Practices. The Child Feeding Questionnaire (CFQ; Birch et al., 2001) was used to assess parent feeding practices. The CFQ is a well validated 31-item self-report questionnaire that measures two domains: (1) parental control in child feeding and (2) parental perceptions and concerns about child obesity (Birch et al., 1998). For the purposes of our study, we examined the parental control domain consisting of the following subscales: restriction $(\alpha=.66)$, pressure to eat $(\alpha=.57)$, and monitoring of eating $(\alpha=.92)$.

\section{Data Analysis Plan}

All analyses were conducted using the Statistical Package for Social Sciences, version 25 (SPSS, 2017). One family had missing data at the post assessment (4\%) and eight families had missing data at the follow-up assessment (33\%). Given previous research demonstrating that type- 1 error rate is inflated in imputation models with small sample sizes and over 30\% missing data, multiple imputation was not performed (McNeish, 2017). The follow-up time point was excluded from analyses and Little's MCAR test revealed that data were missing completely at random $\left(\chi^{2}=424.25, p=.993\right)$. Descriptive analyses were conducted to examine the process outcomes (e.g., attendance and homework completion, treatment satisfaction, and fidelity). Next, preliminary analyses were conducted between demographic variables and all outcome variables to identify any associations. Multiple repeated measures ANOVAs were conducted to examine changes between and within groups on all main health and mechanistic 
outcomes. Although we do present $p$ values, given the small sample size and likelihood of Type II error, we calculated and focused on Hedge's $g$ effect size estimates as opposed to $p$ values (Sullivan \& Feinn, 2012; Neill, 2008). 


\section{STUDY 1: RESULTS}

\section{Preliminary Analyses}

Demographic variables. Preliminary analyses between demographic variables and study outcome variables revealed significant associations between child age, child gender, and family annual income, respectively, and several outcome variables (correlations displayed in Tables 5-8). Therefore, all analyses (excluding analyses which included BMI z-score) controlled for child age, child gender, and family annual income. Analyses including BMI z-score only controlled for family annual income given that BMI z-score already accounts for child age and gender. 
Table 5. Study One: Correlations: Demographics and Health Outcomes

\begin{tabular}{|c|c|c|c|c|c|c|c|c|c|c|c|c|c|}
\hline & $\begin{array}{l}\text { BMI } \\
\text { Z- } \\
\text { score } \\
\text { (C) }\end{array}$ & $\begin{array}{c}\text { BMI } \\
(\mathrm{P})\end{array}$ & $\begin{array}{l}\text { Side- } \\
\text { to- } \\
\text { side } \\
\text { jumps } \\
\text { (C) }\end{array}$ & $\begin{array}{l}\text { SBP } \\
(\mathrm{C})\end{array}$ & $\begin{array}{c}\text { DBP } \\
(\mathrm{C})\end{array}$ & $\begin{array}{l}\mathrm{HR} \\
\text { (C) }\end{array}$ & $\begin{array}{c}\text { SBP } \\
(\mathrm{P})\end{array}$ & $\begin{array}{c}\text { DBP } \\
(\mathrm{P})\end{array}$ & $\begin{array}{l}\mathrm{HR} \\
(\mathrm{P})\end{array}$ & $\begin{array}{c}\text { Child } \\
\text { age }\end{array}$ & $\begin{array}{l}\text { Child } \\
\text { gender }\end{array}$ & $\begin{array}{c}\text { Parent } \\
\text { age }\end{array}$ & $\begin{array}{l}\text { Family } \\
\text { annual } \\
\text { income }\end{array}$ \\
\hline BMI z-score $(\mathrm{C})$ & - & - & - & - & - & - & - & - & - & - & - & - & - \\
\hline $\mathrm{BMI}(\mathrm{P})$ & .27 & - & - & - & - & - & - & - & - & - & - & - & - \\
\hline Side-to-side jumps (C) & -.06 & .03 & - & - & - & - & - & - & - & - & - & - & - \\
\hline $\operatorname{SBP}(C)$ & .11 & .22 & $.51^{* *}$ & - & - & - & - & - & - & - & - & - & - \\
\hline $\mathrm{DBP}(\mathrm{C})$ & .28 & .21 & .38 & $.82 * * *$ &. & - & - & - & - & - & - & - & - \\
\hline $\mathrm{HR}(\mathrm{C})$ & $.41^{*}$ & .07 & -.31 & -.10 & .16 & - & - & - & - & - & - & - & - \\
\hline SBP (P) & .26 & $.60 * *$ & .00 & .26 & .38 & .22 & - & - & - & - & - & - & - \\
\hline DBP (P) & .21 & $.66^{* *}$ & .07 & .27 & .35 & .17 & $.97 * * *$ & - & - & - & - & - & - \\
\hline $\mathrm{HR}(\mathrm{P})$ & .34 & $.63^{* *}$ & -.20 & -.18 & -.08 & .03 & .21 & .27 & - & - & - & - & - \\
\hline Child age & -.28 & .06 & $.63^{* * *}$ & $.41^{*}$ & .28 & $-.49 * *$ & -.05 & .06 & .12 & - & - & - & - \\
\hline Child gender & -.10 & .30 & -.18 & -1.6 & -.06 & .21 & .19 & .30 & .16 & -.09 & - & - & - \\
\hline Parent age & .03 & .02 & -.03 & .32 & .28 & -.27 & .19 & .12 & -.11 & .02 & $-.41^{*}$ & - & - \\
\hline Family annual income & $-.54 * *$ & -.42 & -.04 & -.27 & -.21 & $-.41^{*}$ & -.24 & -.25 & -.26 & .27 & -.35 & .23 & - \\
\hline $\begin{array}{l}\text { Parent highest } \\
\text { education }\end{array}$ & -.34 & -.40 & -.23 & -.36 & -.26 & -.39 & -.16 & -.23 & .03 & -.11 & -.19 & .17 & .39 \\
\hline
\end{tabular}

Note. ${ }^{* * *} p<.001, * * p<.01, * p<.05 . \mathrm{C}=$ child measure, $\mathrm{P}=$ parent measure, $\mathrm{BMI}=$ Body Mass Index, $\mathrm{SBP}=\mathrm{Systolic} \mathrm{Blood}$ Pressure, $\mathrm{DBP}=$ Diastolic Blood Pressure, and HR = Heart Rate. 
Table 6. Study One: Correlations: Demographics and Nutrition Outcomes

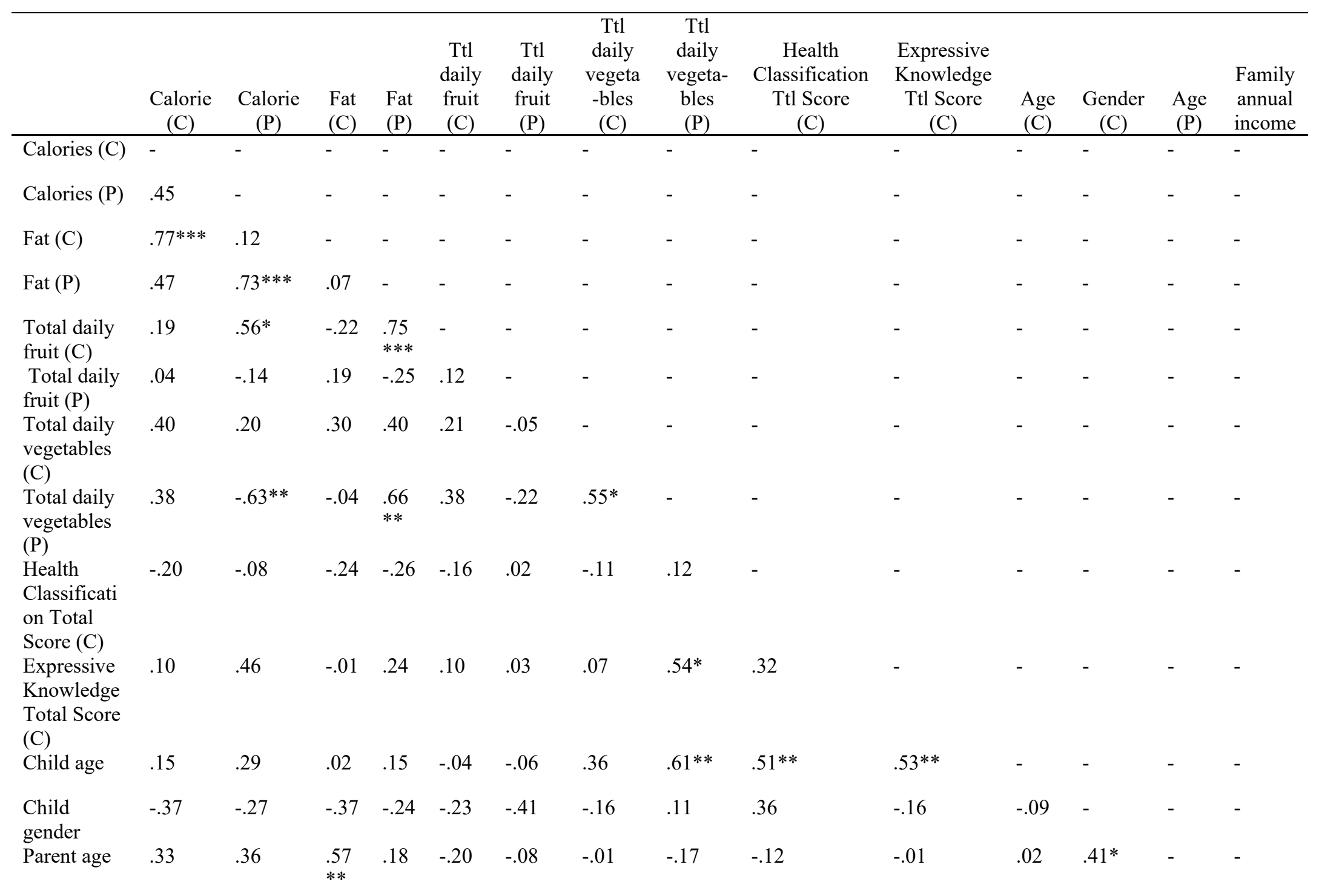




\begin{tabular}{|c|c|c|c|c|c|c|c|c|c|c|c|c|c|c|}
\hline $\begin{array}{l}\text { Family } \\
\text { annual } \\
\text { income }\end{array}$ & .40 & .36 & $\begin{array}{l}.44 \\
*\end{array}$ & .17 & -.14 & .04 & . 20 & .21 & -.29 & .15 & .27 & -.35 & .23 & - \\
\hline $\begin{array}{l}\text { Parent } \\
\text { highest } \\
\text { education }\end{array}$ & .17 & -.19 & $\begin{array}{l}.42 \\
*\end{array}$ & -.19 & -.30 & .36 & -.11 & -.18 & -.13 & .06 & .11 & .19 & .17 & .39 \\
\hline
\end{tabular}


Table 7. Study One: Correlations: Demographics, Physical Activity, and Home Environment Outcomes

\begin{tabular}{|c|c|c|c|c|c|c|c|c|}
\hline & $\begin{array}{c}\text { Family } \\
\text { sedentary } \\
\text { activity } \\
\end{array}$ & $\begin{array}{l}\text { Family } \\
\text { outdoor } \\
\text { physical } \\
\text { activity }\end{array}$ & $\begin{array}{l}\text { Minutes in } \\
\text { mod-to-vig } \\
\text { activity }\end{array}$ & $\begin{array}{c}\text { FNPA } \\
\text { total score }\end{array}$ & $\begin{array}{l}\text { Child } \\
\text { age }\end{array}$ & $\begin{array}{l}\text { Child } \\
\text { gender }\end{array}$ & $\begin{array}{c}\text { Parent } \\
\text { age }\end{array}$ & $\begin{array}{l}\text { Family } \\
\text { annual } \\
\text { income }\end{array}$ \\
\hline $\begin{array}{l}\text { FHLQ: Family } \\
\text { Sedentary activity }\end{array}$ & - & - & - & - & - & - & - & - \\
\hline $\begin{array}{l}\text { FHLQ: Family } \\
\text { outdoor physical } \\
\text { activity }\end{array}$ & .17 & - & - & - & - & - & - & - \\
\hline $\begin{array}{l}\text { FHLQ: Minutes in } \\
\text { moderate to vigorous } \\
\text { activity }\end{array}$ & $.50 * *$ & .34 & - & - & - & - & - & - \\
\hline FNPA: Total Score & .01 & -.17 & .02 & - & - & - & - & - \\
\hline Child age & .12 & $-.42 *$ & -.31 & .13 & - & - & - & - \\
\hline Child gender & .23 & .03 & .28 & .25 & -.09 & - & - & - \\
\hline Parent age & .16 & -.26 & .05 & $-.44 *$ & .02 & $-.41 *$ & - & - \\
\hline $\begin{array}{l}\text { Family annual } \\
\text { income }\end{array}$ & .06 & -.24 & $-.43^{*}$ & .08 & .27 & -.35 & .23 & - \\
\hline $\begin{array}{l}\text { Parent highest } \\
\text { education }\end{array}$ & -.17 & -.03 & -.24 & .11 & -.11 & -.19 & .17 & .39 \\
\hline
\end{tabular}


Table 8. Study One: Correlations: Demographics and Parenting Outcomes

\begin{tabular}{|c|c|c|c|c|c|c|c|c|c|c|c|}
\hline & $\begin{array}{l}\text { Positive } \\
\text { Parenting } \\
\text { Factor } \\
\end{array}$ & $\begin{array}{c}\text { Negative } \\
\text { Parenting } \\
\text { Factor }\end{array}$ & $\begin{array}{l}\text { Parental } \\
\text { Control } \\
\text { in Child } \\
\text { Feeding }\end{array}$ & Restriction & $\begin{array}{c}\text { Pressure } \\
\text { to Eat }\end{array}$ & $\begin{array}{c}\text { Monitoring } \\
\text { of Eating }\end{array}$ & $\begin{array}{l}\text { Total } \\
\text { Stress }\end{array}$ & $\begin{array}{l}\text { Child } \\
\text { age }\end{array}$ & $\begin{array}{l}\text { Child } \\
\text { gender }\end{array}$ & $\begin{array}{l}\text { Parent } \\
\text { age }\end{array}$ & $\begin{array}{l}\text { Family } \\
\text { annual } \\
\text { income }\end{array}$ \\
\hline $\begin{array}{l}\text { Positive Parenting } \\
\text { Factor }\end{array}$ & - & - & - & - & - & - & - & - & - & - & - \\
\hline $\begin{array}{l}\text { Negative } \\
\text { Parenting Factor }\end{array}$ & $-.43 *$ & - & - & - & - & - & - & - & - & - & - \\
\hline Restriction & -.23 & .19 & $.66 * * *$ & - & - & - & - & - & - & - & - \\
\hline Pressure to Eat & .08 & .32 & $62 * * *$ & -.05 & - & - & - & - & - & - & - \\
\hline $\begin{array}{l}\text { Monitoring of } \\
\text { Eating }\end{array}$ & .20 & .02 & .14 & $-.42 *$ & .12 & - & - & - & - & - & - \\
\hline Child age & -.24 & -.12 & .08 & .05 & -.04 & .13 & -.30 & - & - & - & - \\
\hline Child gender & .15 & -.20 & -.25 & $-.45 *$ & -.15 & $.52 * *$ & $.72 * * *$ & -.09 & - & - & - \\
\hline Parent age & -.14 & .13 & .09 & .21 & .09 & -.34 & $.44^{*}$ & .02 & $-.41 *$ & - & - \\
\hline $\begin{array}{l}\text { Family annual } \\
\text { income }\end{array}$ & -.07 & .28 & .31 & .33 & .18 & -.21 & .33 & .27 & -.35 & .23 & - \\
\hline $\begin{array}{l}\text { Parent highest } \\
\text { education }\end{array}$ & .13 & -.15 & .25 & .32 & .07 & -.16 & .14 & -.11 & -.19 & .17 & .39 \\
\hline
\end{tabular}

Note. $* * * p<.001,{ }^{* *} p<.01, * p<.05$. 


\section{Process Outcomes}

Attendance and homework completion. There were no differences in HLSC attendance among both groups $(p=.68)$. Children in HLSC+HLPP attended $87 \%$ of 38 camp days $(M=32.64, S D=5.48)$ and their parents attended $81 \%$ of the 9 HLPP sessions $(M=7.27, S D=1.49)$. Parents completed homework for $59 \%$ of the sessions $(M=4.73$, $S D=2.28)$. Children in HLSC attended $87 \%$ of 38 camp days $(M=33.38, S D=3.07)$.

Treatment satisfaction. There were no significant differences in treatment satisfaction between groups $(F(6,22)=1.64, p=.20)$. Parents were extremely satisfied with HLSC+HLPP. Specifically, on a seven-point Likert scale of strongly disagree to strongly agree, $100 \%$ of parents strongly agreed that their child benefited from the program and $90 \%$ strongly agreed that they benefited from the program, $80 \%$ strongly agreed that they and their child enjoyed the program, $90 \%$ strongly agreed that the program taught them effective strategies that helped change their family's healthy habits, and $90 \%$ strongly agreed that they would recommend HLSC+HLPP to other parents. Regarding HLSC, parents were also satisfied with program. Specifically, 100\% strongly agreed or agreed that their child benefited from the program, $76.9 \%$ of parents strongly agreed or agreed that their family benefited from the program, 100\% strongly agreed or agreed that their child enjoyed the program, $84.6 \%$ strongly agreed or agreed that they enjoyed the program, $69.2 \%$ strongly agreed or agreed that the program taught them and their child effective strategies that helped change their family's healthy habits, and 100\% strongly agreed or agreed that they would recommend HLSC to other parents. Further excerpts of participants' responses to the open-ended satisfaction questions are displayed in Table 9. 


\section{Table 9. Study One: Program Satisfaction}

\begin{tabular}{|c|c|}
\hline Group & Statement \\
\hline HLSC+HLPP & $\begin{array}{l}\text { Please try to spread this program to more areas. I find it so beneficial and would love more kids having the } \\
\text { chance to be part of this program. I wouldn't change anything. }\end{array}$ \\
\hline HLSC+HLPP & Child's self-esteem has increased thanks to positive reinforcement and rewards. Thank you! \\
\hline HLSC+HLPP & $\begin{array}{l}\text { Everyone involved with the program was excellent and I have already recommended it to other parents and } \\
\text { hope we can do it again. }\end{array}$ \\
\hline HLSC+HLPP & $\begin{array}{l}\text { [The counselors] were all amazing with the boys! [The parenting program facilitator] was an awesome } \\
\text { facilitator and really made the parent meetings interesting, fun and insightful. }\end{array}$ \\
\hline HLSC+HLPP & $\begin{array}{l}\text { My child absolutely loved the program and we beg you continue it. Being on the heavier side as a child, I } \\
\text { wish more programs like this existed. I've recommended it to many people. What has helped the most is } \\
\text { portion control. I feel he is more confident and more secure in himself to make the healthy choices. }\end{array}$ \\
\hline HLSC+HLPP & $\begin{array}{l}\text { The entire program was amazing. It really taught my boys the importance of eating healthy and being } \\
\text { physically active. The 'Food of the Day' was definitely a very beneficial component overall. }\end{array}$ \\
\hline HLSC & $\begin{array}{l}\text { All counselors were attentive and caring. I believe that the passion of setting the kids up with a goal and } \\
\text { watching them achieve it has a lot to say of the people involved helping them get to that goal and more! } \\
\text { Thank you for all you do! }\end{array}$ \\
\hline HLSC & $\begin{array}{l}\text { Great team. The lead teachers and staff working there are all professionals and knowledgeable. We loved } \\
\text { the experience and would do it again. My kids learned so much about eating healthier. }\end{array}$ \\
\hline HLSC & Great program for kids and parents. \\
\hline HLSC & I like the fact that he was exercising every day and since it was fun it wasn't like a chore. \\
\hline HLSC & $\begin{array}{l}\text { My daughter came out with knowledge of what's good for her body and what isn't! She is more conscious } \\
\text { of the type of food she should be eating instead of the ones that are not so healthy. She has improved so } \\
\text { much on her stamina: walking, running. Overall, I know this program has brought awareness to both my } \\
\text { daughter and myself. }\end{array}$ \\
\hline
\end{tabular}


Fidelity. Treatment fidelity was completed on $20 \%$ of the HLPP sessions and excellent fidelity was achieved (100\%). Regarding HLSC, $21 \%$ of camp days were observed and fidelity was excellent for both groups (HLSC+HLPP: $M=99.61 \%$, range 96.7-100\%, HLSC: $M=97.43 \%$, range $98-100 \%$ ).

\section{Main Health Outcomes}

Child and parent anthropometrics. After accounting for covariates, there was a main effect of time, $\mathrm{F}(1,20)=16.35, p=.001$, partial $\eta 2=.45$, but no significant interaction between group and time on BMI z-score, $F(1,20)=0.00, p=1.00$, partial $\eta 2=$ .00 . These results indicate that child BMI z-score decreased from pre- to post-treatment in both groups at a similar rate (HLSC+HLPP: $g=-.31$; HLSC: $g=-.31$ ). No statistically significant effects were found for parent BMI (see Table 7).

Parent and child fitness. After accounting for covariates, there was a main effect of time $(F(1,20)=7.65, p=.01$, partial $\eta 2=.30)$, indicating that children's fitness levels, as measured by side-to-side jumps, increased from pre- to post-treatment in both groups with large effect sizes observed (HLSC+HLPP: $g=1.70$; HLSC: $g=1.77$ ). There was not a statistically significant interaction between the intervention group and time on child fitness as measured by side-to-side jumps (see Table 10). No statistically significant effects for the remaining fitness variables were observed including SBP, DBP, and HR for both parent and child (see Table 10). 
Table 10. Study One: Main Health Outcomes

\begin{tabular}{|c|c|c|c|c|c|c|c|}
\hline & $\begin{array}{l}\text { Pre-Tx } \\
M(S E)\end{array}$ & $\begin{array}{l}\text { Post-Tx } \\
M(S E)\end{array}$ & $\begin{array}{c}\text { Time } \mathrm{x} \\
\text { Group } \\
\text { Effect } \\
\quad F \\
\end{array}$ & $\begin{array}{c}\text { Time } \mathrm{x} \\
\text { Group } \\
\text { Effect } \\
p \\
\end{array}$ & $\begin{array}{c}\text { Time } \\
\text { Effect } \\
\quad F\end{array}$ & $\begin{array}{c}\text { Time } \\
\text { Effect } \\
p\end{array}$ & $\begin{array}{l}\text { Pre-Tx to Post-Tx } \\
g[95 \% \mathrm{CI}]\end{array}$ \\
\hline \multicolumn{8}{|l|}{ Main Health Outcomes } \\
\hline BMI z-score $(\mathrm{C})$ & & & .00 & 1.00 & 16.35 & $.001 * * *$ & - \\
\hline HLSC+HLPP & $2.25(.16)$ & $2.07(.18)$ & - & - & - & - & $-.31[-.55,-.06]^{*}$ \\
\hline HLSC & $1.90(.14)$ & $1.73(.16)$ & - & - & - & - & $-.31[-.51,-.11]^{*}$ \\
\hline $\mathrm{BMI}(\mathrm{P})$ & & & .75 & .40 & .25 & .62 & - \\
\hline HLSC+HLPP & $30.72(2.42)$ & $30.19(2.53)$ & - & & - & - & $-.07[-3.50,3.36]$ \\
\hline HLSC & $28.52(2.08)$ & $28.35(2.18)$ & - & - & - & - & $-.02[-2.98,2.93]$ \\
\hline Fitness: Side-to-side jumps (C) & & & .02 & .89 & 7.65 & $.01 * *$ & - \\
\hline HLSC+HLPP & $22.98(2.71)$ & $42.46(4.10)$ & & - & - & - & $1.70[-3.12,6.51]$ \\
\hline HLSC & $21.40(2.37)$ & $41.49(3.59)$ & & - & - & - & $1.77[-2.44,5.99]$ \\
\hline $\operatorname{SBP}(C)$ & & & 0.00 & .96 & .22 & .64 & - \\
\hline HLSC+HLPP & $105.11(1.81)$ & $104.67(3.18)$ & - & - & - & - & $-.05[-3.64,3.53]$ \\
\hline HLSC & $109.36(1.59)$ & $108.69(2.78)$ & - & - & - & - & $-.08[-3.22,3.06]$ \\
\hline $\mathrm{DBP}(\mathrm{C})$ & & & .52 & .48 & .02 & .89 & - \\
\hline HLSC+HLPP & $68.10(1.54)$ & $64.97(3.67)$ & - & - & - & - & $-.34[-4.24,3.57]$ \\
\hline HLSC & $68.85(1.35)$ & $69.00(3.22)$ & - & - & - & - & $.02[-3.40,3.43]$ \\
\hline $\operatorname{HR}(\mathrm{C})$ & & & .13 & .72 & 2.59 & .13 & - \\
\hline HLSC + HLPP & $94.75(4.65)$ & $93.47(5.54)$ & - & - & - & - & $-.08[-7.16,7.01]$ \\
\hline HLSC & 89.17 (4.07) & $90.35(4.85)$ & - & - & - & - & $.07[-6.13,6.27]$ \\
\hline $\operatorname{SBP}(\mathrm{P})$ & & & 2.33 & .15 & .44 & .52 & - \\
\hline HLSC + HLPP & $126.02(5.77)$ & $127.97(6.25)$ & - & - & - & - & $.10[-8.23,8.44]$ \\
\hline HLSC & $126.55(5.47)$ & $120.66(5.92)$ & - & - & - & - & $-.31[-8.21,7.58]$ \\
\hline $\mathrm{DBP}(\mathrm{P})$ & & & .98 & .34 & .51 & .49 & - \\
\hline HLSC+HLPP & $80.00(3.63)$ & $81.81(4.33)$ & - & - & - & - & $.14[-5.39,5.68]$ \\
\hline HLSC & $81.50(3.43)$ & $80.24(4.10)$ & - & - & - & - & $-.10[-5.34,5.14]$ \\
\hline $\mathrm{HR}(\mathrm{P})$ & & & .02 & .91 & 2.15 & .16 & - \\
\hline HLSC + HLPP & $75.19(3.19)$ & $83.51(4.72)$ & - & - & - & - & $.66[-4.93,6.24]$ \\
\hline HLSC & $69.56(3.02)$ & $76.94(4.47)$ & - & - & - & - & $.59[-4.70,5.87]$ \\
\hline
\end{tabular}




\section{Mechanistic Outcomes}

Nutrition. After accounting for covariates, there were no statistically significant main effects or interactions between the intervention group and time on child total calories. However, medium to large effects were observed in both groups on child total calories from pre- to post-treatment (HLSC+HLPP: $g=-.81$; HLSC: $g=-.57$ ). Additionally, there were medium to large effects observed from pre- to post-treatment in reduction of child daily fat grams $(g=-.81)$ and increase in child daily fruit $(g=.67)$ for children in HLSC.

In terms of nutritional health classification and expressive knowledge, after accounting for covariates, there was a main effect of time on nutritional health classification $(F(1,18)=7.72, p=.01$, partial $\eta 2=.30)$, indicating that children in both groups improved their classification after the intervention (see Table 11). There were no significant interactions between time and intervention group. However, large effect sizes were observed in both groups from pre- to post-treatment for both nutritional health classification (HLSC+HLPP: $g=1.54$; HLSC: $g=.82$ ) and expressive knowledge (HLSC+HLPP: $g=1.03$; HLSC: $g=1.06$ ). No statistically significant effects for the remaining nutrition variables were observed (see Table 11). 


\begin{tabular}{|c|c|c|c|c|c|c|c|}
\hline & $\begin{array}{l}\text { Pre-Tx } \\
M(S E)\end{array}$ & $\begin{array}{l}\text { Post-Tx } \\
M(S E)\end{array}$ & $\begin{array}{c}\text { Time } x \\
\text { Group } \\
\text { Effect } \\
\quad F\end{array}$ & $\begin{array}{l}\text { Time } \mathrm{x} \\
\text { Group } \\
\text { Effect } p\end{array}$ & $\begin{array}{l}\text { Time } \\
\text { Effect } F\end{array}$ & $\begin{array}{l}\text { Time } \\
\text { Effect } \\
p\end{array}$ & $\begin{array}{l}\text { Pre-Tx to Post-Tx } \\
\quad G[95 \% \mathrm{CI}]\end{array}$ \\
\hline ASA-24-2016: Calories (C) & & & .19 & .67 & 1.97 & .18 & - \\
\hline HLSC+HLPP & $1254.86(118.14)$ & $955.98(115.20)$ & - & - & - & - & $-.81[-162.52,160.90]$ \\
\hline HLSC & $1445.06(98.12)$ & $1240.17(95.68)$ & - & - & - & - & $-.57[-134.87,133.73]$ \\
\hline ASA-24-2016: Calories (P) & & & 3.59 & .08 & .11 & .75 & - \\
\hline HLSC+HLPP & $1274.15(257.05)$ & $1671.30(232.82)$ & - & - & - & - & $.57[-339.30,340.44]$ \\
\hline HLSC & $1635.44(214.07)$ & $1272.63(193.90)$ & - & - & - & - & $\begin{array}{c}-.54[-283.59 \\
282.51]\end{array}$ \\
\hline ASA-24-2016: Fat (C) & & & 1.24 & .28 & .00 & .97 & - \\
\hline HLSC+HLPP & $36.48(6.76)$ & $32.72(6.46)$ & - & - & - & - & $-.18[-9.34,8.98]$ \\
\hline HLSC & $57.11(5.62)$ & $40.59(5.36)$ & - & - & - & - & $-.81[-8.42,6.80]$ \\
\hline ASA-24-2016: Fat (P) & & & .82 & .38 & .13 & .72 & - \\
\hline HLSC+HLPP & $55.03(25.01)$ & $57.04(12.11)$ & - & - & - & - & $.04[-27.19,27.26]$ \\
\hline HLSC & $74.21(20.83)$ & $49.57(10.09)$ & - & - & - & - & $-.46[-23.13,22.22]$ \\
\hline ASA-24-2016: Total daily fruit (C) & & & 2.49 & .13 & .82 & .38 & - \\
\hline HLSC & $.71(.33)$ & $1.63(.40)$ & - & - & - & - & $.67[.17,1.18]$ \\
\hline ASA-24-2016: Total daily fruit (P) & & & 1.01 & .33 & .27 & .62 & - \\
\hline HLSC+HLPP & $.90(.24)$ & $.51(.15)$ & - & - & - & - & $-.69[-.97,-.42]$ \\
\hline HLSC & $.38(.20)$ & $.31(.12)$ & - & - & - & - & $-.13[-.36, .10]$ \\
\hline ASA-24-2016: Total daily vegetables(C) & & & .87 & .36 & .02 & .90 & - \\
\hline HLSC+HLPP & $.41(.18)$ & $.89(.31)$ & - & - & - & - & $.61[.26, .95]$ \\
\hline HLSC & $.62(.15)$ & $.67(.25)$ & - & - & - & - & $.06[-.22, .35]$ \\
\hline ASA-24-2016: Total daily vegetables(P) & & & .11 & .75 & 2.77 & .12 & - \\
\hline HLSC+HLPP & $1.07(.51)$ & $1.12(.65)$ & - & - & - & - & $.03[-.78, .84]$ \\
\hline HLSC & $1.41(.43)$ & $1.71(.54)$ & - & - & - & - & $.19[-.48, .86]$ \\
\hline DIANA: Health Classification Total & & & 1.96 & .18 & 7.72 & $.01 * *$ & - \\
\hline Score $(\mathrm{C})$ & $29.89(1.79)$ & $37.30(1.02)$ & - & - & - & - & $1.54[-.48,3.56]$ \\
\hline $\begin{array}{l}\text { HLSC+HLPP } \\
\text { HLSC }\end{array}$ & $31.86(1.57)$ & $35.77(.89)$ & - & - & - & - & $.82[-.94,2.59]$ \\
\hline DIANA:Expressive Knowledge Total & & & .01 & .94 & 3.38 & .08 & - \\
\hline $\operatorname{Score}(\mathrm{C})$ & $19.50(.83)$ & $22.00(.62)$ & - & - & - & - & $1.03[.02,2.05]$ \\
\hline
\end{tabular}


Note. Means and SEs are marginal estimates after controlling for children's age and gender, and family income. ${ }^{* *} \mathrm{p}<.01,{ }^{*} \mathrm{p}<.05 . \mathrm{C}=$ child measure, $\mathrm{P}=$ parent measure, ASA-24-2016 = Automated Self-Administered 24-hour Dietary Assessment Tool (Kirkpatrick et al., 2014), DIANA = Dietary Interview Assessment Nutritional Awareness (Graziano, 2015). 
Physical activity. After accounting for covariates, there was a statistically significant interaction between time and intervention group on family frequency of outdoor physical activity $(F(1,18)=5.33, p=.03$, partial $\eta 2=.24)$, with families in the HLSC group spending more time after the intervention participating in outdoor physical activity ( $g$ $=.62)$, compared to families in HLSC+HLPP $(g=-.23)$. No statistically significant effects for the remaining physical activity variables were observed (see Table 12). In terms of effects, there was an increase in minutes spent in moderate to vigorous activity for families in HLSC+HLPP with a small effect observed from pre- to post-treatment $(g=.42)$. However, for families in HLSC, there was a decrease in minutes spent in moderate to vigorous activity $(g=-.35)$.

Family home environment. After accounting for covariates, there were no statistically significant effects found for family home environment (see Table 12). Still, both groups improved on the healthfulness of their home environment from pre- to posttreatment with small to large effects observed (HLSC+HLPP: $g=.40$; HLSC: $g=1.05$ ).

Parenting. After accounting for covariates, there was a main effect of time on monitoring of eating $(F(1,18)=8.50, p=.01$, partial $\eta 2=.32)$, but no group by time interaction $(F(1,18)=.01, p=.94)$. These results indicate that parents across both groups reported similar higher levels of monitoring after the intervention (HLSC+HLPP: $g=.51$; HLSC: $g=.49)$. Furthermore, there was a statistically significant interaction between time and intervention group on parenting stress $(F(1,18)=5.64, p=.03$, partial $\eta 2=.24)$, with parents in HLSC reporting less parenting stress after the intervention $(g=-.39)$, compared to parents in HLSC+HLPP who actually experienced an increase in stress $(g=.59)$. No 
statistically significant effects for the remaining parenting variables were found (see Table 12). 


\begin{tabular}{|c|c|c|c|c|c|c|c|}
\hline & $\begin{array}{l}\text { Pre-Tx } \\
M(S E)\end{array}$ & $\begin{array}{l}\text { Post-Tx } \\
M(S E)\end{array}$ & $\begin{array}{l}\text { Time } \mathrm{x} \\
\text { Group } \\
\text { Effect } \\
\quad F\end{array}$ & $\begin{array}{l}\text { Time } \mathrm{x} \\
\text { Group } \\
\text { Effect } \\
p\end{array}$ & $\begin{array}{l}\text { Time } \\
\text { Effect } \\
\quad F\end{array}$ & $\begin{array}{l}\text { Time } \\
\text { Effect } \\
p\end{array}$ & $\begin{array}{l}\text { Pre-Tx to Post-Tx } \\
\quad G[95 \% \mathrm{CI}]\end{array}$ \\
\hline $\begin{array}{l}\text { Mechanistic Outcomes } \\
\text { Physical Activity }\end{array}$ & & & & & & & \\
\hline $\begin{array}{l}\text { FHLQ: Family Sedentary activity(P) } \\
\text { HLSC+HLPP } \\
\text { HLSC }\end{array}$ & $\begin{array}{l}2.18(.57) \\
2.63(.50)\end{array}$ & $\begin{array}{l}1.82(.53) \\
1.99(.46)\end{array}$ & $\begin{array}{l}.27 \\
- \\
-\end{array}$ & $\begin{array}{l}.61 \\
- \\
-\end{array}$ & $\begin{array}{l}.41 \\
- \\
-\end{array}$ & $\begin{array}{l}.53 \\
- \\
-\end{array}$ & $\begin{array}{c}- \\
-.20[-.96, .56] \\
-.36[-1.02, .31]\end{array}$ \\
\hline $\begin{array}{l}\text { FHLQ: Family outdoor physical } \\
\text { activity (P) } \\
\text { HLSC+HLPP } \\
\text { HLSC }\end{array}$ & $\begin{array}{l}1.76(.34) \\
1.70(.31)\end{array}$ & $\begin{array}{l}1.45(.47) \\
2.54(.43)\end{array}$ & $\begin{array}{c}5.33 \\
- \\
-\end{array}$ & $\begin{array}{c}.03 * \\
- \\
-\end{array}$ & $\begin{array}{c}4.62 \\
- \\
-\end{array}$ & $\begin{array}{c}.05^{*} \\
- \\
-\end{array}$ & $\begin{array}{c}- \\
-.23[-.80, .34] \\
.62[.10,1.14]\end{array}$ \\
\hline $\begin{array}{l}\text { FHLQ: Minutes in moderate to } \\
\text { vigorous activity (P) } \\
\text { HLSC+HLPP } \\
\text { HLSC }\end{array}$ & $\begin{array}{l}27.88(11.52) \\
43.94(10.08)\end{array}$ & $\begin{array}{l}41.33(7.65) \\
32.82(6.69)\end{array}$ & $\begin{array}{c}2.15 \\
- \\
-\end{array}$ & $\begin{array}{l}.16 \\
- \\
-\end{array}$ & $\begin{array}{c}2.30 \\
- \\
-\end{array}$ & $\begin{array}{l}.15 \\
- \\
-\end{array}$ & $\begin{array}{c}- \\
.42[-13.13,13.97] \\
-.35[-12.21,11.51]\end{array}$ \\
\hline $\begin{array}{l}\text { Family Home Environment } \\
\text { FNPA: Total Score (P) } \\
\text { HLSC+HLPP } \\
\text { HLSC }\end{array}$ & $\begin{array}{l}62.93(2.56) \\
54.75(2.24)\end{array}$ & $\begin{array}{l}66.17(2.33) \\
63.10(2.04)\end{array}$ & $\begin{array}{c}3.30 \\
- \\
-\end{array}$ & $\begin{array}{l}.09 \\
- \\
-\end{array}$ & $\begin{array}{l}2.97 \\
- \\
-\end{array}$ & $\begin{array}{l}.10 \\
- \\
-\end{array}$ & $\begin{array}{c}- \\
.40[-2.99,3.79] \\
1.05[-1.924 .02]\end{array}$ \\
\hline $\begin{array}{l}\text { Parenting } \\
\text { APQ: Positive Parenting Factor (P) } \\
\text { HLSC+HLPP } \\
\text { HLSC }\end{array}$ & $\begin{array}{l}69.05(2.01) \\
69.96(1.76)\end{array}$ & $\begin{array}{l}72.68(1.85) \\
70.63(1.62)\end{array}$ & $\begin{array}{c}1.38 \\
- \\
-\end{array}$ & $\begin{array}{l}.25 \\
- \\
-\end{array}$ & $\begin{array}{c}1.64 \\
- \\
-\end{array}$ & $\begin{array}{l}.22 \\
- \\
-\end{array}$ & $\begin{array}{c}- \\
.57[-2.10,3.24] \\
.11[-2.23,2.45]\end{array}$ \\
\hline $\begin{array}{l}\text { APQ: Negative Parenting Factor }(\mathrm{P}) \\
\text { HLSC+HLPP } \\
\text { HLSC }\end{array}$ & $\begin{array}{l}31.40(2.00) \\
26.92(1.75)\end{array}$ & $\begin{array}{l}29.19(1.66) \\
25.24(1.46)\end{array}$ & $\begin{array}{c}.06 \\
- \\
-\end{array}$ & $\begin{array}{l}.81 \\
- \\
-\end{array}$ & $\begin{array}{l}.34 \\
- \\
-\end{array}$ & $\begin{array}{l}.57 \\
- \\
-\end{array}$ & $\begin{array}{l}- \\
-.36[-2.91,2.19] \\
-.28[-2.51,1.95]\end{array}$ \\
\hline $\begin{array}{l}\text { CFQ: Parental Control in Child } \\
\text { Feeding Domain (P) } \\
\text { HLSC+HLPP } \\
\text { HLSC }\end{array}$ & $\begin{array}{l}3.60(.12) \\
3.44(.11)\end{array}$ & $\begin{array}{l}3.42(.16) \\
3.22(1.42)\end{array}$ & $\begin{array}{l}.02 \\
- \\
-\end{array}$ & $\begin{array}{l}.88 \\
- \\
-\end{array}$ & $\begin{array}{c}1.94 \\
- \\
-\end{array}$ & $\begin{array}{l}.18 \\
- \\
-\end{array}$ & $\begin{array}{c}- \\
-.38[-.58,-.18] \\
-.06[-1.45,1.34]\end{array}$ \\
\hline $\begin{array}{l}\text { CFQ: Restriction (P) } \\
\text { HLSC+HLPP } \\
\text { HLSC } \\
\text { CFQ: Pressure to Eat }(\mathrm{P})\end{array}$ & $\begin{array}{l}4.13(.18) \\
3.87(.16)\end{array}$ & $\begin{array}{l}3.74(.23) \\
3.36(.21)\end{array}$ & $\begin{array}{l}.15 \\
- \\
- \\
.13\end{array}$ & $\begin{array}{l}.71 \\
- \\
- \\
.73\end{array}$ & $\begin{array}{c}1.38 \\
- \\
- \\
1.08\end{array}$ & $\begin{array}{l}.25 \\
- \\
- \\
.31\end{array}$ & $\begin{array}{c}- \\
-.57[-.86,-.28] \\
-.75[-1.00,-.49] \\
-\end{array}$ \\
\hline
\end{tabular}


HLSC+HLPP

HLSC

CFQ: Monitoring of Eating $(\mathrm{P})$

HLSC+HLPP

HLSC

PSI: Total Stress

HLSC+HLPP

HLSC

$2.15(.27)$

$2.46(.24)$

$1.93(.33)$

$2.35(.29)$

$4.15(.22)$

$3.60(.19)$

4.57 (.28)

$65.59(3.68)$

$4.00(.24)$

$56.06(6.78)$

Note. Means and SEs are marginal estimates after controlling for children's

measure, $\mathrm{P}=$ parent measure, FHLQ = Family Healthy-Lifestyle Questionnaire (Graziano, unpublished), FNPA = Family Nutrition and

Physical Activity screening tool (Ihmels et al., 2009), APQ = Alabama Parenting Questionnaire (Shelton et al., 1996), CFQ = Child Feeding

Questionnaire (Birch et al. 2001), and PSI = Parenting Stress Index (Abidin, 1995). 


\section{STUDY 1: DISCUSSION}

The current study examined, via a randomized trial, the efficacy of the Healthy Lifestyle Summer Camp and Parenting program (HLSC+PP) compared to the Health Lifestyle Summer Camp (HLSC) on improving child and parent health outcomes as well as mechanistic outcomes (e.g., family home environment, family healthy habits, parenting strategies, and feeding practices). Our results indicated that both HLSC+HLPP and HLSC were feasible and acceptable. Statistically significant group differences were found only for outdoor physical activity and parenting stress. Families in HLSC reported spending more time after the intervention participating in outdoor physical activity compared to families in HLSC+HLPP. Also, parents in HLSC reported less parenting stress after the intervention compared to parents in HLSC+HLPP. However, it's important to note that both groups demonstrated statistically significant improvements after the intervention in child BMI z-score, child fitness (as measured via side-to-side jumps), health classification scores, and parental monitoring. These findings are further discussed below.

Consistent with our hypotheses, there was a statistically significant improvement in child Body Mass Index z-score in both groups from pre- to post-treatment. This indicates that both interventions contribute to beneficial weight changes in children. Our findings are consistent with prior work (Graziano et al., 2017), which demonstrated a reduction in child BMI z-score after HLSC+HLPP at post-treatment and six-eight month follow-up. Unfortunately, we were unable to analyze follow-up data in the current study. Consistent with the Familial Approach to the Treatment of Childhood Obesity: Conceptual Model (Golan \& Weizman, 2001), we would have expected to see maintenance of our findings for 
HLSC+HLPP. Nonetheless, our findings build upon the conceptual model and aforementioned work by showing improvements in child BMI z-score at post-treatment in both the intervention with and without a parenting component (Golan \& Weizman, 2001). Our results imply that in the context of a summer intensive intervention focused on improving child health outcomes, a parenting component may not be necessary. It may be the case that the increased physical activity and monitoring of food in the HLSC curriculum is enough to produce immediate meaningful changes in a child's weight status after the intervention, regardless of parental involvement. This is consistent with Gately et al. (2000) and Gately et al. (2005), who demonstrated reductions in child BMI z-score in both a residential weight loss camp without parental involvement (Gately et al., 2005) and a residential weight loss camp where parents attended a weekend of healthy lifestyle courses (Gately et al., 2000). Future research should examine if these changes are maintained during a follow-up period for both HLSC+HLPP and HLSC as well as in a large sample.

Regarding parents, there were no statistically significant changes in parent Body Mass Index with small effects observed in both groups (HLSC+HLPP $g=-.07$; HLSC $g=$ .02). Given that the foundation of both intervention groups was a summer camp for children, parents in both groups might have been more focused on making changes in their children and were more remiss of their own healthy habits. Furthermore, the HLPP curriculum is presented in a didactic format and does not include in-session physical activity components. Therefore, it is up to the participant to engage in weekly physical activity. Again, parents in HLSC+HLPP may have focused on increasing their child's physical activity instead of their own. Future research could include in-session physical 
activity during interventions that include parents. This is consistent with The Salud Con La Familia study which was a 12-week family-based healthy lifestyle program that included in-session family physical activities (Barkin, et al., 2012). Furthermore, in-session physical activity may produce improvements in family-health outcomes and parenting behaviors. For example, in a parenting intervention for children with behavior problems that consisted of a parenting group followed by a family soccer game, Fabiano et al. (2012) demonstrated improvements in fathers' positive parenting.

In terms of fitness, large effect sizes were observed for child side-to-side jumps in both groups which is consistent with previous work (Graziano et al., 2017). Changes in both groups were expected due to the focus on physical activity in the HLSC curriculum. In terms of blood pressure, small effect sizes were found for child and parent. this is not surprising and may be a result of the short length of the intervention and small BMI reductions (Aucott et al., 2009). However, given the large effects observed in child sideto-side jumps, it can be expected that over time, there would be improvements in child SBP/DBP (Gaya et al., 2009). Future studies should examine long term changes in blood pressure following a healthy-lifestyle intervention.

In terms of nutrition, there were medium to large effects observed after the intervention in the reduction of total daily calories for both groups. A possible explanation is that children in both groups were learning the Stop-Light-Diet system during HLSC and therefore may have been implementing some of these skills at home. Additionally, children were eating three out of five meals per day and having their food monitored during HLSC. It may be the case that children consume excessive calories and unhealthy foods during the school day, as opposed to breakfast and dinner at home. In 
fact, Schanzenbach (2009), demonstrated that kindergarten students who eat lunch from the National School Lunch Program gain more weight by the end of $1^{\text {st }}$ grade compared to students who bring their lunch to school. It would be important for future research to include measures of caloric intake at home and school in order to examine these differences.

Furthermore, HLSC+HLPP demonstrated a medium effect post intervention in increased consumption of child vegetables, while HLSC showed medium to large effects for decreases in child fat grams, and an increase in child daily fruit consumption. A possible explanation is that children in HLSC may have focused on the Stop-Light-Diet system which emphasizes recognizing and reducing fat grams while children in HLSC+HLPP had parents who were focused on increasing consumption of healthy foods (a recommendation and weekly focus in HLPP). Furthermore, consistent with the Familial Approach to the Treatment of Childhood Obesity: Conceptual model (Golan \& Weizman, 2001), the HLPP curriculum includes sessions on behavioral modification strategies, which may have helped parents in HLSC+HLPP during mealtime with getting their child to try new foods (e.g., vegetables). In fact, previous research has demonstrated that using behavioral modification strategies increases fruit and vegetable intake (Jones et la., 2014; Just \& Price, 2013). Moreover, future research should use The Healthy Eating Index (HEI; Krebs-Smith et al., 2018) to assess how well the family's food choices align with the recommendations of the Dietary Guidelines for Americans (USDHHS and USDA, 2015). Using the HEI might be a better indicator of overall nutrition habits rather than examining macronutrients independently. Additionally, children in both groups showed a statistically significant improvement in their nutritional health classification 
after the intervention. This was expected as both groups were learning the Stop-LightDiet system during HLSC which focuses on classifying the healthfulness of foods.

Regarding physical activity, families in the HLSC group spent significantly more time after the intervention participating in outdoor physical activity compared to families in HLSC+HLPP. Given that parents in HLSC+HLPP had to dedicate one evening per week to attend the parenting session, these parents had less opportunities to participate in outdoor activities and therefore this may have contributed to this finding. Moreover, there was an increase in minutes spent in moderate to vigorous activity for families in HLSC+HLPP while families in HLSC had a decrease in minutes spent in moderate to vigorous activity. Hence, HLPP may have helped increase physical activity in families in HLSC+HLPP by including sessions on increasing moderate to vigorous activity and multiple ways of achieving this (e.g., indoor physical activity, daily opportunities for physical activity). This is consistent with a parent-based obesity intervention (McGarvey et al., 2004) that demonstrated an increase in frequency of engaging in active play after educational groups focused on nutrition and physical activity. For HLSC, the reduction in minutes spent in moderate to vigorous activity may have been due to parents not providing opportunities for physical activity at home since children were spending the day in a summer camp which included physical activity and therefore not needing additional physical activity. Furthermore, frequency of sedentary activity was reduced in both groups, with small effects observed (HLSC+HLPP: $g=-.20$; HLSC: $g=-.36$ ), which is consistent with prior work that found a reduction in sedentary behaviors after a 10-session family-based intervention (Moores et al., 2018). 
Both intervention groups improved the healthfulness of their home environment from pre- to post-treatment with HLSC showing a large effect $(g=1.05)$. This is not surprising as the HLSC curriculum includes education on improving the home environment (e.g., food and beverage choices, screen time, child physical activity). Consistent with the Hunter Illawarra Kids Challenge Using Parent Support (HIKCUPS; Collins et al., 2010) study which found an increase in monitoring after the intervention, parents across both HLSC+HLPP and HLSC reported similar higher levels of monitoring after the intervention. It is plausible that since parents in both groups were concerned about their child's health status and sought an obesity intervention, that both groups would focus on monitoring their child's food intake after the intervention. Furthermore, parents in the HLSC+HLPP reported higher stress after the intervention compared to parents in the HLSC. It is likely that parents in the HLSC+HLPP felt more stressed at the end of the intervention because they had the added pressure of attending parenting groups and implementing new skills weekly compared to parents in the HLSC who were not learning new skills. Guilfoyle et al. (2010) suggests that caregivers who are beginning weight management treatment for their child likely experience parenting stress especially when the new healthy behaviors are in contrast to their own current behaviors (e.g. fast-food consumption). Therefore, parents in the HLSC+HLPP who are focusing on changing their own health behaviors in addition to their child's, may experience more stress than parents in the HLSC who do not have the added parent component.

\section{Study Limitations}

Limitations of this study should be noted. First, mechanistic data were self-report and therefore may be subject to rater bias. Objective measures should be employed in 
future studies. Specifically, dietary data can be collected via wearable digital devices as done in Gemming et al. (2015) which showed that wearing a digital device increased underreporting of dietary intake between 6-8\% compared to multiple-pass 24 -hour dietary recalls. Second, given the small sample size and the significant number of families who did not complete the follow-up assessment (33\%), we were unable to examine maintenance effects. Future research should take into account the attrition difficulties at follow-up seen in this study to ensure a sufficient sample size is obtained in order to examine whether findings are maintained over time. Third, the parenting group was not examined alone and therefore we were unable to examine the unique contributions of the parenting program. Future intervention studies should include a parent-only comparison group as suggested by the Familial Approach to the Treatment of Childhood Obesity conceptual model (Golan \& Weizman, 2001).

\section{Conclusions}

Despite the aforementioned limitations, this study demonstrates the feasibility, acceptability, and improvement of child health outcomes after both the HLSC+HLPP and HLSC. Future research should examine these findings after a follow-up period to determine if the findings are maintained or if there are group differences. Furthermore, integrating technology and obesity interventions could be beneficial for families that would otherwise not have access to this type of program as well as for families that may not have the flexibility in their schedules to attend live sessions. Online health interventions for children and adolescents appear to be a rapid area of research (Vidmar et al., 2019; Rodriguez-Rocha \& Kim, 2019; Bradley et al., 2019). The Time2bHealthy program, a parent-based online childhood obesity program for children ages two-five 
years demonstrated improvements in child health outcomes after the intervention compared to a control group (Hammersley et al., 2019). Moreover, a recent review of electronic-health interventions, suggests the need for transforming successful in person interventions into online formats, and including younger age groups (Hammersley, 2016). Future work in the HLSC+HLPP can include transforming the parenting component to self-directed online modules and online discussion groups to examine whether the results are comparable to the current study. 


\section{STUDY 2: CURRENT STUDY}

The Obesity-Related Behavioral Intervention Trials Model (ORBIT Model; Czajkowski et al., 2015) is a model for developing behavioral treatments to prevent and/or manage chronic disease developed by experts in the field (e.g., National Institutes of Health Office of Behavioral and Social Sciences Research (OBSSR), the National Heart, Lung, and Blood Institute (NHLBI), the National Cancer Institute (NCI), the National Institute of Diabetes, Digestive and Kidney Diseases (NIDDK), the Eunice Kennedy Shriver National Institute of Child Health and Human Development (NICHD), and investigators from the ORBIT consortium). In accordance with Phase IIa of the ORBIT model (Czajkowski et al., 2015), the purpose of this study was to examine, via an open trial, the feasibility, acceptability, and initial promise of implementing the Healthy Lifestyle Parenting Program (HLPP) within a community setting. We expected that it would be feasible and acceptable to provide HLPP in the community as evidenced by a minimum attendance rate of $50 \%$ and a minimum satisfaction rating of $80 \%$. In accordance with previous research suggesting the importance of parental involvement in child healthy habits (Graziano et al., 2017; Collins et al., 2011; Coto et al., 2019) and the Familial Approach to the Treatment of Childhood Obesity conceptual model (Golan \& Weizman, 2001) we expected that families would significantly improve their health outcomes (e.g., BMI and fitness) from pre-treatment to three-month follow-up. Within the mechanistic outcomes, we expected that families who complete HLPP would significantly improve their family home environment, family healthy habits (i.e., nutrition, physical activity), parenting strategies, and child feeding practices. 


\section{STUDY 2: METHOD}

\section{Participants and Recruitment}

Following institutional review board approval, recruitment was conducted at local schools during health screenings where graduate students measured children's BMI and provided parents with results and flyers. Also, flyers were displayed in the waiting rooms of local children's hospitals, pediatrician's offices, and libraries. Additionally, study staff promoted the group at elementary school open houses and community resource fairs. Interested parents called the study center $(n=71)$ and spoke with study staff who described the study and scheduled them for a screening appointment to determine eligibility. Families were eligible if a) the child was between four and nine years of age; b) the child had a BMI $\geq$ the $85^{\text {th }}$ percentile for weight based on the Centers for Disease Control and Prevention age/gender norms; c) the parent spoke and understood English/Spanish; and d) the family was able to participate in an eight-week parenting program. Families were excluded if the child had dietary or exercise restrictions, was previously diagnosed with a developmental delay or pervasive developmental disorder, was on medication that may affect weight loss/gain, or was enrolled in another weight control or exercise program. Figure 1 provides a CONSORT Flow diagram detailing participant recruitment and participation.

Eighteen children were enrolled in the parenting program. Six families did not participate in the intervention (reasons for not participating included: no longer having time to participate, drive is too far, no-show). The final sample consisted of 12 children $\left(M_{\text {age }}=6.67\right.$ years; $75 \%$ male; $83.3 \%$ Hispanic/Latino; see Table 13$)$ classified as overweight $(n=2)$ or obese $(n=10)$ and their caregivers $\left(M_{\text {age }}=37.25\right.$ years; $100 \%$ 
female; 75\% Hispanic/Latino; see Table 13). Mean family annual income was $\$ 32,916.67$. 
Table 13. Study Two: Participant Demographic Variables

Total sample $(n=12)$

\section{Demographic Variables}

Child gender ( $\%$ male)

$67 \%$

Mean child age (Range)

$6.67(4-9)$

Child ethnicity (\%)

Hispanic/Latino

$83.3 \%$

Caregiver gender ( $\%$ female)

$100 \%$

Mean caregiver age (Range)

$37.25(27-65)$

Caregiver ethnicity (\%)

Hispanic/Latino

$75 \%$

Mean Annual Income (SD)

$\$ 32,916.67(\$ 35,894.94)$

Caregiver Highest educational level completed (\%)

Some college

$41.7 \%$

Associate's degree

$41.7 \%$

Bachelor's degree

$16.7 \%$

Caregiver marital status (\%)

Single, never married

$8.3 \%$

Living with a partner

$8.3 \%$

Married

$75 \%$

Divorced

$8.3 \%$ 


\section{Procedure}

Parents attended nine weekly HLPP sessions at a community center and focused on learning behavioral modification strategies and supporting their child's engagement in healthy nutrition and physical activity habits (Graziano et al., 2017; described further below). Families completed all measures at a baseline assessment before the start of treatment, a post-treatment assessment ( 1 week after treatment), and a three-month followup assessment which is consistent with other obesity interventions (Edwards et al., 2006; Stovitz et al., 2014). Families were compensated with a $\$ 25$ gift card at the completion of each assessment.

\section{Intervention Description}

The HLPP is a nine-session parenting group held weekly lasting 1.5-2 hours. A graduate student with expertise in pediatric obesity was the HLPP therapist. The nutrition component focused on teaching parents about the Stop-Light Diet System (Epstein \& Squires, 1988) as well as the MyPlate (U.S. Department of Agriculture, 2019) and encouraging the use of these skills at home. Additionally, food monitoring via food logs and a phone application was completed by the parent. The physical activity component included education on monitoring and limiting sedentary activities (e.g., minimizing screen time) while promoting physical activities (e.g., going on family walks). Lastly, parents were taught behavior modification strategies adapted from Parent Child Interaction Therapy (Eyberg \& Hood, 2003) such as, attending to desired behaviors via labeled praises and differential attention for picky eating. See Table 4 for a summary of session topics. 


\section{Measures}

\section{Process Measures}

Attendance, Treatment Satisfaction, and Fidelity. Parent attendance at HLPP sessions was recorded via sign-in sheets completed at the beginning of the sessions. Homework (i.e. food log forms) were collected from parents during each HLPP session. Furthermore, parents were asked to keep track of their own weekly dietary intake by logging their daily food consumption in an electronic application (Myfitness Pal). Total number of days the parent tracked was calculated for each family. Treatment satisfaction was measured via an adapted standard satisfaction questionnaire developed for behavioral treatments (MTA Cooperative Group, 1999). Parents indicated their degree of satisfaction across a seven-point Likert scale on various topics as well as provided an overall rating of treatment satisfaction. Fidelity was assessed via checklists (see Figure 3) completed on $20 \%$ of the recorded HLPP sessions by a research assistant who was blind to group assignment.

\section{Main Health Outcome Measures}

Child and Parent Anthropometrics. Parent and child height and weight were measured by calibrated stadiometer and portable digital scale following standard anthropometric procedures (Cameron, 1986) by trained personnel in triplicate (using the medium value; Ward \& Anderson, 1998). Body Mass Index (BMI; weight in kg/height in meters squared) was calculated for both parents and children, and child BMI was transformed into z-scores using national norms from the CDC (Kuczmarski et al., 2000).

Parent and Child Fitness. Child physical fitness was assessed via side-to-side jumps which is part of the Karlsruhe Motor Screening (KMS) test battery (Bos et al., 
2004). Children are asked to jump with both legs from one side of a strip on the floor to the other as fast as possible for 30 seconds. In accordance with previous research, greater number of side-to-side jumps indicate better physical fitness (Bayer et al., 2009). Parent physical fitness was assessed via heart rate and blood pressure measured in triplicate and averaged. Routine physical activity has been associated with lower blood pressure in adults (Ahmed \& Ndumele, 2014). Child heart rate and blood pressure was also assessed in triplicate and averaged.

\section{Mechanistic Outcome Measures}

Nutrition. Dietary Intake: Child and parent dietary intake was assessed via the Automated Self-Administered 24-hour Dietary Assessment Tool (ASA24-2016; Kirkpatrick et al., 2014). The ASA24-2016 is a valid web-based tool that enables multiple automated self-administered 24-hour recalls and food records (Kirkpatrick et al., 2014; Thompson et al., 2015). The ASA24 uses the validated United States Department of Agriculture's (USDA) Automated Multiple-Pass Method (AMPM; Raper et al., 2004) which is the method used in the dietary interview component of the National Health and Nutrition Examination Survey. Parents were asked to recall and describe foods and drinks consumed at each meal during the previous day including portion sizes. Pictures of portion sizes were provided to aid in estimation. Parents also completed the ASA24-2016 for their child's previous day food and drink consumption. Consistent with previous research (Aeberli et al., 2008; Lin et al., 2012; Riera-Crichton \& Tefft, 2014), we examined dietary intake at a macronutrient (e.g., fat grams, calories) level as well as number of total daily fruit and vegetables consumed. Nutritional Awareness and Knowledge. Nutritional awareness and knowledge was assessed via The Dietary Interview Assessment of 
Nutritional Awareness (DIANA; Graziano, 2015). The DIANA is a 24-item measure of children's nutritional expressive knowledge and health classification. Total scores were calculated for Part A (expressive knowledge; $\alpha=.66$ ) and total relative scores were calculated for Part B (health classification; $\alpha=.51$ ), with higher scores indicating greater nutritional knowledge.

Physical Activity. The Family Healthy Lifestyle Questionnaire (FHLQ; Graziano, in preparation) is a 12-item self-report measure of frequency of family's healthy habits scored on a 7-point Likert scale. Family participation in physical activity was assessed via the following items from the FHLQ (Graziano, in preparation): How much time does your family typically spend watching television or playing videos games per day?, How many minutes a day does your child spend in active play/exercise (faster breathing sweating)?, How many minutes a day do you spend in active play/exercise (faster breathing sweating)?, and How often does your family go outside to play a physical activity (ride a bike, jump rope, soccer, basketball)?.

Family Home Environment. The Family Nutrition and Physical Activity (FNPA; Ihmels et al., 2009) screening tool was used as a measure of the home environment. The screening tool assesses aspects of the food and physical activity environment inside of the child's home. The FNPA is comprised of 20-items in ten domains: family meals, family eating practices, food choices, beverage choices, restriction/reward, screen time, healthy environment, family physical activity, child physical activity, and family schedule/sleep routine. Reliability and validity are well-established for the FNPA (Peyer \& Welk, 2017; Ihmels et al., 2009). For the purposes of the current study, the total score was used with higher scores indicating a more favorable home environment $(\alpha=.61)$. 
Parenting. Parenting Strategies. The Alabama Parenting Questionnaire (APQ; Shelton et al., 1996) measures five dimensions of parenting: involvement, positive parenting, poor monitoring/supervision, inconsistent discipline, and corporal punishment via 42 -items. Items use a 5 -point Likert scale $(1=$ Never to $5=$ Always $)$. The APQ has been found to have good internal consistency across the positive parenting $(\alpha=.80)$ and involvement $(\alpha=.80)$ scales, good criterion validity in differentiating clinical and nonclinical groups (Shelton et al., 1996). The current study examined the positive parenting factor $(\alpha=.90$ consisting of the involvement and positive parenting subscales and the negative parenting factor $(\alpha=.86)$ consisting of the following subscales: poor monitoring/supervision, inconsistent discipline and corporal punishment. Parenting Stress. Parents completed the Parenting Stress Index/Short Form (PSI; Abidin, 1995) to assess the source and degree of parenting stress. The PSI contains 36 items rated on a 6-point Likert scale $(1=$ Strongly Disagree to $5=$ Strongly Agree $)$ and yields subscales assessing parental distress, stress related to parent-child interactions, stress related to the child's behavior, and a total score. This measure demonstrates good test-retest reliability (.68-.85), internal consistency (.85-.91) and concurrent validity (Abidin, 1995). Higher scores indicate increased total parenting stress. For the purposes of the current study, we used the total parenting stress score $(\alpha=.78)$. Parent Feeding Practices. The Child Feeding Questionnaire (CFQ; Birch et al., 2001) was used to assess parent feeding practices. The CFQ is a well validated 31-item self-report questionnaire that measures two domains: (1) parental control in child feeding and (2) parental perceptions and concerns about child obesity (Birch et al., 1998). For the purposes of the current study, we examined the parental 
control domain consisting of the following subscales: restriction $(\alpha=.77)$, pressure to eat $(\alpha=.87)$, and monitoring of eating $(\alpha=.92)$.

\section{Data Analysis Plan}

All analyses were conducted using the Statistical Package for Social Sciences, version 25 (SPSS, 2017). Preliminary analyses were conducted between demographic variables and all outcome variables to identify any associations. Next, descriptive analyses were conducted to examine the process outcomes (e.g., attendance and homework completion, treatment satisfaction, and fidelity). One-way repeated measures ANOVAs with a Bonferroni correction were conducted to examine within-subject changes from pre- to post-treatment and 3-month follow-up assessment on all main health outcomes and mechanistic outcomes. Although we do present statistical findings ( $p$ values as well as Hedge's $g$ effect size estimates), the goal of a Phase IIa study is to show clinically significant impact on the behavioral risk factor rather than statistical significance (Czajkowski et al., 2015). 


\section{STUDY 2: RESULTS}

\section{Preliminary Analyses: Demographic Variables}

Preliminary analyses between demographic variables and study outcome variables revealed significant associations between child age, child gender, and family annual income, respectively, and several outcome variables (correlations displayed in Tables 1417). Therefore, all analyses (excluding analyses which included BMI z-score) controlled for child age, child gender, and family annual income. Analyses including BMI z-score only controlled for family annual income given that the BMI z-score already accounts for child age and gender. 
Table 14. Study Two: Correlations: Demographics and Health Outcomes

\begin{tabular}{|c|c|c|c|c|c|c|c|c|c|c|c|c|c|}
\hline & $\begin{array}{c}\text { BMI } \\
\text { Z- } \\
\text { score } \\
(\mathrm{C}) \\
\end{array}$ & $\begin{array}{c}\text { BMI } \\
(\mathrm{P})\end{array}$ & $\begin{array}{c}\text { Side- } \\
\text { to- } \\
\text { side } \\
\text { jumps } \\
\text { (C) }\end{array}$ & $\begin{array}{c}\text { SBP } \\
(\mathrm{C}) \\
\end{array}$ & $\begin{array}{c}\text { DBP } \\
(\mathrm{C}) \\
\end{array}$ & $\begin{array}{l}\text { HR } \\
(\mathrm{C}) \\
\end{array}$ & $\begin{array}{c}\text { SBP } \\
(\mathrm{P}) \\
\end{array}$ & $\begin{array}{c}\text { DBP } \\
(\mathrm{P})\end{array}$ & $\begin{array}{l}\text { HR } \\
(\mathrm{P}) \\
\end{array}$ & $\begin{array}{c}\text { Child } \\
\text { age }\end{array}$ & $\begin{array}{c}\text { Child } \\
\text { gender }\end{array}$ & $\begin{array}{c}\text { Parent } \\
\text { age }\end{array}$ & $\begin{array}{l}\text { Family } \\
\text { annual } \\
\text { income }\end{array}$ \\
\hline BMI z-score (C) & - & - & - & - & - & - & - & - & - & - & - & - & - \\
\hline $\mathrm{BMI}(\mathrm{P})$ & .32 & - & - & - & - & - & - & - & - & - & - & - & - \\
\hline Side-to-side jumps (C) & -.27 & -.15 & - & - & - & - & - & - & - & - & - & - & - \\
\hline $\operatorname{SBP}(C)$ & .18 & -.48 & .15 & - & - & - & - & - & - & - & - & - & - \\
\hline $\mathrm{DBP}(\mathrm{C})$ & .11 & -.18 & -.05 & $.88 * * *$ & - & - & - & - & - & - & - & - & - \\
\hline $\operatorname{HR}(\mathrm{C})$ & -.16 & .59 & .08 & -.40 & -.37 & - & - & - & - & - & - & - & - \\
\hline SBP (P) & -.41 & -.13 & .54 & .39 & .23 & -.16 & - & - & - & - & - & - & - \\
\hline DBP (P) & -.74 & .03 & .71 & .20 & .04 & .19 & $.90 * *$ & - & - & - & - & - & - \\
\hline $\operatorname{HR}(\mathrm{P})$ & -.20 & .45 & $.89 * *$ & -.10 & -.18 & .30 & .43 & .50 & - & - & - & - & - \\
\hline Child age & -.50 & -.24 & $.80 * *$ & .07 & -.08 & .00 & $.78 *$ & $.89 * *$ & .70 & - & - & - & - \\
\hline Child gender & -.46 & .68 & -.15 & -.39 & -.20 & .04 & -.03 & .03 & -.20 & .04 & - & - & - \\
\hline Parent age & -.07 & -.36 & .49 & .27 & .10 & -.39 & $.88 * *$ & .68 & .51 & .50 & -.21 & - & - \\
\hline Family annual income & $.58 *$ & -.39 & .04 & .09 & -.14 & -.60 & -.36 & -.56 & -.12 & -.17 & -.24 &. .08 & - \\
\hline $\begin{array}{l}\text { Parent highest } \\
\text { education }\end{array}$ & .34 & .28 & .06 & -.03 & .01 & .21 & -.17 & .14 & -.43 & -.16 & .00 & -.35 & .06 \\
\hline
\end{tabular}

Note. ${ }^{* * *} p<.001, * * p<.01, * p<.05 . \mathrm{C}=$ child measure, $\mathrm{P}=$ parent measure, $\mathrm{BMI}=$ Body Mass Index, $\mathrm{SBP}=\mathrm{Systolic} \mathrm{Blood}$ Pressure, $\mathrm{DBP}=$ Diastolic Blood Pressure, and HR = Heart Rate. 
Table 15. Study Two: Correlations: Demographics and Nutrition Outcomes

\begin{tabular}{|c|c|c|c|c|c|c|c|c|c|c|c|c|c|c|}
\hline & $\begin{array}{c}\text { Calorie } \\
\text { (C) }\end{array}$ & $\begin{array}{l}\text { Calorie } \\
\text { (P) }\end{array}$ & $\begin{array}{l}\text { Fat } \\
\text { (C) }\end{array}$ & $\begin{array}{l}\text { Fat } \\
(\mathrm{P})\end{array}$ & $\begin{array}{l}\text { Ttl } \\
\text { daily } \\
\text { fruit } \\
\text { (C) }\end{array}$ & $\begin{array}{l}\text { Ttl } \\
\text { daily } \\
\text { fruit } \\
(\mathrm{P})\end{array}$ & $\begin{array}{c}\text { Ttl } \\
\text { daily } \\
\text { vegeta- } \\
\text { bles } \\
\text { (C) }\end{array}$ & $\begin{array}{c}\text { Ttl } \\
\text { daily } \\
\text { vegeta- } \\
\text { bles } \\
\text { (P) }\end{array}$ & $\begin{array}{c}\text { Health } \\
\text { Classification } \\
\text { Ttl Score }\end{array}$ & $\begin{array}{c}\text { Expressive } \\
\text { Knowledge } \\
\text { Ttl Score }\end{array}$ & $\begin{array}{l}\text { Age } \\
\text { (C) }\end{array}$ & $\begin{array}{l}\text { Gender } \\
\text { (C) }\end{array}$ & $\begin{array}{l}\text { Age } \\
(\mathrm{P})\end{array}$ & $\begin{array}{l}\text { Family } \\
\text { annual } \\
\text { income }\end{array}$ \\
\hline Calories (C) & - & - & - & - & - & - & - & - & - & - & - & - & - & - \\
\hline Calories (P) & .66 & - & - & - & - & - & - & - & - & - & - & - & - & - \\
\hline Fat $(\mathrm{P})$ & .42 & $.77 *$ & .34 & - & - & - & - & - & - & - & - & - & - & - \\
\hline $\begin{array}{l}\text { Total daily } \\
\text { fruit (C) }\end{array}$ & .48 & .33 & .16 & .29 & - & - & - & - & - & - & - & - & - & - \\
\hline $\begin{array}{l}\text { Total daily } \\
\text { fruit }(\mathrm{P})\end{array}$ & $.90 * *$ & .69 & $\begin{array}{l}.84 \\
*\end{array}$ & .31 & .21 & - & - & - & - & - & - & - & - & - \\
\hline $\begin{array}{l}\text { Total daily } \\
\text { vegetables } \\
\text { (C) }\end{array}$ & .33 & -.27 & .61 & -.37 & -.30 & .26 & - & - & - & - & - & - & - & - \\
\hline $\begin{array}{l}\text { Total daily } \\
\text { vegetables } \\
\text { (P) }\end{array}$ & .24 & -.08 & -.12 & -.01 & $.77 *$ & .09 & -.34 & - & - & - & - & - & - & - \\
\hline $\begin{array}{l}\text { Health } \\
\text { Classification } \\
\text { Total Score } \\
\text { (C) }\end{array}$ & -.21 & -.52 & -.04 & -.65 & -.06 & -.34 & .59 & -.25 & - & - & - & - & - & - \\
\hline $\begin{array}{l}\text { Expressive } \\
\text { Knowledge } \\
\text { Total Score } \\
\text { (C) }\end{array}$ & .03 & .41 & -.25 & .13 & .45 & .18 & -.65 & .29 & .57 & - & - & - & - & - \\
\hline Child age & .33 & -.34 & .38 & -.68 & .09 & .28 & .70 & .21 & $.72 * *$ & .28 & - & - & - & - \\
\hline Child gender & -.61 & -.23 & -.57 & .08 & .01 & $.82 *$ & -.34 & -.16 & .38 & .25 & .04 & - & - & - \\
\hline Parent age & -.04 & .66 & .18 & -.67 & -.50 & .02 & $.80 *$ & -.14 & .10 & -.09 & .50 & -.21 & - & - \\
\hline
\end{tabular}




\begin{tabular}{|c|c|c|c|c|c|c|c|c|c|c|c|c|c|c|}
\hline $\begin{array}{l}\text { Family } \\
\text { annual } \\
\text { income }\end{array}$ & -.47 & -.04 & -.25 & -.17 & -.72 & -.16 & .01 & $-.79 *$ & .19 & .25 & -.17 & -.24 & .08 & - \\
\hline $\begin{array}{l}\text { Parent } \\
\text { highest } \\
\text { education }\end{array}$ & .38 & .64 & .18 & $\begin{array}{l}.81 \\
*\end{array}$ & .69 & .12 & -.47 & .33 & .05 & .44 & -.16 & .00 & -.35 & .06 \\
\hline
\end{tabular}


Table 16. Study Two: Correlations: Demographics, Physical Activity, and Home Environment Outcomes

\begin{tabular}{|c|c|c|c|c|c|c|c|c|}
\hline & $\begin{array}{l}\text { Family } \\
\text { sedentary } \\
\text { activity } \\
\end{array}$ & $\begin{array}{l}\text { Family } \\
\text { outdoor } \\
\text { physical } \\
\text { activity }\end{array}$ & $\begin{array}{l}\text { Minutes in } \\
\text { mod-to-vig } \\
\text { activity }\end{array}$ & $\begin{array}{l}\text { FNPA } \\
\text { total score }\end{array}$ & $\begin{array}{c}\text { Child } \\
\text { age }\end{array}$ & $\begin{array}{l}\text { Child } \\
\text { gender }\end{array}$ & $\begin{array}{c}\text { Parent } \\
\text { age }\end{array}$ & $\begin{array}{l}\text { Family } \\
\text { annual } \\
\text { income }\end{array}$ \\
\hline $\begin{array}{l}\text { FHLQ: Family } \\
\text { Sedentary activity }\end{array}$ & - & - & - & - & - & - & - & - \\
\hline $\begin{array}{l}\text { FHLQ: Family } \\
\text { outdoor physical } \\
\text { activity }\end{array}$ & -.40 & - & - & - & - & - & - & - \\
\hline $\begin{array}{l}\text { FHLQ: Minutes in } \\
\text { moderate to vigorous } \\
\text { activity }\end{array}$ & -.24 & $.74 * *$ & - & - & - & - & - & - \\
\hline FNPA: Total Score & -.52 & -.05 & -.11 & - & - & - & - & - \\
\hline Child age & .20 & -.06 & .35 & -.04 & - & - & - & - \\
\hline Child gender & .19 & -.03 & -.10 & .00 & .04 & - & - & - \\
\hline Parent age & .24 & .07 & .42 & .06 & .50 & -.21 & - & - \\
\hline $\begin{array}{l}\text { Family annual } \\
\text { income }\end{array}$ & -.54 & .33 & .48 & .02 & .17 & -.24 & .08 & - \\
\hline $\begin{array}{l}\text { Parent highest } \\
\text { education }\end{array}$ & -.04 & .38 & .08 & $-.70 * *$ & -.16 & .00 & -.35 & .06 \\
\hline
\end{tabular}


Table 17. Study Two: Correlations: Demographics and Parenting Outcomes

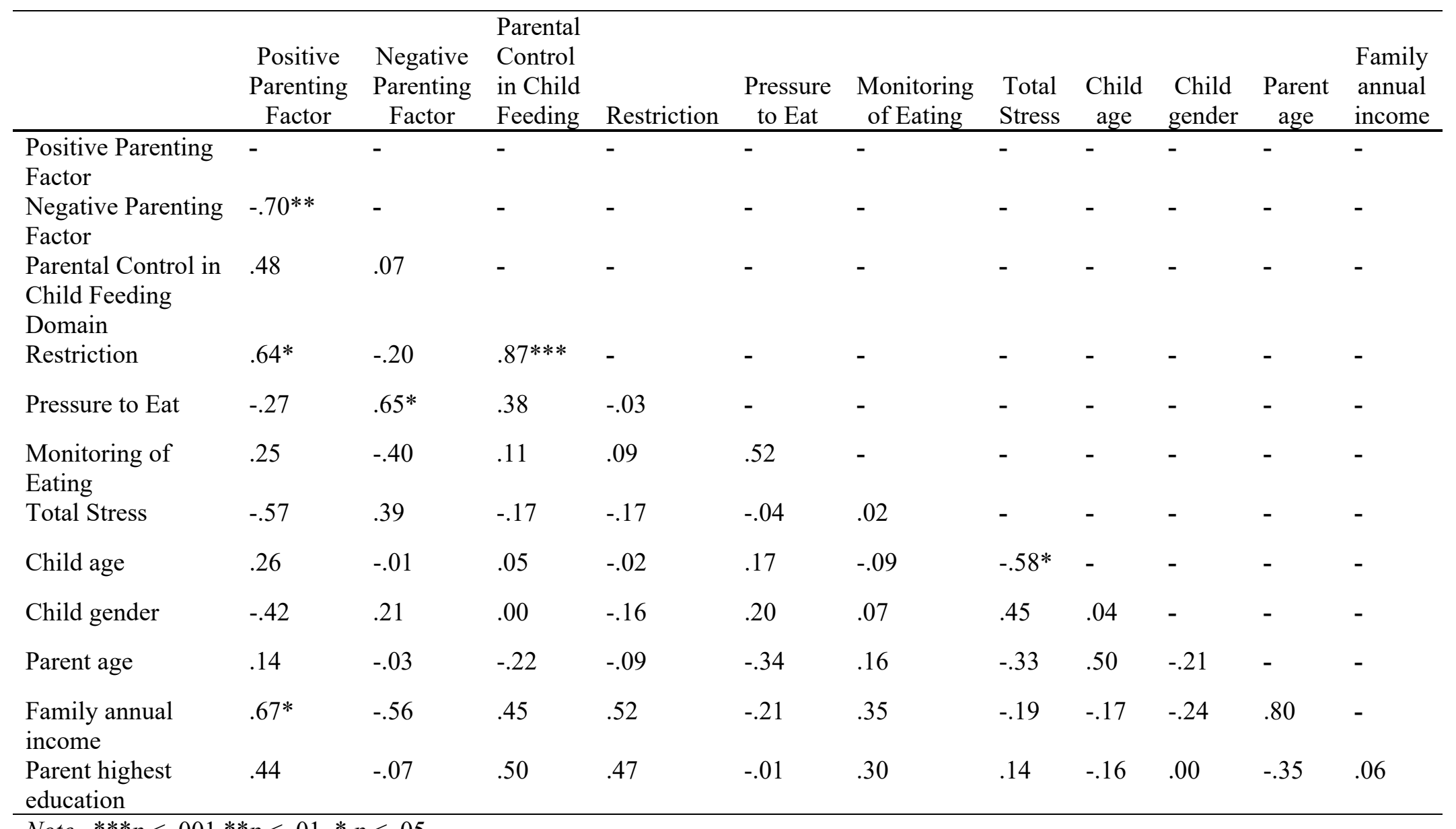

Note. $* * * p<.001,{ }^{*} * p<.01, * p<.05$. 


\section{Process Outcomes}

Attendance and Homework completion. Overall, parents attended 55\% of the nine HLPP sessions $(M=5, S D=2.83)$. A further breakdown revealed that five parents attended only two sessions, two parents attended five-six sessions, and five parents attended more than seven sessions. Parents completed homework for only $25 \%$ of the sessions $(M=2.08, S D=2.54)$. Upon further exploration of homework completion, it was noted that four parents completed homework at least half of the sessions and eight parents did not complete homework during any sessions. In terms of parent self-monitoring, out of the eight families who completed treatment, three did not use the MyFitnessPal application. For the remaining five families who participated in the intervention, the mean number of days parents used the application was 30.6, indicating that families used the application $55 \%$ of the days during the intervention period.

Treatment satisfaction. Parents were extremely satisfied with HLPP. Specifically, on a seven-point Likert scale of strongly disagree to strongly agree, $87.5 \%$ of parents strongly agreed that their family benefited from the program, $87.5 \%$ strongly agreed that they enjoyed the program, $87.5 \%$ strongly agreed that the program taught them effective strategies that helped change their family's healthy habits, and $87.5 \%$ strongly agreed that they would recommend the HLPP to other parents. Further excerpts of open-ended satisfaction questions are displayed in Table 18. 


\section{Table 18. Study Two: Program Satisfaction}

\begin{tabular}{ll}
\hline Parent & Statement \\
\hline 1 & I enjoyed learning and sharing healthy lifestyle eating and living styles \\
& and will include the strategies in our lifestyle. \\
& Our family is forever changed. We move more. We eat so much better. \\
& Everyone is eating more fruits and vegetables. My kids friends are telling \\
their parents about go, slow, and whoa foods! We are putting down our \\
devices to get outside as a family. And I know weight loss wasn't the goal \\
but watching my son get to a more healthy goal weight is going to impact \\
him for the rest of his life. He's learning and practicing making healthy \\
decisions every day. I can't recommend this program enough and I am so \\
thankful to the funders for making it possible for us to participate. \\
I really enjoyed how involved and non-judgmental the 'teacher' was. Even \\
though I struggled with the routine and getting in the mindset to eat \\
healthier, she was always very encouraging for me to just keep trying. \\
The education sessions provided in small groups was very helpful. Having \\
the open discussion with other parents allowed me to share information \\
and scenarios that helped me better. \\
Weekly goals were amazing. Making goals where we were at and not \\
what the ideal is. Learning about what kids nutritional needs was mind \\
blowing. The easy system of go, slow, and whoa, kids really get that. \\
Learning from the group was key and the instructor was great and \\
knowledgeable. It was nice to have childcare there and food there for \\
dinner. You thought of everything to make it easy for families
\end{tabular}


Fidelity. Treatment fidelity was completed on $20 \%$ of the HLPP sessions and excellent fidelity was achieved (100\%).

\section{Main Health Outcomes}

Child and parent anthropometrics. No statistically significant effect was found for child Body Mass Index z-score. However, mean child Body Mass Index z-score did decrease over time with a small effect size observed from pre- to post-treatment $(g=-.37)$ and a medium effect size observed from pre-treatment to follow-up ( $g=-.52$; see Table 19). In terms of clinically significant changes (as defined by an improvement in child BMI Z-score of .18 or greater; Reinehr et al., 2009) 50\% of children improved (see Figure 5). No effect was found for parent Body Mass Index. In terms of clinically significant changes (as defined by a $5 \%$ reduction in parent BMI) $13 \%$ of parents improved (see Figure 5 ). 
Table 19. Study Two: Results: Main Health Outcomes

\begin{tabular}{|c|c|c|c|c|c|c|c|c|}
\hline & $\begin{array}{l}\text { Pre-Tx } \\
M(S E)\end{array}$ & $\begin{array}{l}\text { Post-Tx } \\
M(S E)\end{array}$ & $\begin{array}{c}\mathrm{FU} \\
M(S E)\end{array}$ & $\begin{array}{c}\text { Time } \\
\text { Effect } \\
F\end{array}$ & $\begin{array}{c}\text { Time } \\
\text { Effect } \\
p\end{array}$ & $\begin{array}{c}\text { Pre-Tx to } \\
\text { Post-Tx } \\
g[95 \% \mathrm{CI}]\end{array}$ & $\begin{array}{l}\text { Pre-Tx to } \\
\text { FU } \\
g[95 \% \mathrm{CI}]\end{array}$ & $\begin{array}{l}\text { Post-Tx to } \\
\text { FU } \\
g[95 \% \mathrm{CI}]\end{array}$ \\
\hline \multicolumn{9}{|l|}{ Main Health } \\
\hline BMI z-score (C) & $2.41(.10)$ & $2.29(.12)$ & $2.23(.13)$ & .28 & .63 & $\begin{array}{l}-.37[-.52 \\
\quad-.22]\end{array}$ & $\begin{array}{c}-.52[-.68,- \\
.35]\end{array}$ & $-.16[-.33, .01]$ \\
\hline $\mathrm{BMI}(\mathrm{P})$ & $\begin{array}{l}30.10 \\
(2.02)\end{array}$ & $29.83(2.00)$ & $\begin{array}{l}29.43 \\
(1.74)\end{array}$ & 1.06 & .39 & $\begin{array}{c}-.04[- \\
2.83,2.74]\end{array}$ & $\begin{array}{c}-.12[-2.73 \\
2.50]\end{array}$ & $\begin{array}{c}-.07[-2.67 \\
2.53]\end{array}$ \\
\hline $\begin{array}{l}\text { Side-to-side } \\
\text { jumps }(\mathrm{C})\end{array}$ & $\begin{array}{l}31.75 \\
(4.30)\end{array}$ & $44.25(4.37)$ & $\begin{array}{l}45.13 \\
(2.32)\end{array}$ & .61 & .57 & $\begin{array}{c}.96[-5.04 \\
6.97]\end{array}$ & $\begin{array}{c}1.30[-3.49 \\
6.08]\end{array}$ & $\begin{array}{c}.08[-4.76 \\
4.93]\end{array}$ \\
\hline $\mathrm{SBP}(\mathrm{C})$ & $\begin{array}{l}114.38 \\
(5.63)\end{array}$ & $112.83(2.44)$ & $\begin{array}{l}109.38 \\
(3.34)\end{array}$ & 1.84 & .22 & $\begin{array}{c}-.12[- \\
6.13,5.89]\end{array}$ & $\begin{array}{c}-.36[-6.77 \\
6.05]\end{array}$ & $\begin{array}{c}-.39[-4.45, \\
3.66]\end{array}$ \\
\hline $\mathrm{DBP}(\mathrm{C})$ & $\begin{array}{l}72.54 \\
(9.12)\end{array}$ & $67.79(2.32)$ & $\begin{array}{l}64.42 \\
(2.04)\end{array}$ & 1.74 & .24 & $\begin{array}{c}-.24[- \\
9.46,8.98]\end{array}$ & $\begin{array}{c}-.41[-9.57 \\
8.75\end{array}$ & $\begin{array}{c}-.52[-3.54 \\
2.51]\end{array}$ \\
\hline $\mathrm{HR}(\mathrm{C})$ & $\begin{array}{l}91.00 \\
(2.31)\end{array}$ & $88.96(5.99)$ & $\begin{array}{l}92.58 \\
(8.04)\end{array}$ & .70 & .52 & $\begin{array}{c}-.15[- \\
6.44,6.14]\end{array}$ & $\begin{array}{c}.09[-8.11 \\
8.29]\end{array}$ & $\begin{array}{c}.17[-9.65 \\
10.00]\end{array}$ \\
\hline $\mathrm{SBP}(\mathrm{P})$ & $\begin{array}{l}130.71 \\
(6.69)\end{array}$ & $120.10(5.97)$ & $\begin{array}{l}134.00 \\
(7.81)\end{array}$ & .22 & .81 & $\begin{array}{c}-.59[- \\
9.38,8.20]\end{array}$ & $\begin{array}{c}.16[-9.92 \\
10.24]\end{array}$ & $\begin{array}{c}.71[-8.92 \\
10.34]\end{array}$ \\
\hline $\mathrm{DBP}(\mathrm{P})$ & $\begin{array}{l}82.57 \\
(2.61)\end{array}$ & $79.52(2.40)$ & $\begin{array}{l}87.86 \\
(5.01)\end{array}$ & .43 & .67 & $\begin{array}{c}-.43[- \\
3.90,3.04]\end{array}$ & $\begin{array}{c}.47[-5.06 \\
6.00]\end{array}$ & $\begin{array}{c}.75[-4.69 \\
6.19]\end{array}$ \\
\hline $\operatorname{HR}(\mathrm{P})$ & $\begin{array}{l}77.43 \\
(3.53) \\
\end{array}$ & $73.86(2.55)$ & $\begin{array}{l}76.67 \\
(4.53) \\
\end{array}$ & 2.55 & .16 & $\begin{array}{c}-.41[- \\
4.67,3.85]\end{array}$ & $\begin{array}{c}-.07[-5.69 \\
5.56] \\
\end{array}$ & $\begin{array}{c}.27[-4.82 \\
5.36] \\
\end{array}$ \\
\hline
\end{tabular}


Figure 5. Clinically Significant Change: Child BMI z-score and Parent BMI

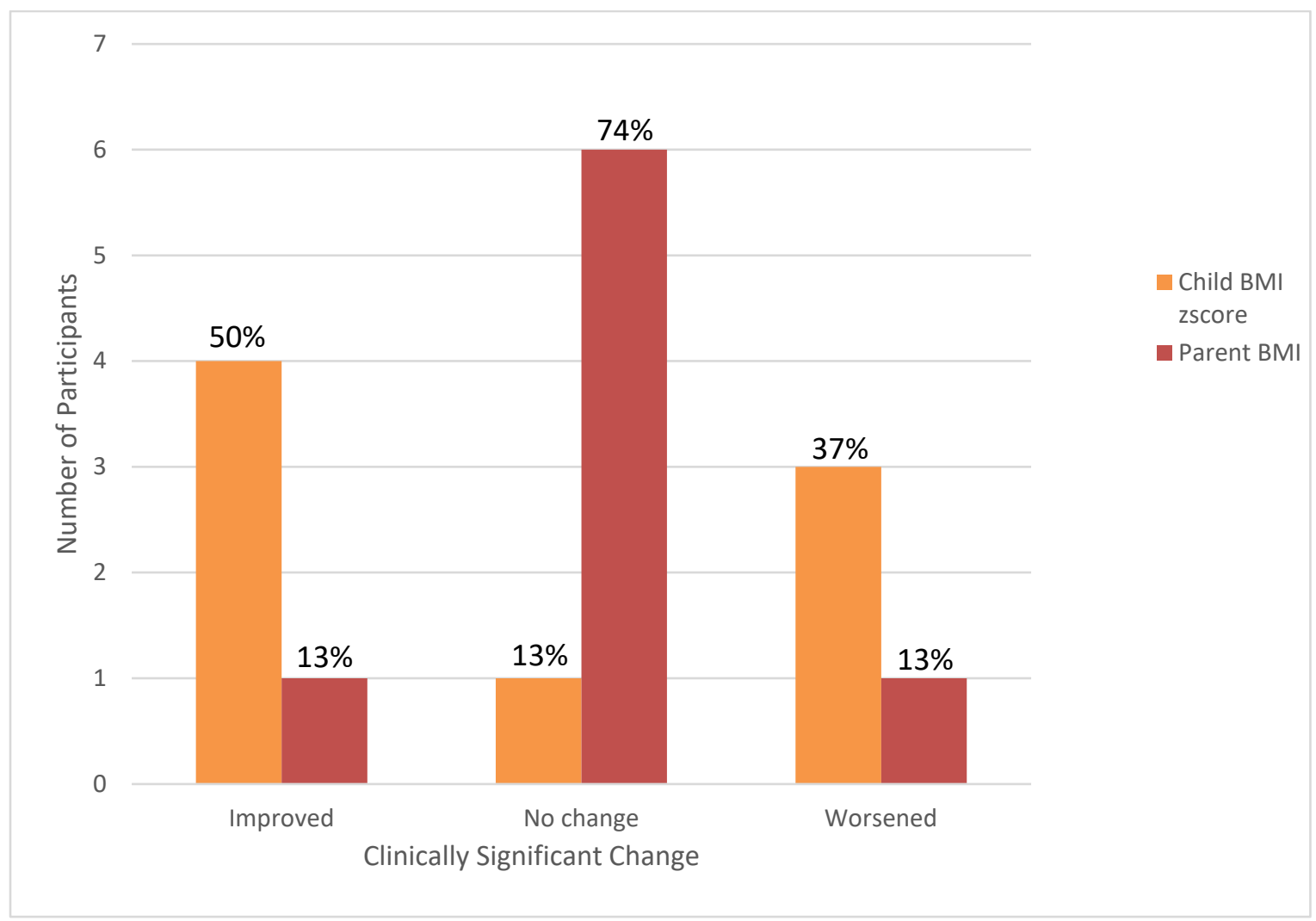


Parent and child fitness. Despite no statistically significant effects, large effect sizes were observed for child fitness, as measured by side-to-side jumps, from pre- to posttreatment $(g=.96)$ as well as pre-treatment to follow-up $(g=1.30)$. Regarding child blood pressure, there were no statistically significant effects, yet reductions in SBP and DBP yielded small effect sizes from pre- to post-treatment (SBP $g=-.12$; DBP $g=-.24$ ) and pretreatment to follow-up (SBP $g=-.36$; DBP $g=-.41$ ). No statistically significant effects were found for parent blood pressure. Parent blood pressure decreased from pre- to posttreatment (SBP $g=-.59$; DBP $g=-.43$ ). However, parent blood pressure increased to greater levels than pre-treatment during the follow-up assessment (SBP $g=.16$; DBP $g=$ $.47)$.

\section{Mechanistic Outcomes}

Nutrition. There were marginal significant effects for child $[F(2,6)=4.06, p=$ $.08)]$ and parent fat intake $[F(2,6)=3.69, p=.09)]$, respectively, with large effect sizes from pre- to post-treatment as well as pre-treatment to follow-up (see Table 20). No statistically significant effects for the remaining nutrition variables were observed. However, there were large effect sizes from pre- to post-treatment for child calories $(g=$ $.89)$ and parent calories $(g=-1.03)$. In terms of nutritional health classification and expressive knowledge, there was a statistically significant effect for health classification $[F(2,8)=5.26, p=.04)]$ but not for expressive knowledge. 
Table 20. Study Two: Results: Nutrition

\begin{tabular}{|c|c|c|c|c|c|c|c|c|}
\hline & $\begin{array}{l}\text { Pre-Tx } \\
M(S E)\end{array}$ & $\begin{array}{l}\text { Post-Tx } \\
M(S E)\end{array}$ & $\begin{array}{c}\mathrm{FU} \\
M(S E)\end{array}$ & $\begin{array}{l}\text { Time } \\
\text { Effect } \\
\quad F \\
\end{array}$ & $\begin{array}{c}\text { Time } \\
\text { Effect } \\
p \\
\end{array}$ & $\begin{array}{l}\text { Pre-Tx to Post-Tx } \\
g[95 \% \mathrm{CI}]\end{array}$ & $\begin{array}{l}\text { Pre-Tx to FU } \\
g[95 \% \mathrm{CI}]\end{array}$ & $\begin{array}{l}\text { Post-Tx to FU } \\
g[95 \% \mathrm{CI}]\end{array}$ \\
\hline \multicolumn{9}{|l|}{ Mechanistic } \\
\hline \multicolumn{9}{|l|}{$\begin{array}{l}\text { Outcomes } \\
\text { Nutrition }\end{array}$} \\
\hline $\begin{array}{l}\text { ASA-24-2016: } \\
\text { Calories (C) }\end{array}$ & $\begin{array}{l}1567.35 \\
(149.40)\end{array}$ & $\begin{array}{l}1204.16 \\
(138.55)\end{array}$ & $\begin{array}{l}1391.76 \\
(131.57)\end{array}$ & 1.55 & .29 & $\begin{array}{l}-.89[200.57, \\
198.79]\end{array}$ & $\begin{array}{l}-.44[-195.53, \\
194.65]\end{array}$ & $\begin{array}{l}.49[-186.75 \\
187.73]\end{array}$ \\
\hline $\begin{array}{l}\text { ASA-24-2016: } \\
\text { Calories (P) }\end{array}$ & $\begin{array}{l}1765.09 \\
(282.80)\end{array}$ & $\begin{array}{l}1170.42 \\
(58.86)\end{array}$ & $\begin{array}{l}1265.49 \\
(191.64)\end{array}$ & 1.44 & .31 & $\begin{array}{l}-1.03[-284.11, \\
282.05]\end{array}$ & $\begin{array}{l}-.73[-335.51 \\
334.05]\end{array}$ & $\begin{array}{l}.24[-196.23, \\
196.70]\end{array}$ \\
\hline $\begin{array}{l}\text { ASA-24-2016: Fat } \\
\text { (C) }\end{array}$ & $67.84(8.08)$ & $44.30(6.06)$ & $52.44(3.75)$ & 4.06 & $.08+$ & $\begin{array}{l}-1.17[-11.06, \\
8.73]\end{array}$ & $-.87[-9.59,7.86]$ & $.57[-6.41,7.56]$ \\
\hline $\begin{array}{l}\text { ASA-24-2016: Fat } \\
\text { (P) }\end{array}$ & $72.83(8.89)$ & $39.48(4.32)$ & $52.63(8.97)$ & 3.69 & $.09+$ & $\begin{array}{l}-1.69[-11.38, \\
8.00]\end{array}$ & $\begin{array}{l}-.80[-13.18 \\
11.58]\end{array}$ & $\begin{array}{l}.66[-9.09 \\
10.42]\end{array}$ \\
\hline $\begin{array}{l}\text { ASA-24-2016:Total } \\
\text { daily fruit (C) }\end{array}$ & $.49(.16)$ & $.53(.16)$ & $.14(.13)$ & 1.02 & .42 & $.09[-.13, .31]$ & $-.85[-1.06,-.65]$ & $\begin{array}{l}-.93[-1.14,- \\
.073]\end{array}$ \\
\hline $\begin{array}{l}\text { ASA-24-2016:Total } \\
\text { daily fruit }(\mathrm{P})\end{array}$ & $.85(.20)$ & $.47(.23)$ & $.77(.62)$ & .88 & .46 & $-.64[-.93,-.34]$ & $-.06[-.70, .57]$ & $.23[-.42, .87]$ \\
\hline $\begin{array}{l}\text { ASA-24-2016:Total } \\
\text { daily vegetables (C) }\end{array}$ & $.63(.35)$ & $.99(.55)$ & $.77(.23)$ & .10 & .42 & $.28[-.36, .92]$ & $.17[-.24, .58]$ & $-.18[-.77, .40]$ \\
\hline $\begin{array}{l}\text { ASA-24-2016: Total } \\
\text { daily vegetables }(\mathrm{P})\end{array}$ & $1.20(.17)$ & $1.21(.52)$ & $.61(.22)$ & .62 & .57 & $.01[-.53, .55]$ & $-1.07[-1.34,-.80]$ & $-.53[-1.09, .02]$ \\
\hline $\begin{array}{l}\text { DIANA: Health } \\
\text { Classification Total } \\
\text { Score (C) }\end{array}$ & $35.13(.33)$ & $37.38(.70)$ & $36.63(.51)$ & 5.26 & $.04 * *$ & $1.38[.62,2.14]$ & $1.16[.56,1.76]$ & $-.41[-1.26, .44]$ \\
\hline $\begin{array}{l}\text { DIANA: Expressive } \\
\text { Knowledge Total } \\
\text { Score (C) }\end{array}$ & $21.38(.83)$ & $21.88(.47)$ & $22.63(.90)$ & 1.24 & .34 & $.25[-.69,1.18]$ & $.48[-.71,1.68]$ & $.35[-.64,1.34]$ \\
\hline
\end{tabular}


Physical activity. There was a statistically significant effect for family frequency of sedentary activity $[F(1,4)=7.46, p=.05)]$, with a small effect from pre- to post-treatment $(g=-.29)$. There were no statistically significant effects for child and parent minutes spent in moderate to vigorous activity or family frequency of outdoor physical activity.

Family home environment. There were no statistically significant effects found for family home environment. Changes from pre- to post-treatment $(g=.64)$ and pretreatment to follow-up $(g=.68)$ yielded medium effect sizes, indicating a healthier home environment.

Parenting. In terms of parenting strategies, no statistically significant effects were found. There were small to medium effects for two domains in parental child feeding practices: parental control in child feeding (pre to post: $g=-.51$; pre to follow-up: $g=-.68$ ) and restriction (pre to post: $g=-.48$; pre to follow-up: $g=-.69$ ). There was a statistically significant effect for total stress $[F(2,8)=9.16, p=.01)]$. 
Table 21. Study Two: Results: Physical Activity, Home Environment, Parenting

\begin{tabular}{|c|c|c|c|c|c|c|c|c|}
\hline & $\begin{array}{l}\text { Pre-Tx } \\
M(S E)\end{array}$ & $\begin{array}{c}\text { Post-Tx } \\
M(S E)\end{array}$ & $\begin{array}{c}\mathrm{FU} \\
M(S E)\end{array}$ & $\begin{array}{l}\text { Time } \\
\text { Effect } \\
\quad F \\
\end{array}$ & $\begin{array}{l}\text { Time } \\
\text { Effect } \\
p \\
\end{array}$ & $\begin{array}{l}\text { Pre-Tx to Post-Tx } \\
g[95 \% \mathrm{CI}]\end{array}$ & $\begin{array}{l}\text { Pre-Tx to FU } \\
g[95 \% \mathrm{CI}]\end{array}$ & $\begin{array}{l}\text { Post-Tx to FU } \\
g[95 \% \mathrm{CI}]\end{array}$ \\
\hline \multicolumn{9}{|l|}{$\begin{array}{l}\text { Mechanistic Outcomes } \\
\text { Physical Activity }\end{array}$} \\
\hline $\begin{array}{l}\text { FHLQ: Family } \\
\text { Sedentary activity }(\mathrm{P})\end{array}$ & $2.13(.42)$ & $1.75(.45)$ & - & 7.46 & $.05 * *$ & $-.29[-.90, .31]$ & - & - \\
\hline $\begin{array}{l}\text { FHLQ: Family } \\
\text { outdoor physical } \\
\text { activity }(\mathrm{P})\end{array}$ & $2.38(.78)$ & $2.38(.76)$ & - & 1.07 & .36 & $.00[-1.07,1.07]$ & - & - \\
\hline $\begin{array}{l}\text { FHLQ: Minutes in } \\
\text { moderate to vigorous } \\
\text { activity }(\mathrm{P})\end{array}$ & $\begin{array}{l}30.88 \\
(7.75)\end{array}$ & $\begin{array}{l}31.25 \\
(10.50)\end{array}$ & - & 2.39 & .20 & $\begin{array}{l}.01[-12.78, \\
12.80]\end{array}$ & - & - \\
\hline $\begin{array}{l}\text { Family Home Environment } \\
\text { FNPA: Total Score (P) }\end{array}$ & $\begin{array}{l}60.13 \\
(1.77)\end{array}$ & $\begin{array}{l}64.50 \\
(2.73)\end{array}$ & $\begin{array}{l}64.13 \\
(2.14)\end{array}$ & 1.11 & .38 & $.64[-2.55,3.82]$ & $.68[-2.04,3.40]$ & $\begin{array}{l}-.05[-3.45 \\
3.35]\end{array}$ \\
\hline \multicolumn{9}{|l|}{ Parenting } \\
\hline $\begin{array}{l}\text { APQ: Positive Parenting } \\
\text { Factor }(\mathrm{P})\end{array}$ & $76.13(.46)$ & $\begin{array}{l}74.63 \\
(2.05)\end{array}$ & $\begin{array}{l}75.63 \\
(1.66)\end{array}$ & .60 & .57 & $-.34[-2.40,1.72]$ & $\begin{array}{l}-.14[-1.83 \\
1.55]\end{array}$ & $.18[-2.41,2.77]$ \\
\hline $\begin{array}{l}\text { APQ: Negative Parenting } \\
\text { Factor }(\mathrm{P})\end{array}$ & $\begin{array}{l}24.63 \\
(2.39)\end{array}$ & $\begin{array}{l}24.00 \\
(1.22)\end{array}$ & $\begin{array}{l}26.63 \\
(1.91)\end{array}$ & 1.05 & .39 & $-.11[-2.74,2.52]$ & $.31[-2.69,3.30]$ & $.55[-1.68,2.77]$ \\
\hline $\begin{array}{l}\text { CFQ: Parental Control } \\
\text { in Child Feeding } \\
\text { Domain }(\mathrm{P})\end{array}$ & $3.49(.25)$ & $3.09(.28)$ & $3.00(.24)$ & .10 & .91 & $-.51[-.87,-.15]$ & $-.68[-1.01,-.34]$ & $-.12[-.48, .24]$ \\
\hline CFQ: Restriction (P) & $4.05(.33)$ & $3.44(.50)$ & $3.27(.42)$ & .69 & .53 & $-.48[-1.07, .10]$ & $-.69[-1.21,-.17]$ & $-.12[-.76, .51]$ \\
\hline CFQ: Pressure to Eat $(\mathrm{P})$ & $1.88(.44)$ & $1.75(.26)$ & $1.41(.24)$ & 1.52 & .28 & $-.12[-.62, .39]$ & $-.44[-.93, .05]$ & $-.45[-.80,-.11]$ \\
\hline $\begin{array}{l}\text { CFQ: Monitoring of } \\
\text { Eating }(\mathrm{P})\end{array}$ & $4.17(.30)$ & $3.96(.20)$ & $4.42(.13)$ & .80 & .48 & $-.28[-.63, .07]$ & $.36[.05, .68]$ & $.91[.68,1.15]$ \\
\hline PSI: Total Stress & $\begin{array}{l}74.25 \\
(9.96) \\
\end{array}$ & $\begin{array}{l}74.13 \\
(12.49)\end{array}$ & $\begin{array}{l}70.00 \\
(10.56)\end{array}$ & 9.16 & $.01 * * *$ & $\begin{array}{l}.00[-15.66, \\
15.65]\end{array}$ & $\begin{array}{l}-.14[-14.36, \\
14.08]\end{array}$ & $\begin{array}{l}-.12[-16.15 \\
15.91]\end{array}$ \\
\hline
\end{tabular}

Note. All analyses co-varied for children's age and gender, and family income. ${ }^{* *} p<.01, * * p<.05,+p<.09 . \mathrm{C}=$ child measure, $\mathrm{P}=$ parent measure, FHLQ $=$ Family Healthy-Lifestyle Questionnaire (Graziano, unpublished), FNPA = Family Nutrition and Physical Activity screening tool (Ihmels et al., 2009), APQ = Alabama Parenting Questionnaire (Shelton et al., 1996), CFQ = Child Feeding Questionnaire (Birch et al., 2001), and PSI = Parenting Stress Index (Abidin, 1995). 


\section{STUDY 2: DISCUSSION}

This study examined via an open trial (Phase IIa of the ORBIT model;

Czajkowski et al., 2015) the feasibility, acceptability, and initial promise of delivering the Healthy Lifestyle Parenting Program (HLPP) within a community setting. There was some difficulty in recruitment yet families that completed the bulk of the program reported high levels of satisfaction. While no statistically significant effects were found for health outcomes, child nutrition knowledge significantly improved, and family frequency of sedentary activity significantly decreased. These findings are further discussed below.

Strong recruitment efforts were employed via multiple avenues (social media, email blasts, school health screeners, health care provider referrals, open houses, and health fairs) and 1,354 flyers were distributed. Furthermore, to overcome potential barriers to participation, it was publicized that childcare and dinner would be provided, convenient locations would be available (at their child's school, a community center, central location in Miami), and participant payments would be provided. However, despite the recruitment efforts, only $5 \%$ of families expressed interest in the study $(n=$ 71). Given that this program was advertised in a predominately Hispanic area, the low response rates might be due to a cultural factor. Particularly, previous research has found that Hispanic mothers do not perceive their overweight children as being overweight (Rich et al., 2005; Hackie \& Bowles, 2007), and therefore may not think that this program is applicable to their families. It is important for future work to continue to focus on how best to engage families to participate in relevant interventions. 
Similarly, retention was just as difficult, with only $66 \%$ of parents completing the program. Specifically, 18 families were allocated to the intervention, yet only 12 received the intervention due to drop-out (reasons included: too long of a drive and recently giving birth). Additionally, four of the families discontinued treatment after two sessions due to the location being too far away or too late in the evening. A recent review of retention rates in obesity trials targeting minority children documented similar difficulties in retention (58\%-93\%), especially in interventions targeting overweight or obese children Hispanics, and that are provided within the community setting (Cui et al., 2015). Future interventions should provide the option of various locations that are easily accessible with multiple time slots, or a group-based internet intervention which may be more appealing for working families. This is consistent with previous work in obesity interventions which have demonstrated lower levels of attrition (9-12\%) using online-based interventions (Polzien et al., 2007; Hammersley et al., 2019). Furthermore, future obesity interventions may benefit from using a consumer preference approach, where participants engage in discrete-choice conjoint experiments (DCE; Oreme 2006). By using DCE, researchers can get a better understanding of what treatment modality parents are most likely to engage in. Interventions can then be adapted to meet those needs, such as, providing individual versus group sessions. This is consistent with previous literature in child mental health which used DCE and demonstrated three categories of participants each with different preferences for utilization (e.g., parents who preferred coaching calls from a therapist versus parents who were more amenable to group settings; Cunningham et al., 2008). Finding ways to meet families where they are and in the way they feel most comfortable may be the next logical step in pediatric obesity interventions. 
HLPP was partially feasible, with parents attending $55 \%$ of the sessions.

Furthermore, homework, which consisted of weekly food logs indicating what their child ate daily, was only completed by $25 \%$ of the entire sample that received the intervention $(n=12)$. Though, if the four families that discontinued treatment were removed, then homework completion would be $50 \%$, which is consistent with other behavioral parent training interventions (Fabiano et al., 2009; Jensen \& Grimes, 2010). Additionally, in a study comparing a maintenance-tailored therapy to a standard behavior therapy for treatment of obesity, homework completion rates were also low $(52 \%$ and $33 \%$, respectively), but did predict greater weight loss (Jeffrey et al., 2009). Furthermore, parents were asked to keep track of their own weekly dietary intake by logging their daily food consumption in an electronic application (Myfitness Pal). Parents only used the application 55\% of the days during the intervention period. Self-monitoring has been found to be an active ingredient in obesity interventions (Dombrowski et al., 2005; Michie et al., 2013) and the lack of significant weight loss results may be reflective of the limited self-monitoring completed by parents in this study. Regardless of homework completion challenges, high levels of acceptability were found for families that completed the program, which is a milestone needed in order to approach the next phase in the ORBIT model (Czajkowski et al., 2015).

Although the goal of this study was to determine proof of concept and clinically significant changes as defined by the ORBIT model (Czajkowski et al., 2015), we provided statistical effects in order to offer an additional interpretation of the program's potential impact. Consistent with prior work (Graziano et al., 2017; Golan et al., 2006), we found a decrease in child Body Mass Index z-score with a small effect size observed 
from pre- to post-treatment $(g=-.37)$ and a medium effect size observed from pretreatment to follow-up $(g=-.52)$. Additionally, $50 \%$ of children showed clinically significant changes in BMI z-score. Therefore, HLPP may have contributed to the positive health changes in the children. Furthermore, all parents maintained their enrollment weight status at follow-up, with only one parent (13\%) exhibiting clinically significant change in their own BMI (as defined by a $5 \%$ reduction in parent BMI). It is plausible that parents were more adherent to the dietary changes they were implementing for their child (the target client) but more lenient on themselves. For example, a parent can send a healthy lunch in a child's lunchbox to school and the child does not have any other option, while a parent can prepare themselves a healthy lunch and choose to eat at a restaurant with co-workers instead. Within a family lifestyle intervention framework, future studies should examine not only the increase in knowledge gained by parents but also the extent to which parents implement the skills learned within the family system.

In terms of other health outcomes, large effect sizes were observed for child fitness, which is consistent with a previous trial of the HLPP within a summer camp setting (Graziano et al., 2017). There were no meaningful effects found for child and parent blood pressure. This is not surprising given that the intervention was only 8 -weeks and changes in blood pressure may not be evident in such a short amount of time or with such a small reduction in weight (Aucott et al., 2009). However, improvements in physical activity and BMI are associated with improvements in SBP/DBP (Gaya et al., 2009), therefore, we would expect the improvement in child side-to-side jumps to lead to an eventual improvement in child blood pressure. This highlights the importance of parents continuing to engage in these activities in the long term. In terms of nutritional 
mechanistic outcomes, we found that HLPP had medium to large effects in reducing total calories and fat intake for both children and parents. However, there were only small effects for an increase in the consumption of fruits and vegetables. A possible explanation is that the sessions including the Stop-Light-Diet system focus on recognizing and reducing fat grams. Parents may have focused on this dietary change and as a result lowered their families' fat and caloric intake. This is consistent with other research studies that have used the Stop-Light-Diet system. Specifically, Nabors et al. (2015) found reductions in consumption of sweets after the nutrition intervention compared to the control group, yet, no differences in fruit and vegetable consumption Additionally, families in an intervention aimed at decreasing fat and sugar showed no significant increase in fruit and vegetable intake compared to families in an intervention aimed at increasing fruit and vegetable intake (Epstein et al., 2001). Furthermore, children made large improvements on classifying the healthfulness of foods. The simplicity of the StopLight-Diet and parent encouragement throughout the initial sessions to engage their children in the classification of foods may have contributed to these findings. This reinforces that for young children, parents are the vehicle of change (Golan, 2006). Regarding physical mechanistic outcomes, consistent with prior work that has found a reduction in sedentary behaviors after family-based interventions (Nemet et al., 2011; Moores et al., 2018), we found a decrease in family frequency of sedentary activity. However, there were no differences in time spent in moderate to vigorous activity or frequency of outdoor physical activity. HLPP sessions focus on reducing sedentary activity and suggest ways to replace the time in those activities (e.g., family walks after dinner). Hence, families could have reduced their sedentary activity and replaced it with a 
light activity, which our questionnaire did not capture. This is also consistent with Pate et al. (2008) who highlights that current measurements of physical activity do not take into account the full continuum of physical activity, dichotomizing it to sedentary activity or moderate to vigorous activity. Given the limitations of measuring physical activity via parent questionnaires, future work examining the HLPP should utilize objective measures of physical activity, such as accelerometers. Nevertheless, sedentary behavior has been found to be independently positively associated with metabolic risk, regardless of physical activity (Bankoski et al., 2011). Therefore, the HLPP impact on reducing sedentary activity might be the first step towards improving children's metabolic risk.

Consistent with other family lifestyle interventions (Golley et al., 2007; Stein et al., 2005; Haines et al., 2016; Domoff \& Niec, 2018), the HLPP aimed to make changes in the home environment and parenting strategies. After the HLPP, there were medium effects indicating a healthier home environment. While only small effects were noted for overall positive and negative parenting, larger effects were found for more specific nutrition related parenting strategies. Specifically, decreases in parental control in child feeding and restriction were observed. This is an important finding given that, excessive parental control and restriction are associated with poorer food choices, and obesity (Zive et al., 1998; Birch et al., 2001; Birch et al., 2003; Liang et al., 2016). Lastly, it is important to note that decreases in parenting stress were only noted at the follow-up assessment. It may be the case that making lifestyle changes can be stressful in the beginning, but once the adjustment period is over and positive changes are noticeable, then one feels less stressed. 


\section{Study Limitations}

Limitations of this study should be considered. First, mechanistic data were selfreport measures and are subject to rater bias. More objective measures, such as requesting pictures of meals along with the dietary recalls would be helpful to support the self-report measures. For example, some studies suggest that you need to collect at least three nonconsecutive days of 24-hour dietary recalls (Yunsheng et al., 2009; Johnson et al., 1996), while more recent studies are moving toward a biomarker to identify nutrition intake (Aguiar et al., 2014; Woodside et al., 2017). In terms of measuring feeding practices and parenting, family mealtime interactions can be recorded as a more objective measure (Berge et al., 2013; Berge et al., 2014). Second, as mentioned previously, the physical activity measure used in the study (FHLQ) did not assess light physical activity and therefore we were unable to capture this data. Future studies should ensure to capture the entire spectrum of physical activity. Third, the sample size was very small and therefore some findings may not have been significant due to limited power. However, this study followed the Phase IIa ORBIT model (Czajkowski et al., 2015) which focused on establishing a proof of concept and clinically significant change. Additionally, we included effect sizes in our results to further examine the initial promise of the HLPP within a community setting. Future studies should apply these results to the next step in the ORBIT model, Phase IIb which includes a larger sample and control group (Czajkowski et al., 2015).

\section{Conclusions}

Despite the aforementioned limitations, this study demonstrates the potential of The Healthy Lifestyle Parenting Program (HLPP) provided within a community setting in 
producing clinically meaningful health and mechanistic changes in families. Future research should address the attrition observed in the HLPP. Given previous work demonstrating improvements in attrition when adding a child treatment group (Jensen \& Grimes, 2010), HLPP may benefit from including a child component. Additionally, given that the reasons for drop-out provided in the current study were primarily related to transportation and scheduling problems, facilitating groups via an online conferencing platform (e.g., zoom) may also improve attrition. Moreover, consistent with a review of parent-only pediatric obesity interventions for young children which called for properly designed longitudinal studies (Loveman et al., 2015) and following the ORBIT model of treatment development, the next iteration of HLPP should be examined within a randomized controlled trial to confirm these preliminary findings and whether dissemination of HLPP is warranted. 


\section{CLINICAL IMPLICATIONS}

In terms of the clinical implications of our findings, first it is important to point out that both studies had difficulties with recruitment and participation. While this is consistent with the pediatric obesity literature, implications suggest finding convenient ways for families to participate is critical. For example, offering self-directed online modules and discussion groups might make it more feasible for parents to participate and can still include group participation. Additionally, utilizing discrete-choice conjoint experiments may illuminate the preferences of families and thereby improve participation in pediatric obesity interventions by providing more individualized treatment. Participation and attrition in pediatric obesity interventions might also be improved by expanding inclusion criteria. The current studies only include families with children above the $85^{\text {th }}$ percentile for weight, however, previous research demonstrates that children who are not overweight and are picky eaters have similar difficulties meeting nutritional needs (e.g., decreased fruit and vegetable consumption; Cooke et al., 2006). Future interventions, especially in this young age group, should aim to improve healthy lifestyle behaviors and prevention efforts instead of focusing on families with elevated anthropometrics. Second, adherence to important elements, such as self-monitoring, in our studies was poor which may explain the lack of significant health improvements, particularly within parents themselves. Future research should examine how to maximize self-monitoring, as it is an active ingredient in obesity interventions (Michie et al. 2013). Integrating self-monitoring with automated applications (e.g., cell phone step and activity trackers) may improve adherence and should be investigated. Within young children, such self-monitoring is done via parents and therefore motivating parents to be effective 
role models is important (Borrello et al., 2015). Third, despite the lack of parenting effects across both studies, the moderate effect sizes suggest that this is still an important mechanism to target in future family-based obesity work. Particularly, restriction of foods is common when trying to lose weight, however, previous research has found that restriction is associated with poorer food choices (Zive et al., 1998; Birch et al., 2001). Therefore, providing psychoeducation to parents on parenting strategies and their association with health behaviors can be a simple component that can be added within a primary healthcare setting. For example, Schwartz et al. (2007), showed some promise in implementing an obesity intervention within a primary care setting. Integrating of such intervention mechanisms within a healthcare setting may provide cost savings compared to costly summer camp settings. Fourth, our sample was primarily low-income and Hispanic in both studies. This is a significant strength given the astounding rates of overweight and obesity in Hispanic children ages 6-to-11-years (46.2\%) compared to compared to white children (29.4\%; Ogden et al., 2014). Successful interventions are particularly important in this sample as obese Hispanic children are more susceptible to weight related health problems (e.g., insulin resistance, elevated liver enzymes) compared to obese white children (Goran et al., 2002; Schwimmer et al., 2005). Therefore, culturally appropriate recruitment strategies as well as interventions specific for Hispanic families are needed.

Furthermore, previous research has demonstrated differences in parenting styles, child feeding practices, and perception of obesity among Hispanic parents (Hughes et al., 2005; Varela et al., 2004; Arredondo et al., 2006; Mejia dr Grubb et al., 2018).

Specifically, Hispanic mothers tend to be more permissive in their parenting and engage 
in more indulgent feeding practices (Hughes et al., 2005). However, acculturation may play a role in the relationship between ethnicity and parental feeding practices. In a study comparing mothers who were first-generation immigrants with mothers born in the United States, Power et al. (2015) demonstrated that first-generation immigrant mothers had more authoritarian and less indulgent feeding practices and that greater maternal acculturation was associated with less restriction of food. Therefore, it may be the case that the increase in parental monitoring found in the current study is due to mothers being first-generation immigrants who were learning skills and feeding practices more consistent with the United States culture thereby contributing to an increase in acculturation. Future research should examine the role of acculturation within pediatric obesity interventions.

Lastly and most importantly, when considering effect sizes across both studies (considering our small sample sizes) our findings highlight that while a child-based only intervention may have some benefits, the addition of a parent component or even solely focusing on parents yields comparable outcomes. When viewed in conjunction with the cost of an intensive child intervention, such as a summer camp, this study points to a parent-based only intervention as an effective way to impact children's health, particularly in this young age group. It is important to note however, that as children get older and are more independent, family-based interventions may be more suitable (Skelton et al., 2012). Focusing on the family as an interconnected system can be accomplished by not just enrolling parents in interventions, but also other caregivers (e.g., grandparents). In fact, previous work has found that children who had a grandparent as a primary caregiver had a significantly higher BMI z-score than those living with one 
or both parents (Formisano et al., 2013). Moreover, given the current climate where technology has become primary in providing services, finding ways to combine technology and pediatric obesity interventions is a critical priority. Future work should examine whether providing an online health intervention that includes extended caregivers can improve child health outcomes and improve attrition. 


\section{LIST OF REFERENCES}

Abidin, R. (1995). Parenting Stress Index-Manual (3rd ed). Odessa, FL: Psychological Assessment Resources.

Adab, P., Pallan, M. J., Lancashire, E. R., Hemming, K., Frew, E., Barrett, T., ... \& Daley, A. (2018). Effectiveness of a childhood obesity prevention programme delivered through schools, targeting 6 and 7 year olds: Cluster randomised controlled trial (WAVES study). British Medical Journal, 360, k211.

Aeberli, I., Beljean, N., Lehmann, R., l'Allemand, D., Spinas, G. A., \& Zimmermann, M. B. (2008). The increase of fatty acid-binding protein aP2 in overweight and obese children: interactions with dietary fat and impact on measures of subclinical inflammation. International Journal of Obesity, 32(10), 1513.

Ahmed, H. M., \& Ndumele, C. E. (2014). Physical Activity. IASPC Manual of Preventive Cardiology, 163.

Alliance, A. (2014). America after 3PM: Afterschool programs in demand. Washington, DC: Afterschool Alliance.

Annesi, J. J., \& Vaughn, L. L. (2011). Effects of extension of the Youth Fit For Life intervention program by video vs. instructor supervision. Archives of Exercise in Health \& Disease, 2(2).

Arredondo, E. M., Elder, J. P., Ayala, G. X., Campbell, N., Baquero, B., \& Duerksen, S. (2006). Is parenting style related to children's healthy eating and physical activity in Latino families?. Health Education Research, 21(6), 862-871.

Aucott, L., Rothnie, H., McIntyre, L., Thapa, M., Waweru, C., \& Gray, D. (2009). Longterm weight loss from lifestyle intervention benefits blood pressure? A systematic review. Hypertension, 54(4), 756-762.

Bankoski, A., Harris, T. B., McClain, J. J., Brychta, R. J., Caserotti, P., Chen, K. Y., ... \& Koster, A. (2011). Sedentary activity associated with metabolic syndrome independent of physical activity. Diabetes Care, 34(2), 497-503.

Barton, S. B., Walker, L. L., Lambert, G., Gately, P. J., \& Hill, A. J. (2004). Cognitive change in obese adolescents losing weight. Obesity Research, 12(2), 313-319.

Başkale, H., \& Bahar, Z. (2011). Outcomes of nutrition knowledge and healthy food choices in 5-to 6-year-old children who received a nutrition intervention based on Piaget's theory. Journal for Specialists in Pediatric Nursing, 16(4), 263-279. 
Baumrind, D. (1966). Effects of authoritative parental control on child behavior. Child Development, 887-907.

Bayer, O., Bolte, G., Morlock, G., Rückinger, S., \& von Kries, R. (2009). A simple assessment of physical activity is associated with obesity and motor fitness in preschool children. Public Health Nutrition, 12(08), 1242-1247.

Berry, D. C., McMurray, R. G., Schwartz, T. A., Hall, E. G., Neal, M. N., \& Adatorwovor, R. (2017). A cluster randomized controlled trial for child and parent weight management: Children and parents randomized to the intervention group have correlated changes in adiposity. BMC Obesity, 4(1), 39.

Biener, A. I., Cawley, J., \& Meyerhoefer, C. (2017). The medical care costs of youth obesity: An instrumental variables approach (No. w23682). National Bureau of Economic Research.

Birch, L. L., Fisher, J. O., \& Davison, K.K. (2003). Learning to overeat: maternal use of restrictive feeding practices promotes girls' eating in the absence of hunger. American Journal of Clinical Nutrition, 78(2), 215-220.

Birch, L. L., Fisher, J. O., Grimm-Thomas, K., Markey, C. N., Sawyer, R., \& Johnson, S. L. (2001). Confirmatory factor analysis of the Child Feeding Questionnaire: a measure of parental attitudes, beliefs and practices about child feeding and obesity proneness. Appetite, 36(3), 201-210.

Birch, L. L., Johnson, S. L., Grimm-Thomas, K., \& Fisher, J. O. (1998). The child feeding questionnaire (CFQ). An instrument for assessing parental child feeding attitudes and strategies. Operational definitions of factors, scoring and summing instructions. Unpublished manuscript, Pennsylvania State University.

Borrello, M., Pietrabissa, G., Ceccarini, M., Manzoni, G. M., \& Castelnuovo, G. (2015). Motivational interviewing in childhood obesity treatment. Frontiers in Psychology, 6,1732 .

Bös, K., Bappert, S., Tittlbach, S., \& Woll, A. (2004). Karlsruhe's motoric screening for nursery school children (KMS 3-6). Sportunterricht, 53(3), 79-87.

Cameron, N. (1986). The methods of auxological anthropometry. In: Falkner F, Tanner JM, editors. Human Growth: Methodology; Ecological, Genetic, and Nutritional Effects on Growth. New York, NY: Plenum Press.

Castro, D. C., Samuels, M., \& Harman, A. E. (2013). Growing healthy kids: a community garden-based obesity prevention program. American Journal of Preventive Medicine, 44(3), S193-S199. 
Coleman, K. J., Tiller, C. L., Sanchez, J., Heath, E. M., Sy, O., Milliken, G., \& Dzewaltowski, D. A. (2005). Prevention of the epidemic increase in child risk of overweight in low-income schools: the El Paso coordinated approach to child health. Archives of Pediatrics \& Adolescent Medicine, 159(3), 217-224.

Collins, C., Morgan, P., Okely, A., Burrows, T., Cliff, D., Jones, R., ... \& Baur, L. (2010). HIKCUPS (Hunter Illawarra Kids Challenge Using Parent Support) reduces BMI zscore up to 2 years: Results of a multi-site randomized trial for overweight children: T3: PO. 188. Obesity Reviews, 11.

Collins, C. E., Okely, A. D., Morgan, P. J., Jones, R. A., Burrows, T. L., Cliff, D. P., ... \& Baur, L. A. (2011). Parent diet modification, child activity, or both in obese children: an RCT. Pediatrics, 127(4), 619-627.

Cooke, L., Carnell, S., \& Wardle, J. (2006). Food neophobia and mealtime food consumption in 4-5 year old children. International Journal of Behavioral Nutrition and Physical Activity, 3(1), 1-6.

Coon, K. A., \& Tucker, K. L. (2002). Television and children's consumption patterns. Minerva Pediatrica, 54(5), 423-436.

Coto, J., Pulgaron, E.R., Graziano, P., Bagner, D.M., Villa, M., \& Delamater, A.M. (2018). Association of parental role modeling and child health behaviors. Maternal and Child Health Journal, 23(7), 943-950.

Cunningham, C. E., Deal, K., Rimas, H., Buchanan, D. H., Gold, M., Sdao-Jarvie, K., \& Boyle, M. (2008). Modeling the information preferences of parents of children with mental health problems: A discrete choice conjoint experiment. Journal of Abnormal Child Psychology, 36(7), 1123.

Cuttler, L., Singer, M., Simpson, L., Gallan, A., Nevar, A., \& Silvers, J.B. (2008). Health Policy Brief: Obesity in children and families across Ohio. Ohio Family Health Survey.

Daniels, S. R. (2006). The consequences of childhood overweight and obesity. The Future of Children, 16, 47-67.

Danner, F. W. (2008). A national longitudinal study of the association between hours of TV viewing and the trajectory of BMI growth among US children. Journal of Pediatric Psychology, 33(10), 1100-1107.

Davis, J. N., Ventura, E. E., Cook, L. T., Gyllenhammer, L. E., \& Gatto, N. M. (2011). LA Sprouts: a gardening, nutrition, and cooking intervention for Latino youth improves diet and reduces obesity. Journal of the American Dietetic Association, 111(8), 1224-1230. 
Davison, K. K., \& Birch, L. L. (2001). Childhood overweight: a contextual model and recommendations for future research. Obesity Reviews, 2(3), 159-171.

Deshmukh-Taskar, P., Nicklas, T.A., Morales, M., Yang, S.J. , Zakeri, I., \& Berenson, G.S. (2006). Tracking of overweight status from childhood to young adulthood: the Bogalusa Heart Study. European Journal of Clinical Nutrition, 60, 48-57.

Doak, C. M., Visscher, T. L. S., Renders, C. M., \& Seidell, J. C. (2006). The prevention of overweight and obesity in children and adolescents: a review of interventions and programmes. Obesity Reviews, 7(1), 111-136.

Domoff, S. E., \& Niec, L. N. (2018). Parent-child interaction therapy as a prevention model for childhood obesity: A novel application for high-risk families. Children and Youth Services Review, 91, 77-84.

Donnelly, J. E., Jacobsen, D. J., Whatley, J. E., Hill, J. O., Swift, L. L., Cherrington, A., ... \& Reed, G. (1996). Nutrition and physical activity program to attenuate obesity and promote physical and metabolic fitness in elementary school children. Obesity Research, 4(3), 229-243.

Ebbeling, C. B., Pawlak, D. B., \& Ludwig, D. S. (2002). Childhood obesity: Public-health crisis, common sense cure. The Lancet, 360(9331), 473-482.

Edwards, C., Nicholls, D., Croker, H., Van Zyl, S., Viner, R., \& Wardle, J. (2006). Familybased behavioural treatment of obesity: Acceptability and effectiveness in the UK. European Journal of Clinical Nutrition, 60(5), 587.

Ek, A., Chamberlain, K. L., Sorjonen, K., Hammar, U., Malek, M. E., Sandvik, P., ... \& Ejderhamn, J. (2019). A parent treatment program for preschoolers with obesity: a randomized controlled trial. Pediatrics, 144(2), e20183457.

Ello-Martin, J. A., Ledikwe, J. H., \& Rolls, B. J. (2005). The influence of food portion size and energy density on energy intake: Implications for weight management. The American Journal of Clinical Nutrition, 82(1), 236S-241S.

El Mikati, H. K., Boateng, A. O., McKinney, B. M., Haberlin-Pittz, K., Pike, J., Perry, P., ... \& Yazel-Smith, L. (2020). Forever-Fit Summer Camp: The impact of a 6-week summer healthy lifestyle day camp on anthropometric, cardiovascular, and physical fitness measures in youth with obesity. Journal of Primary Care \& Community Health, 11.

Epstein, L. H., Gordy, C. C., Raynor, H. A., Beddome, M., Kilanowski, C. K., \& Paluch, R. (2001). Increasing fruit and vegetable intake and decreasing fat and sugar intake in families at risk for childhood obesity. Obesity Research, 9(3), 171-178. 
Epstein, L. H., Paluch, R. A., Roemmich, J. N., \& Beecher, M. D. (2007). Family-based obesity treatment, then and now: Twenty-five years of pediatric obesity treatment. Health Psychology, 26(4), 381.

Epstein, L. H., Roemmich, J. N., Robinson, J. L., Paluch, R. A., Winiewicz, D. D., Fuerch, J. H., \& Robinson, T. N. (2008). A randomized trial of the effects of reducing television viewing and computer use on body mass index in young children. Archives of Pediatrics \& Adolescent Medicine, 162(3), 239-245.

Epstein, L.H., \& Squires, S. (1988). The Stop-Light Diet for Children. Boston, MA: Litle, Brown, and Company.

Epstein, L. H., Valoski, A. M., Vara, L. S., McCurley, J., Wisniewski, L., Kalarchian, M. A., ... \& Shrager, L. R. (1995). Effects of decreasing sedentary behavior and increasing activity on weight change in obese children. Health Psychology, 14(2), 109.

Epstein, L. H., Valoski, A., Wing, R. R., \& McCurley, J. (1990). Ten-year follow-up of behavioral, family-based treatment for obese children. Journal of the American Medical Association, 264(19), 2519-2523.

Fabiano, G. A., Chacko, A., Pelham Jr, W. E., Robb, J., Walker, K. S., Wymbs, F., ... \& Shulman, S. (2009). A comparison of behavioral parent training programs for fathers of children with attention-deficit/hyperactivity disorder. Behavior Therapy, 40(2), 190-204.

Fahlman, M. M., Dake, J. A., McCaughtry, N., \& Martin, J. (2008). A pilot study to examine the effects of a nutrition intervention on nutrition knowledge, behaviors, and efficacy expectations in middle school children. Journal of School Health, $78(4), 216-222$.

Fernandez, M. A., Butler, A. M., \& Eyberg, S. M. (2011). Treatment outcome for low socioeconomic status African American families in parent-child interaction therapy: A pilot study. Child \& Family Behavior Therapy, 33(1), 32-48.

Formisano, A., Hunsberger, M., Bammann, K., Vanaelst, B., Molnar, D., Moreno, L. A., ... \& Siani, A. (2014). Family structure and childhood obesity: results of the IDEFICS Project. Public Health Nutrition, 17(10), 2307-2315.

Gately, P. J., Cooke, C. B., Barth, J. H., Bewick, B. M., Radley, D., \& Hill, A. J. (2005). Children's residential weight-loss programs can work: a prospective cohort study of short-term outcomes for overweight and obese children. Pediatrics, 116(1), 73-77. 
Gately, P. J., Cooke, C. B., Butterly, R. J., Mackreth, P., \& Carroll, S. (2000). The effects of a children's summer camp programme on weight loss, with a 10 month followup. International Journal of Obesity, 24(11), 1445.

Gaya, A. R., Alves, A., Aires, L., Martins, C. L., Ribeiro, J. C., \& Mota, J. (2009). Association between time spent in sedentary, moderate to vigorous physical activity, body mass index, cardiorespiratory fitness and blood pressure. Annals of Human Biology, 36(4), 379-387.

Gerards, S. M., Sleddens, S. F., Dagnelie, P. C., De Vries, N. K., \& Kremers, S. P. (2011). Interventions addressing general parenting to prevent or treat childhood obesity. International Journal of Pediatric Obesity, 6(sup3), e28-45.

Głąbska, D., Guzek, D., Mellová, B., Zadka, K., Żywczyk, K., \& Gutkowska, K. (2019). The National After-School Athletics Program participation as a tool to reduce the risk of obesity in adolescents after one year of intervention: A Nationwide Study. International Journal of Environmental Research and Public Health, 16(3), 405.

Golan, M., Kaufman, V., \& Shahar, D. R. (2006). Childhood obesity treatment: Targeting parents exclusively v. parents and children. British Journal of Nutrition, 95(5), 1008-1015.

Goran, M. I., Bergman, R. N., Cruz, M. L., \& Watanabe, R. (2002). Insulin resistance and associated compensatory responses in African-American and Hispanic children. Diabetes Care, 25(12), 2184-2190.

Gordon-Larsen, P., Nelson, M. C., Page, P., \& Popkin, B. M. (2006). Inequality in the built environment underlies key health disparities in physical activity and obesity. Pediatrics, 117(2), 417-424.

Gortmaker, S. L., Must, A., Sobol, A. M., Peterson, K., Colditz, G. A., \& Dietz, W. H. (1996). Television viewing as a cause of increasing obesity among children in the United States, 1986-1990. Archives of Pediatrics \& Adolescent Medicine, 150(4), 356-362.

Gow, M. L., Van Doorn, N., Broderick, C. R., Hardy, L. L., Ho, M., Baur, L. A., ... \& Garnett, S. P. (2016). Sustained improvements in fitness and exercise tolerance in obese adolescents after a 12 week exercise intervention. Obesity Research \& Clinical Practice, 10(2), 178-188.

Graziano, P. A. (2015). How well do preschoolers identify healthy foods? Development and preliminary validation of the Dietary Interview Assessing Nutritional Awareness (DIANA). Appetite, 92, 110-117. 
Graziano, P. A., Garcia, A., \& Lim, C. S. (2017). Summer Healthy-Lifestyle Intervention Program for young children who are overweight: Results from a nonrandomized pilot trial. Journal of Developmental \& Behavioral Pediatrics, 38(9), 723-727.

Graziano, P.A., \& Lim, C. The family healthy-lifestyle questionnaire. Unpublished manuscript.

Graziano, P. A., Slavec, J., Hart, K., Garcia, A., \& Pelham, W. E. (2014). Improving school readiness in preschoolers with behavior problems: Results from a summer treatment program. Journal of Psychopathology and Behavioral Assessment, 36(4), 555-569.

Gruber, K. J., \& Haldeman, L. A. (2009). Peer Reviewed: Using the family to combat childhood and adult obesity. Preventing Chronic Disease, 6(3), 1-10.

Haines, J., Rifas-Shiman, S. L., Gross, D., McDonald, J., Kleinman, K., \& Gillman, M. W. (2016). Randomized trial of a prevention intervention that embeds weight-related messages within a general parenting program. Obesity, 24(1), 191-199.

Haire-Joshu, D., Elliott, M. B., Caito, N. M., Hessler, K., Nanney, M. S., Hale, N., ... \& Brownson, R. C. (2008). High 5 for Kids: The impact of a home visiting program on fruit and vegetable intake of parents and their preschool children. Preventive Medicine, 47(1), 77-82.

Hawkes, C., Smith, T. G., Jewell, J., Wardle, J., Hammond, R. A., Friel, S., ... \& Kain, J. (2015). Smart food policies for obesity prevention. The Lancet, 385(9985), 24102421.

Haycraft, E., Karasouli, E., \& Meyer, C. (2017). Maternal feeding practices and children's eating behaviours: A comparison of mothers with healthy weight versus overweight/obesity. Appetite, 116, 395-400.

Hendrie, G. A., Coveney, J., \& Cox, D. N. (2012). Defining the complexity of childhood obesity and related behaviours within the family environment using structural equation modelling. Public Health Nutrition, 15(1), 48-57.

Hesketh, K. D., \& Campbell, K. J. (2010). Interventions to prevent obesity in 0-5 year olds: an updated systematic review of the literature. Obesity, $18(\mathrm{~S} 1)$.

Hingle, M. D., O'Connor, T. M., Dave, J. M., \& Baranowski, T. (2010). Parental involvement in interventions to improve child dietary intake: a systematic review. Preventive Medicine, 51(2), 103-111. 
Hood, K. K., \& Eyberg, S. M. (2003). Outcomes of parent-child interaction therapy: Mothers' reports of maintenance three to six years after treatment. Journal of Clinical Child and Adolescent Psychology, 32(3), 419-429.

Howe, C. A., Harris, R. A., \& Gutin, B. (2010). A 10-month physical activity intervention improves body composition in young black boys. Journal of Obesity, 2011, 1-8.

Huberty, J. L., Dinkel, D. M., \& Beets, M. W. (2014). Evaluation of GoGirlGo!; A practitioner based program to improve physical activity. BMC Public Health, 14(1), 118.

Huelsing, J., Kanafani, N., Mao, J., \& White, N.H. (2010). Camp Jump Start: Effects of a residential summer weight-loss camp for older children and adolescents. Pediatrics, 125(4), e884-e890.

Hughes, S. O., Power, T. G., Fisher, J. O., Mueller, S., \& Nicklas, T. A. (2005). Revisiting a neglected construct: parenting styles in a child-feeding context. Appetite, 44(1), 83-92.

Ihmels, M. A., Welk, G. J., Eisenmann, J. C., \& Nusser, S. M. (2009). Development and preliminary validation of a Family Nutrition and Physical Activity (FNPA) screening tool. International Journal of Behavioral Nutrition and Physical Activity, $6(1), 14$.

Ihmels, M. A., Welk, G. J., Eisenmann, J. C., Nusser, S. M. \& Myers, E. (2009). Prediction of BMI change in young children with the Family Nutrition and Physical Activity (FNPA) screening tool. Annals of Behavioral Medicine, 38, 60-68.

Janicke, D. M., Sallinen, B. J., Perri, M. G., Lutes, L. D., Huerta, M., Silverstein, J. H., \& Brumback, B. (2008). Comparison of parent-only vs family-based interventions for overweight children in underserved rural settings: outcomes from project STORY. Archives of Pediatrics \& AdolescentMmedicine, 162(12), 1119-1125.

Jensen, S. A., \& Grimes, L. K. (2010). Increases in parent attendance to behavioral parent training due to concurrent child treatment groups. Child \& Youth Care Forum, 39(4), 239-251.

Jetter, K. M., \& Cassady, D. L. (2006). The availability and cost of healthier food alternatives. American Journal of Preventive Medicine, 30(1), 38-44.

Jones, B. A., Madden, G. J., Wengreen, H. J., Aguilar, S. S., \& Desjardins, E. A. (2014). Gamification of dietary decision-making in an elementary-school cafeteria. PloS one, 9(4). 
Just, D. R., \& Price, J. (2013). Using incentives to encourage healthy eating in children. Journal of Human Resources, 48(4), 855-872.

Katz, D. L., O’Connell, M., Yeh, M. C., Nawaz, H., Njike, V., Anderson, L. M., ... \& Dietz, W. (2005). Public health strategies for preventing and controlling overweight and obesity in school and worksite settings: a report on recommendations of the Task Force on Community Preventive Services. Morbidity and Mortality Weekly Report: Recommendations and Reports, 54(10), 1-12.

Kirkpatrick, S.I., Subar, A.F., Douglass, D., Zimmerman, T.P., Thompson, F.E., Kahle, L.L., George, S.M., Dodd, K.W., \& Potischman, N. (2014). Performance of the Automated Self-Administered 24-hour Recall relative to a measure of true intakes and to aninterviewer-administered 24-h recall. The American Journal of Clinical Nutrition, 100, 233-40.

Kirschenbaum, D. S. (2010). Weight-loss camps in the US and the immersion-to-lifestyle change model. Childhood Obesity, 6(6), 318-323.

Kirschenbaum, D., Craig, R., Kelly, K., \& Germann, J. (2007). Immersion programs for treating pediatric obesity: Follow-up evaluations of Wellspring Camps and Academy of the Sierras, a boarding school for overweight teenagers. Obesity Management, 3, 261-266.

Krebs-Smith, S. M., Pannucci, T. E., Subar, A. F., Kirkpatrick, S. I., Lerman, J. L., Tooze, J. A., ... \& Reedy, J. (2018). Update of the healthy eating index: HEI-2015. Journal of the Academy of Nutrition and Dietetics, 118(9), 1591-1602.

Kremers, S. P., Brug, J., de Vries, H., \& Engels, R. C. (2003). Parenting style and adolescent fruit consumption. Appetite, 41(1), 43-50.

Kropski, J. A., Keckley, P. H., \& Jensen, G. L. (2008). School-based obesity prevention programs: an evidence-based review. Obesity, 16(5), 1009-1018.

Kuczmarski, R.J., Ogden, C.L., Grummer-Strawn, L.M., Flegal, K.M., Guo ,S.S., Wei, R., Mei, Z., Curtin, L.R., Roche, A.F., \& Johnson, C.L. (2000). CDC growth charts: United States. Advance Data, 314, 1-27.

Lazorick, S., Fang, X., \& Crawford, Y. (2016). The MATCH program: Long-term obesity prevention through a middle school based intervention. Childhood Obesity, 12(2), 103-112.

Lee, J. W., Lee, H. S., Chang, N., \& Kim, J. M. (2009). The relationship between nutrition knowledge scores and dietary behavior, dietary intakes and anthropometric parameters among primary school children participating in a nutrition education program. Korean Journal of Nutrition, 42(4), 338-349. 
Liang, J., Matheson, B. E., Rhee, K. E., Peterson, C. B., Rydell, S., \& Boutelle, K. N. (2016). Parental control and overconsumption of snack foods in overweight and obese children. Appetite, 100, 181-188.

Lin, B. H., \& Morrison, R. M. (2002). Higher fruit consumption linked with lower body mass index. Food Review/National Food Review, 25(1482-2016-121538), 28-32.

Lin, P.H., Wang, Y., Grambow, S.C., Goggins, W., \& Almirall, D. (2012) Dietary saturated fat intake is negatively associated with weight maintenance among the PREMIER participants. Obesity, 20, 571-575.

Lobstein, T., Baur, L., \& Uauy, R. (2004). Obesity in children and young people: a crisis in public health. Obesity Reviews, 5, 4-85.

Luby, J., Lenze, S., \& Tillman, R. (2012). A novel early intervention for preschool depression: Findings from a pilot randomized controlled trial. Journal of Child Psychology and Psychiatry, 53(3), 313-322.

Ludwig, D. S., Peterson, K. E., \& Gortmaker, S. L. (2001). Relation between consumption of sugar-sweetened drinks and childhood obesity: a prospective, observational analysis. The Lancet, 357(9255), 505-508.

Luepker, R. V., Perry, C. L., McKinlay, S. M., Nader, P. R., Parcel, G. S., Stone, E. J., ... \& Kelder, S. H. (1996). Outcomes of a field trial to improve children's dietary patterns and physical activity: the Child and Adolescent Trial for Cardiovascular Health (CATCH). Journal of the American Medical Association, 275(10), 768-776.

Mazzeo, S. E., Kelly, N. R., Stern, M., Gow, R. W., Cotter, E. W., Thornton, L. M., ... \& Bulik, C. M. (2014). Parent skills training to enhance weight loss in overweight children: Evaluation of NOURISH. Eating Behaviors, 15(2), 225-229.

McNeish, D. (2017). Missing data methods for arbitrary missingness with small samples. Journal of Applied Statistics, 44(1), 24-39.

Mejia de Grubb, M. C., Salemi, J. L., Gonzalez, S. J., Sanderson, M., Zoorob, R. J., Mkanta, W., \& Levine, R. S. (2018). Parenting style and perceptions of children's weight among US Hispanics: a qualitative analysis. Health Promotion International, 33(1), 132-139.

Moores, C.J., Miller, J., Daniels, L.A., Vidgen, H.A., \& Magarey, A.M. (2018). Pre-post evaluation of a weight management service for families with overweight and obese children, translated from the efficacious lifestyle intervention Parenting, Eating and Activity for Child Health (PEACH). British Journal of Nutrition, 119(12), 14341445 . 
Moreno, L. A., \& Rodriguez, G. (2007). Dietary risk factors for development of childhood obesity. Current Opinion in Clinical Nutrition \& Metabolic Care, 10(3), 336-341.

Morgan, P. J., Collins, C. E., Lubans, D. R., Callister, R., Lloyd, A. B., Plotnikoff, R. C., ... \& Okely, A. D. (2019). Twelve-month outcomes of a father-child lifestyle intervention delivered by trained local facilitators in underserved communities: The Healthy Dads Healthy Kids dissemination trial. Translational Behavioral Medicine, $9(3), 560-569$.

MTA Cooperative Group. (1999). A 14-month randomized clinical trial of treatment strategies for attention-deficit/hyperactivity disorder. Archives of General Psychiatry, 56, $1073-1086$.

Nabors, L., Burbage, M., Woodson, K. D., \& Swoboda, C. (2015). Implementation of an after-school obesity prevention program: helping young children toward improved health. Issues in Comprehensive Pediatric Nursing, 38(1), 22-38.

Niemeier, B. S., Hektner, J. M., \& Enger, K. B. (2012). Parent participation in weightrelated health interventions for children and adolescents: A systematic review and meta-analysis. Preventive Medicine, 55(1), 3-13.

Niinikoski, H., Lagström, H., Jokinen, E., Siltala, M., Rönnemaa, T., Viikari, J., Raitakari, O.T., Jula, A., Marniemi, J., Näntö-Salonen, K., \& Simell, O. (2007). Impact of repeated dietary counseling between infancy and 14 years of age on dietary intakes and serum lipids and lipoproteins: the STRIP study. Circulation, 116, 1032- 1040.

Ochoa, A., \& Berge, J. M. (2017). Home environmental influences on childhood obesity in the Latino population: a decade review of literature. Journal of Immigrant and Minority Health, 19(2), 430-447.

Ogden, C.L., Carroll, M.D., Kit, B.K., \& Flegal, K.M. (2012). Prevalence of obesity and trends in Body Mass Index among US children and adolescents, 1999-2010. Journal of the American Medical Association, 307(5), 483-490.

Ogden, C.L., Carroll, M.D., Kit, B.K., \& Flegal, K.M. (2014). Prevalence of childhood and adult obesity in the United States, 2011-2012. Journal of the American Medical Association, 311(8), 806-814.

Orme, B. (2010). Getting started with conjoint analysis: strategies for product design and pricing research second edition. Madison: Research Publishers LLC.

Pate, R. R., O'neill, J. R., \& Lobelo, F. (2008). The evolving definition of" sedentary". Exercise and Sport Sciences Reviews, 36(4), 173-178. 
Peyer, K.L., \& Welk, G. (2017). Construct validity of an obesity risk screening tool in two age groups. International Journal of Environmental Research and Public Health, 14(4), 419.

Post, P., \& Palacios, R. (2019). Aggie Play: A gender-relevant physical activity program for girls. Journal of Sport and Exercise Psychology, 41(4), 194-205.

Power, T. G., O'Connor, T. M., Orlet Fisher, J., \& Hughes, S. O. (2015). Obesity risk in children: the role of acculturation in the feeding practices and styles of low-income Hispanic families. Childhood Obesity, 11(6), 715-721.

Quinlan, N. P., Kolotkin, R. L., Fuemmeler, B. F., \& Costanzo, P. R. (2009). Psychosocial outcomes in a weight loss camp for overweight youth. International Journal of Pediatric Obesity, 4(3), 134-142.

Raper, N., Perloff, B., Ingwersen, L., Steinfeldt, L., \& Anand, J. (2004). An overview of USDA's dietary intake data system. Journal of Food Composition and Analysis, $17(3-4), 545-55$.

Resnicow, K., McMaster, F., Bocian, A., Harris, D., Zhou, Y., Snetselaar, L., ... \& Hollinger, D. (2015). Motivational interviewing and dietary counseling for obesity in primary care: an RCT. Pediatrics, 135(4), 649-657.

Rhee, K. E., Lumeng, J. C., Appugliese, D. P., Kaciroti, N., \& Bradley, R. H. (2006). Parenting styles and overweight status in first grade. Pediatrics, 117(6), 2047-2054.

Riera-Crichton, D., \& Tefft, N. (2014). Macronutrients and obesity: Revisiting the calories in, calories out framework. Economics \& Human Biology, 14, 33-49.

Robinson, T.N. (1999). Reducing children's television viewing to prevent obesity: a randomized controlled trial. Journal of the American Medical Association, 282, $1561-1567$.

Rodriguez Rocha, N. P., \& Kim, H. (2019). eHealth Interventions for fruit and vegetable intake: A Meta-analysis of effectiveness. Health Education \& Behavior, 46(6), 947-959.

Ros, R., Hernandez, J., Graziano, P. A., \& Bagner, D. M. (2016). Parent training for children with or at risk for developmental delay: The role of parental homework completion. Behavior Therapy, 47(1), 1-13.

Sahoo, K., Sahoo, B., Choudhury, A. K., Sofi, N. Y., Kumar, R., \& Bhadoria, A. S. (2015). Childhood obesity: Causes and consequences. Journal of Family Medicine and Primary Care, 4(2), 187. 
Sahota, P., Rudolf, M.C., Dixey, R., Hill, A.J., Barth, J.H., \& Cade, J. (2001). Evaluation of implementation and effect of primary school based intervention to reduce risk factors for obesity. British Medical Journal, 323, 1027-1029.

Savage, J. S., Fisher, J. O., \& Birch, L. L. (2007). Parental influence on eating behavior: Conception to adolescence. The Journal of Law, Medicine \& Ethics, 35(1), 22-34.

Schrempft, S., van Jaarsveld, C. H., Fisher, A., Fildes, A., \& Wardle, J. (2016). Maternal characteristics associated with the obesogenic quality of the home environment in early childhood. Appetite, 107, 392-397.

Schwartz, R. P., Hamre, R., Dietz, W. H., Wasserman, R. C., Slora, E. J., Myers, E. F., ... \& Resnicow, K. A. (2007). Office-based motivational interviewing to prevent childhood obesity: A feasibility study. Archives of Pediatrics \& Adolescent Medicine, 161(5), 495-501.

Schwimmer, J. B., McGreal, N., Deutsch, R., Finegold, M. J., \& Lavine, J. E. (2005). Influence of gender, race, and ethnicity on suspected fatty liver in obese adolescents. Pediatrics, 115(5), e561-e565.

Shelton, K.K., Frick, P.J., \& Wootton, J. (1996). Assessment of parenting practices in families of elementary school-age children. Journal of Clinical and Child Adolescent Psychology, 25, 317-329

Sherman, J. B., Alexander, M. A., Clark, L., Dean, A., Welter, L., Allan, J. D., \& RyanWenger, N. M. (1992). Instruments measuring maternal factors in obese preschool children. Western Journal of Nursing Research, 14(5), 555-575.

Skelton, J. A., Buehler, C., Irby, M. B., \& Grzywacz, J. G. (2012). Where are family theories in family-based obesity treatment?: Conceptualizing the study of families in pediatric weight management. International Journal of Obesity, 36(7), 891-900.

Skouteris, H., McCabe, M., Swinburn, B., Newgreen, V., Sacher, P., \& Chadwick, P. (2011). Parental influence and obesity prevention in pre-schoolers: a systematic review of interventions. Obesity Reviews, 12(5), 315-328.

Stiglic, N., \& Viner, R. M. (2019). Effects of screentime on the health and well-being of children and adolescents: a systematic review of reviews. British Medical Journal, 9(1), e023191.

Stovitz, S. D., Berge, J. M., Wetzsteon, R. J., Sherwood, N. E., Hannan, P. J., \& Himes, J. H. (2014). Stage 1 treatment of pediatric overweight and obesity: a pilot and feasibility randomized controlled trial. Childhood Obesity, 10(1), 50-57. 
Stradmeijer, M., Bosch, J., Koops, W., \& Seidell, J. (2000). Family functioning and psychosocial adjustment in overweight youngsters. International Journal of Eating Disorders, 27, 110-114.

Taveras, E. M., Sandora, T. J., Shih, M. C., Ross-Degnan, D., Goldmann, D. A., \& Gillman, M. W. (2006). The association of television and video viewing with fast food intake by preschool-age children. Obesity, 14(11), 2034-2041.

Thompson, F. E., Dixit-Joshi, S., Potischman, N., Dodd, K. W., Kirkpatrick, S. I., Kushi, L. H., ... \& Clancy, H. A. (2015). Comparison of interviewer-administered and automated self-administered 24-hour dietary recalls in 3 diverse integrated health systems. American Journal of Epidemiology, 181(12), 970-978.

U.S. Department of Health and Human Services and U.S. Department of Agriculture. 2015 - 2020 Dietary Guidelines for Americans. 8th Edition. December 2015. Available at https://health.gov/our-work/food-and-nutrition/2015-2020-dietary-guidelines/.

Utter, J., Scragg, R., \& Schaaf, D. (2006). Associations between television viewing and consumption of commonly advertised foods among New Zealand children and young adolescents. Public Health Nutrition, 9(5), 606-612.

Varela, R. E., Vernberg, E. M., Sanchez-Sosa, J. J., Riveros, A., Mitchell, M., \& Mashunkashey, J. (2004). Parenting style of Mexican, Mexican American, and Caucasian-non-Hispanic families: social context and cultural influences. Journal of Family Psychology, 18(4), 651.

Vidmar, A. P., Pretlow, R., Borzutzky, C., Wee, C. P., Fox, D. S., Fink, C., \& Mittelman, S. D. (2019). An addiction model-based mobile health weight loss intervention in adolescents with obesity. Pediatric Obesity, 14(2), e12464.

Vollmer, R. L., \& Baietto, J. (2017). Practices and preferences: Exploring the relationships between food-related parenting practices and child food preferences for high fat and/or sugar foods, fruits, and vegetables. Appetite, 113, 134-140.

Walker, L. L. M., Gately, P. J., Bewick, B. M., \& Hill, A. J. (2003). Children's weight-loss camps: psychological benefit or jeopardy?. International Journal of Obesity, 27(6), 748 .

Walker, R. E., Keane, C. R., \& Burke, J. G. (2010). Disparities and access to healthy food in the United States: A review of food deserts literature. Health \& Place, 16(5), $876-884$.

Ward, Z. J., Long, M. W., Resch, S. C., Giles, C. M., Cradock, A. L., \& Gortmaker, S. L. (2017). Simulation of growth trajectories of childhood obesity into adulthood. New England Journal of Medicine, 377, 2145-2153. 
Whitaker, R., Wright, J., Pepe, M., Seidel, K., \& Dietz, W. (1997). Predicting obesity in young adulthood from childhood and parental obesity. New England Journal of Medicine, 337, 869-873.

Wieland, M. L., Biggs, B. K., Brockman, T. A., Johnson, A., Meiers, S. J., Sim, L. A., ... \& Novotny, P. J. (2020). Club Fit: Development of a physical activity and healthy eating intervention at a Boys \& Girls Club after school program. The Journal of Primary Prevention, 41(2), 153-170.

Worsley, A. (2002). Nutrition knowledge and food consumption: can nutrition knowledge change food behaviour?. Asia Pacific Journal of Clinical Nutrition, 11, S579-S585.

Wrotniak, B. H., Epstein, L. H., Paluch, R. A., \& Roemmich, J. N. (2004). Parent weight change as a predictor of child weight change in family-based behavioral obesity treatment. Archives of Pediatrics \& Adolescent Medicine, 158(4), 342-347.

Yackobovitch-Gavan, M., Wolf Linhard, D., Nagelberg, N., Poraz, I., Shalitin, S., Phillip, M., \& Meyerovitch, J. (2018). Intervention for childhood obesity based on parents only or parents and child compared with follow-up alone. Pediatric Obesity, 13(11), 647-655.

Yavuz, H. M., \& Selcuk, B. (2018). Predictors of obesity and overweight in preschoolers: The role of parenting styles and feeding practices. Appetite, 120, 491-499.

Yee, A. Z., Lwin, M. O., \& Ho, S. S. (2017). The influence of parental practices on child promotive and preventive food consumption behaviors: a systematic review and meta-analysis. International Journal of Behavioral Nutrition and Physical Activity, 14(1), 47.

Yin, Z., Gutin, B., Johnson, M. H., Hanes Jr, J., Moore, J. B., Cavnar, M., ... \& Barbeau, P. (2005). An environmental approach to obesity prevention in children: Medical College of Georgia FitKid Project year 1 results. Obesity Research, 13(12), 21532161.

Zive, M. M., Frank-Spohrer, G. C., Sallis, J. F., McKenzie, T. L., Elder, J. P., Berry, C. C., ... \& Nader, P. R. (1998). Determinants of dietary intake in a sample of white and Mexican-American children. Journal of the American Dietetic Association, 98(11), 1282-1289.

Zizza, C., Siega-Riz, A. M., \& Popkin, B. M. (2001). Significant increase in young adults' snacking between 1977-1978 and 1994-1996 represents a cause for concern!. Preventive Medicine, 32(4), 303-310. 


\section{APPENDICES}

Parents as Role Models: Associations Between Parent and Young Children's Weight, Dietary Intake, and Physical Activity in a Minority Sample.

This manuscript has been published in The Maternal and Child Health Journal

Coto, J., Pulgaron, E.R., Graziano, P., Bagner, D.M., Villa, M., \& Delamater, A.M. (2018). Parents as Role Models: Associations Between Parent and Young Children's Weight, Dietary Intake, and Physical Activity in a Minority Sample. Maternal and Child Health Journal, 23(7), 943-950. 


\title{
Parents as Role Models: Associations Between Parent and Young Children's Weight, Dietary Intake, and Physical Activity in a Minority Sample
}

\author{
Jennifer Coto' 1 - Elizabeth R. Pulgaron ${ }^{2}$ - Paulo A. Graziano ${ }^{1}$ - Daniel M. Bagner ${ }^{1}$ - Manuela Villa ${ }^{2}$. Jamil A. Malik \\ Alan M. Delamater ${ }^{2}$
}

OSpringer Sdence+Business Medla, LLC, part of Springer Nature 2019

\begin{abstract}
Objective We examined the association between parent and child fruit and vegetable (F\&V) intake, physical activity (PA), and body mass index in an ethnic minority and low-income sample. Methods The study sample consisted of 86 children ages 5-7 years ( $80 \%$ Hispanic) and their parents. Three parent health variables (healthy weight, recommended $\mathrm{F} \& \mathrm{~V}$ servings per day, and recommended weekly PA) were used to create a healthy role model index. Associations between the parent index and comesponding child health behaviors and weight were exarnined. Results Most parents (53.5\%) were not healthy role models, $30.2 \%$ were limited healthy role models, $16.3 \%$ were good role models, and none were excellent role models; most parents and children did not meet guidelines for healthy weight, F\&V intake, and PA. Parents who scored higher on the index were more likely to have children with higher levels of F\&V. Furthermore, parents who had a healthy weight were 3.7 times more likely to have a child who had a healthy weight. Additionally, parents who were consuming the recommended servings of F\&V per day were 10 times more likely to have children who were also consuming the recommended servings of F\&V per day compared to parents who were not consuming the recommended servings of F\&V per day. Conclusions for Practice These findings suggest the important role of parental modeling of healthy behaviors to their young children among minority/low-income farmilies. Parents may serve as an important mechanism of change for children's health status by increasing their own healthy lifestyle behaviors.
\end{abstract}

Keywords Pediatric obesity · Parental role modeling · Dietary intake · Physical activity

\section{Significance}

What is already known on this subject? Pediatric obesity is a significant public health concern. Parental obe sity increases the risk of pediatric obesity into adulthood. What this study adds? Findings highlight the important role of parental modeling of healthy behaviors to their young children among minority/low income families. Parents can serve as an

\section{Jennifer Cotb}

hernajen fiued

1 Department of Psychology, Florida International University, 11200 SW 8th Street, Miami, FL. 33199, USA

2 University of Miami, $1601 \mathrm{NW} 12$ Avenux, Miami, FL. 33136, USA

3 National Institute of Psychology, Quaid-LAzam Univensity. slamahad, Pakistan important mechanism of change on their children's health by increasing their own healthy lifestyle behaviors.

\section{Association of Parental Role Modeling with Child Weight and Health Behaviors}

\section{Public Health Concern of Pediatric Obesity}

Pediatric obesity represents a significant public health concern, with epidemiological research indicating that $31.8 \%$ of children between the ages of 2 and 19 years are overweight or obese (Ogden et al. 2014). Rates of pediatric overweight and obesity are especially high among children from racial and ethnic minority backgrounds with recent estimates as high as $38.9 \%$ (Ogden et al. 2014). Demographic variables associated with racial and ethnic minority status, such as powerty level, access to fresh foods, and high saturation of 
fast-food restaurants in low socioeconomic (SES) communities, are also associated with increased rates of pediatric obesity (Morland et al. 2006; Powell et al. 2007). For example, children living in high poverty neighborhoods have a $50 \%$ higher chance of being overweight than those not living in poverty (Delva et al. 2006). Furthermore, parental obesity increases the risk of pediatric obesity into adulthood with overweight children who have an obese parent having twioc the risk of becoming an obese adult (Whitaker et al. 1997). However, few studies have examined the influence of parents on obesity and related health behaviors among young children from ethnic minority and low-income backgrounds (Kumanyika and Grier 2006).

\section{Recommended Healthy Practices}

To help reduce rates of obesity, the U.S. Department of Health and Human Services (USDHHS 2008) and the Department of Agriculture (USDA; McGuire 2011) developed research-based guidelines for healthy weight, nutrition, and physical activity, as indicated below:

\section{Weight}

Children with a body mass index (BMI) between the 85 th and 95th peroentile are considered overweight, and $\geq$ the 95th percentile are considered obese (Barlow and Dietz 1998). For adults, a BMI score between 25 and $29.9 \mathrm{~kg}$ $\mathrm{m}^{2}$ is considered overweight, and $\geq 30 \mathrm{~kg} / \mathrm{m}^{2}$ is considered obese (NHLBI 1998).

\section{Nutrition}

The USDHHS and USDA recommended that children and adults eat five or more servings of fruits and/or vegetables (F\&V) per day (McGuire 2011). The U.S. national average for consuming the recommended $F \& V$ is $1 \%$ for adults and $2 \%$ for children (USDHHS 2010) indicating that the vast majority of children and adults do not meet the recommended amounts of F\&V.

\section{Physical Activity (PA)}

The U.S. Department of Health and Human Services (2008) states that children and adolescents should engage in at least 60 min of daily PA. Furthermore, the 60 min of PA should be either moderate (e.g., brisk walking, bicycling at less than 10 miles per hour) or vigorous (e.g., running, swimming laps) in intensity and should include vigorous PA at least 3 days per woek (USDHHS 2008). For adults, recommendations are for at least 150 min of moderate or vigorous PA per week (USDHHS 2008). In the United States, $<20 \%$ of adults meet the recommended PA guidelines, and $<20 \%$ of adolescents meet the youth guidelines (State of the Plate 2010 ). Additionally, only $42 \%$ of children ages $6-11$ years have at least 1 h per day of moderate to PA (Troiano et al. 2008).

\section{Parents as Role Models}

Previous research has shown an association betwen parental modeling of F\&V intake and their child's F\&V intake. For example, research has demonstrated in a sample of middleclass non-Hispanic white 5-year-old females that higher kvels of reported F\&V intake in their mothers was associated with higher levels of girls' F\&V intake (Fisher et al. 2002). Veroecken et al. (2010) focused on non-Hispanic white families and found a positive association between children and parents F\&V intake; however, weight was not examined.

Similar to the effect of parent modeling of F\&V intake, parent modeling of PA (i.e., engaging in more PA) has been shown to be positively associated with children's PA levels. For example, in a sample of middle-class non-Hispanic white 4-7-year-old children, those with physically active mothers were two times as likely to be active compared to children of inactive mothers (Moore et al. 1991). Furthermore, research has demonstrated that middle-class 5-year-old non-Hispanic white girls living with parents who reported low PA kevels and high-caloric dietary intake had significantly higher BMI and skinfold thickness than girls living with parents with high PA levels and lower-caloric dietary intake (Davison and B irch 2002).

A few studies have shown Hispanic youth engage in less PA overall, are sedentary when their parents are sedentary, and receive less parental support to be active (Ruiz et al. 2011; Hoefer et al. 2001). Despite the documented relation between parent and child PA, relatively few studies have included children and families from low-income, ethnic minority backgrounds, and none examined the combination of parental BMI, PA, and F\&V intake as a single index of healthy role model status.

\section{Purpose of Study}

Given the association between healthy lifestyle habits (i.e., healthy eating and PA) and lifelong wellbeing (Matheson et al. 2012), the purpose of this study was to address significant gaps in the pediatric obesity literature by examining the relationship between child and parent BMI, F\&V consumption, and PA kevels in a sample of families primarily from minority and low-income backgrounds. We hypothesized that the majority of children and their parents would not meet recommended guidelines. We also predicted that parents who were "healthy role models" would be more likely to have children who ate more F\&V, had greater levels of 
PA, and had lower BMI Z-scores compared to parents who were kess healthy role models.

\section{Methods}

\section{Procedures}

Participants were recruited from two elementary schools as part of a larger school-based intervention study to prevent obesity in which students at one school received an active intervention. The current study combines baseline data from all participants at both schools. Following institutional review board approwal, letters introducing the study were distributed to all parents of children in Kindergarten and lst grade classrooms ( $N=$ approximately 600 ). Forms indicating that parents were interested in the study were returned by 234 parents. A research associate then contacted interested families to schedule a study visit. One parent and one child from each family were consented during the study visit $(N=86)$. The schools were located in predominately low-income ( $56 \%$ on free/reduced lunch) neighborhoods in a southeastern metropolitan city. A majority ( $98 \%$ ) of parents identified themselves and their child as being from an ethnic minority background ( see Table 1).
The study sample $(N=86)$ was representative of the community and school population in terms of income and ethnic minority background. Since this was a pilot study and feasibility study, our aim was not to recruit a very large sample of children at the two schools.

\section{Measures}

\section{Child and Parent Anthropometrics}

Parent and child height and weight were measured by calibrated stadiometer (Seca 214; Seca North America East, Hanover, MD) and portable digital scale (Tanita Model BC551; Tanita Corp of America, Arlington Heights, IL) in triplicate by trained research staff and then used the mean height and weight to calcualte BMI (weight in $\mathrm{kg} / \mathrm{height}$ in meters squared) for both parents and children; child BMI scores were transformed into $\mathrm{z}$-scores based on national norms (Kuczmarski 2000).

\section{Child and Parent Dietary Intake}

Assessment of parent and child dietary intake was obtained by a 24-h dietary recall which has been shown to be a valid measure of dietary intake (Block 1982; Johnson et al. 1996). Research associates trained by a nutritionist administered

\begin{tabular}{|c|c|c|}
\hline & Parent (\%) $N=86$ & Child $(\%) N=86$ \\
\hline \multicolumn{3}{|l|}{ Racdethnicity } \\
\hline Hispanic Whit & 80.2 & 80.2 \\
\hline Hispanic Caribbean B lack & 11.6 & 9.3 \\
\hline American Indian/A laskan Native & 2.3 & 3.5 \\
\hline Non-Hispanic Whit & 2.3 & 2.3 \\
\hline Caribbean Black & 2.3 & 2.3 \\
\hline Asian & 1.2 & 1.2 \\
\hline A frican American & - & 1.2 \\
\hline \multicolumn{3}{|l|}{ Paxnt country of birth } \\
\hline Honduras & 23 & - \\
\hline Cuba & 21 & - \\
\hline Nicaragua & 20 & - \\
\hline Other & 36 & - \\
\hline Sea (female) & 86 & 59.3 \\
\hline Children with free or roduced lunch & - & 56 \\
\hline Child gradk (Kindergarten) & - & 38.4 \\
\hline \multirow[t]{2}{*}{ Parental education (completed high school or less) } & 61.4 & \\
\hline & Mean (SD) & Mean (SD) \\
\hline$A_{\mathrm{p}} \mathrm{e}$ (years) & $35.40(6.72)$ & $6.71(56)$ \\
\hline Total family inovene & $\$ 30,414.84(\$ 25,654.56)$ & - \\
\hline
\end{tabular}

Only a subset of parents reporbed total family income $(N=71)$, child race $(N=77)$, and parent race $(N=74)$ 
two 24-h dietary recalls to the parent and child, respectively. Parents were asked to recall and describe foods and drinks consumed at each meal during the previous day including portion sizes. Pictures of portion sizes were prowided to aid in estimation. Children also completed 24-h dietary intake recalls for intake ower the previous day with the help of their parent who confirmed accuracy of their child's report or provided information about the child's intake if the child could not recall (Block 1982). In the case that the child's report was discrepant with the parent's report, the parent's report was used. Consistent with previous research (Mink et al. 2010), a research associate entered the collected meal information for the 24-h period into Nutritionist Pro-V (Axxya Systems 2006), a nutrition analysis software. Child and parent F\&V intake (servings per day) was used as a key measure of dietary behavior given the USDHHS and USDA daily serving recommendations (MoGuire 2011) at the time this data was collected.

\section{Child and Parent PA}

Child PA was assessed via accelerometetry. Each child wore a uniaxial accelerometer (Lifecorder, Suzuken Co. Ltd, Japan) on their waist belt for 7 days. Participants were instructed to wear the accelerometer device from the time of awakening until just before bedtime, and to remove the device while bathing or swimming. The device provided activity data in $4 \mathrm{~s}$ epochs over 2-min periods as levels of intensity. Intensity levels range from zero to nine with zero being no activity. The intensity of a 2-min period is measured as the most frequent intensity recorded during the 30 four-second epochs in that $2 \mathrm{~min}$. Accelerometry data was analyzed to exclude non-active/sloep time and mild levels of exertion, thereby including only moderate to vigorous PA. To increase the validity of PA data, it is recommended that days with maximum hours of wear time be included (Migueles et al. 2017). Non-wear/sleep time is defined as 40 consecutive minutes of zero activity recording. Donaldson et al. (2016) showed that 4 valid days of measurement are comparable to 1 woek. Therefore, the 4 best days (i.e., days with the most data recorded) of the 7 days worn were used in the analyses.

Parent PA kevels were assessed via the modifiable activity questionnaire, which assesses previous 12-month PA during leisure and work and has been shown to be reliable and valid (Kriska et al. 1990; Pereira et al. 1997). Participants were asked to provide information on the number of months, times per week, and duration in a day that they participated in a list of common activities and any other activities that may not have been listed. Total time participating in the activity and time spent participating in moderate to vigorous PA was calculated.

\section{Data Analysis Plan}

All analyses were conducted using SPSS 22. Descriptive analyses were conducted for child zBMI, parent BMI, child and parent F\&V intake (servings per day), child daily minutes of moderate to vigorous $\mathrm{PA}$, and parent weekly minutes of moderate to vigorous PA. A healthy parental role model index score was calculated by the sum of the three dichotomous $(0=\mathrm{No}, 1=$ Yes $)$ health status indicators: (1) healthy BMI; (2) recommended servings of F\&V per day; and (3) recornmended minutes of moderate to vigorous PA. Parents were classified as "unhealthy" role models (score of 0), "limited healthy" role models (score of 1), "good healthy" role models (score of 2), or "excellent healthy" role models (score of 3). Regression analyses between the parental role model index and child zBMI scores, F\&V intake, and PA, respectively, were examined. Odds ratios examined the relationships between each health status indicator for both parent and child.

\section{Results}

\section{Preliminary Analyses}

Nine families had missing data on at least one variable. According to Little's MCAR test, data were missing completely at random $\left(\chi^{2}=31.75, p>05\right)$. Outlier analyses were conducted and no outliers were found. No significant associations between outcome variables and demographic variables were found and therefore no covariates were included in the analy ses.

\section{Parental Role Modeling and Child Health Outcomes}

A majority of parents ( $54 \%$ ) were classified as unhealthy role models and did not meet the recommendations for BMI, F\&V or PA; 30\% of parents were classified as limited healthy role models; $16 \%$ of parents were classified as good healthy role models; and none of the parents in the sample were classified as excellent healthy role models (see Table 2).

Descriptives for individual parent and child health status indicators are included in Table 2. Most parents and children did not meet the guidelines for healthy weight $(87 \%$ and $43 \%$, respectively), F\&V consumption ( $89 \%$ and $91 \%$, respectively), or PA (68\% and $83 \%$, respectively). A significant association was found between the healthy parent role model index score and child-reported F\&V intake, $F(1,77)=4.96, p=.029$, indicating that parents who were healthier role models had children with higher $F \& V$ intake. No associations were found between the healthy parent role 
model index score and child zBMI $F(1,84)=.16, p=.69$, or child PA $F(1,70)=.05, p=.82$, respectively (sce Table 3 ).

Several significant associations were found between individual parent health status indicators (i.e., healthy weight, meets recommended F\&V and PA guidelines) and corresponding child health status indicators (see Table 4).

Parents who were a healthy weight were 3.7 times more likely to have a child who had a healthy weight compared to parents who did not have a healthy weight. Similarly, parents who were consurning the recommended servings of $\mathrm{F} \& \mathrm{~V}$ per day were 10 times more likely to have children who were also consurning the recommended servings of F\&V per day compared to parents who were not consurning the recommended servings of F\&V per day. However, no significant association between parents and children meeting the recommended amount of PA per day were found.

\section{Discussion}

We found most of the parents and nearly half of the children were in the overweight or obese ranges. These high rates illustrate the need for obesity interventions among young. ethnic minority children and their farmilies. Consistent with

Table 2 Descriptive analyses

\begin{tabular}{|c|c|c|}
\hline & Parent mean (SD) $N=86$ & Child mean (SD) $N=86$ \\
\hline BMI & $29.37(5.87)$ & $.94(1.11) \mathrm{z}$-socort \\
\hline Percent overweight or obese & $87 \%$ & $43 \%$ \\
\hline F\&V Intake ( $\$$ of F\&V/day) & $2.12(2.60)$ & $2.37(2.23)$ \\
\hline Percont not meeting F\&V recommendations & $89 \%$ & $91 \%$ \\
\hline Amount of moderate to vigorous activity & $18.5 .69(277.68) \mathrm{min} / \mathrm{wk}$ & $35.76(20.76) \mathrm{min} / \mathrm{d} y \mathrm{y}$ \\
\hline \multirow[t]{2}{*}{ Percent not meeting PA recommendations } & $68 \%$ & $83 \%$ \\
\hline & Parent $(\%)$ & \\
\hline Unheal thy role model (0/3) & 53.5 & \\
\hline Limikd healthy role model (1/3) & 30.2 & \\
\hline Good bealthy role model (2/3) & 163 & \\
\hline Excellent heal thy role model ( $3 / 3)$ & 0 & \\
\hline
\end{tabular}

Table 3 Associations between healthy parent role model inde: and child bealth outcomes

\begin{tabular}{|c|c|c|c|c|c|}
\hline & $\beta$ & $B(S E B)$ & $95 \% \mathrm{CI}$ & Model $\mathrm{R}^{2}$ & F test statistic \\
\hline \multicolumn{6}{|l|}{ Dietary intale } \\
\hline Child daily fruit and ve getable intake & 25 & $.08(04)$ & $009, .157$ & .06 & $4.96^{*}$ \\
\hline \multicolumn{6}{|l|}{ Anthropometrics } \\
\hline Child zBMI & -.04 & $-.03(.07)$ & $-.18, .12$ & .002 & .16 \\
\hline \multicolumn{6}{|l|}{ Physical activity } \\
\hline $\begin{array}{l}\text { Child daily minutes in moderate to } \\
\text { vigorous activity }\end{array}$ & 03 & $.001(.004)$ & $-008,01$ & .001 & .05 \\
\hline
\end{tabular}

Table 4 Associations between individual parent health status indicators and corresponding child bealth status indicators

\begin{tabular}{llll}
\hline & $N(86)$ & OR & $95 \% \mathrm{CI}$ \\
\hline $\begin{array}{l}\text { Dietary intals } \\
\text { Parent meets recommended daily fruit and vegetable intake }\end{array}$ & 9 & $10.05 *$ & $1.74,57.90$ \\
$\begin{array}{l}\text { Anthropometrics } \\
\text { Parent healthy weight }\end{array}$ & 19 & $3.70 *$ & $1.13,12.50$ \\
$\begin{array}{l}\text { Physical activity } \\
\text { Parent meets recommended daily minutes in moderate to vigor- } \\
\text { ous activity }\end{array}$ & 26 & 1.81 & $.49,6.70$ \\
\hline
\end{tabular}

-Signifes a statistically significant odds ratio at $p<.05$ 
prior work in Caucasian samples, we also found that most parents and children did not meet the F\&V and PA recommendations (Kim et al. 2014; Troiano et al. 2008; USDHHS 2010; State of the Plate 2010). Our findings replicate and extend such findings by including a young mostly Hispanic sample. Additionally, we found that child weight was not related to meeting F\&V and PA recommendations. Given the documented relationship between meeting recommended guidelines and health problems (Huang et al. 2011; Janssen and Leblane 2010), it is important to find ways to improve adherence to F\&V and PA recommendations in America's largest growing minority sample.

Parents considered healthy role models were more likely to have a child with higher F\&V intake. These results are consistent with previous research on the relation between parental and child consumption of $F \& V$ in primarily white, non-Hispanic populations (Fisher et al. 2002; Wardle et al. 2005). Moreover, parents who met the criteria for positive health status indicators (i.e., healthy weight and meeting daily F\&V recommendations) were more likely to have children who also had these respective positive health status indicators. Thus, the combination of healthy role modeling behaviors is associated with child healthy habits (i.e., incre ased child F\&V consumption) but also parents who meet criteria for individual recommendations impact their child's healthy habits in that domain. It could be the case that children who have a healthy weight are moeting the recommendations for F\&V consumption and PA. However, no significant association was found between BMI and F\&V consumption, and PA, respectively, in this sample. This highlights an important association between childhood obesity and parental role modeling and is a potential target for intervention. Given the low rates of adherence to recommendations in this sample, these findings suggest that targeting parents of young children to improve their own dietary intake and PA may be a useful strategy to help improve their children's health behaviors and BMI.

The parent healthy role model index was not significantly related to child zBMI or PA. Given the young age of the children in the current sample, parents' unhe althy behaviors may not yet be reflected in their child's weight or amount of PA. However, the parent healthy role model index was associated with child F\&V intake, which has been found to be related to child weight (Epstein et al. 2001). A longitudinal study to assess the impact of parental healthy role modeling in early childhood on later child health factors would help explore this possible relation further.

Results have important clinical implications, such as promoting increases in parent $\mathrm{F} \& \mathrm{~V}$ consumption and $\mathrm{PA}$ in interventions as a means of increasing F\&V intake in children to reduce the risk of child obesity. Other research also suggests parents serve as role models and reinforce healthy eating and PA in their children (Epstein et al. 2001; Foster et al. 2005; Wyse et al. 2011; Bere et al. 2005). Interventions that aim to improwe child health outcomes via parental factors have been shown to be effective but have not focused solely on parent F\&V intake or parent PA (Wyse et al. 2011; Bere et al. 2005). A telephone intervention used by Wyse et al. (2011) focused on parental modeling, but parent F\&V consumption was not measured. Findings from Wrotniak et al. (2004) showed that parents who lost weight had children who did better in family-based behavioral weight control programs for overweight children than parents who did not lose weight. Therefore, future research should examine in the context of a randomized controlled trial the extent to which increases in parental F\&V consumption and PA results in positive child health outcomes.

Furthermore, current obesity interventions focus on many different components (c.g., limiting fats, reducing calories, increasing PA, and limiting sedentary activity) for both parents and children that may require drastic changes to daily lifestyle. Previous research has found that when treatments are simplified, adherence is improwed (Haynes et al. 2002). Having too many goals to work on at once for both parents and children and goals that require drastic changes may be overwhelming and difficult for families to achieve (Foster et al. 2005). Given the relation between parent healthy behaviors and child F\&V consumption, an intervention for parents of young children that solely focuses on increasing parent $F \& V$ consumption and PA may be more feasible for farnilies and cost efficient.

\section{Study Strengths and Limitations}

Strengths of the study include the focus on young ethnic minority children, the examination of parental and child BMI and health behaviors, the use of validated self-report procedures for assessment of dietary intake and PA, and the use of accelerometry for objective assessment of PA in the children. However, several limitations should be considered when interpreting the findings. First, this study used a cross-sectional design and therefore causal inferenoes cannot be made. Second, the parental dietary and PA data were self-report measures and are subject to rater bias. While these methods have boen previously validated, inclusion of more objective measures (e.g., accelerometery) would help corroborate self-report data. Third, although the healthy parental role model index used in the analysis has clear face validity, more data is needed to confirm the criterionrelated validity of the index. Additionally, future research that aims to focus on nutrition in particular, would benefit from including a more thorough indicator of nutrition, such as the Healthy Eating Index (Guenther et al. 2014). Fourth, the sample was $90 \%$ Hispanic and therefore the findings may only generalize to this subgroup of minorities. 
However, Hispanics are America's largest growing minority sample. Lastly, although interest forms were sent home to 600 families, and 234 of these families expressed interest, only 86 farnilies were consented and participated in the study. Although, these 86 families were representative of the school and community demographics. Additionally, given that this was part of a pilot study, the sample size was relatively small, and some findings may not have been significant due to limited power. Furthermore, this small sample size may have led to overestimated OR's. The literature would benefit from additional studies with a larger sample of similarly high-risk farnilies.

\section{Conclusions}

Despite these limitations, this study illustrates the association of parent and child BMI and F\&V intake, indicating the potential effect of parental modeling on their young children's weight and F\&V intake. Studies of family behavioral lifestyle interventions for child obesity focus on measuring children's weight outcomes and places less emphasis on parental health and lifestyle behaviors. Thus, interventions for pediatric obesity may benefit by targeting parental weight, diet, and PA in future randomized controlled trials.

\section{Implications for Research and Practice}

Future research should examine in the context of a randomized controlled trial the extent to which increases in parental F\&V consumption and improved BMI results in positive child health outcomes. Clinically, interventions should focus on promoting increases in parent F\&V consumption and PA as a means of increasing F\&V intake in children to reduce the risk of child obesity. Focusing on parents may be more practical for farnilies to implement and cost efficient.

Acknowledgements This research was supported by grants from the National Institutes of Health (Grant Nos. 1R34 DKOF 4552 and T32 HD07510). Contribution of JM in the preparation of this manuscrip was supported by a grant (no. 21-6VHEC/R\&DVPFCR/2017) from the Higher Education Commission of Pakistan.

Author Contributions AD, JC, \& EP, conceived and carried out the study and analyzed data. MV assisted with study procedures. JM, PC, \&DB analyzed data. All authors were involved in writing the paper and had final approval of the submitted and published versions.

\section{References}

Barlow, S. E., \& Dietz, W. H. (1998). Obesity evaluation and troatment Expert committee recommendations. Pediatrics, $102(3)$, e22-e29
Bere, E., Veierst, M. B _ \& Klepp, K. I. (2005). The Norwegian school fruit programme: Evaluating paid vs. no-cost subscriptions. Preventive Medicine, 4I(2), 463-470.

Block, G. (1982). A review of validations of dietary assessment methods. American Journal of Epidemiology, 11S(4), 492-505.

Davison, K. K.. \& Birch, L. L. (2002). Obesigenic families: Parents' physical activity and dietary intake patterns predict girls' risik of overweight. Intermational Journal of Oberity, 26(9), 1186.

Delva, J., O'Malley, P. M. \& Johnston, L. D. (2006). Racial/ethnie and socioeconomic status differences in overweight and healthrelated behaviors among A merican students: National trends 1986-2003. Jowrnal of Adolescent Health, 39(4), 536-545.

Donaldson, S. C. Montoye, A. Tuttle, M. S., \& Kaminsky, L. A. (2016). Variability of objectively me asured seckntary behavior. Medicine and Science in Sports and Exercise, 48(4), 755-761

Epstein, L. H., Gordy, C. C, Raynor, H. A., Beddome, M., Kilanowski, C. K., \& Paluch, R. (2001). Increasing fruit and veretable intake and decreasing fat and sugar intale in families at risk for childhood obesity. Obesity, 9(3), 171-178.

Fisber, J. O., Mitchell, D. C, Smiciklas-Wright, H., \& Birch, L. L. (2002). Parental influences on young girls' fruit and ve getable, micronutrient, and fat intakss. Journal of the Academy of Nutri. tion and Dietetics, 102(1), 58-64.

Fuster, G. D., Makris, A.P , \& Bailer, B. A. (2005). Behavioral treat. ment of obesity-. The A merican Journal of Clinical Nutrì ion, $82(1), 230 \mathrm{~S}-235 \mathrm{~S}$.

Guenther, P. M., Kirkpatrick, S. I., Reedy, J., Krebs-Smith, S. M. Buckman, D. W., Dodd, K. W., Casavale, K. O., \& Carroll, R. J. (2014). The beal thy eating index-2010 is a valid and reliable measure of diet quality according to the 2010 dictary guidelines for Americans. The Journal of Nutrition, 144(3), 399-407.

Haynes, R. B., McDonald, H. P., \& Gary, A. X. (2002). Helping patients follow prescribed treatment: Clinical applications. Journal of the American Medical Association, 288(22). 2880-2883.

Hoefer, W. R., MeKenzie, T. L., Sallis, J. F., Marshall, S. J., \& Conway, T. L. (2001). Parental provision of transportation for adolesoent physical activity. American Journal of Preventive Medicine, 21 (1), $48-51$.

Huang, J. S., Gottschalk, M., Norman, G. J., Calfus, K. J., Sallis, J. F. \& Petrick, K. (2011). Complianoe with behavioral guidelines for diet, physical activity and sedentary behwiors is re lated to insulin resistance among overweight and obese youth. BMC Research Notes, 4(1), 29 .

Janssen, L, \& LeBlanc, A. G. (2010), Systematic neview of the bealth benefits of physical activity and fitness in school-aged children and youth. International Jowrnal of Behaviaral Nutrition and PhysicalActivity, 7(1), 40 .

Johnson, R. K., Driscoll, P., \& Goran, M. I. (1996). Comparison of multiple-pass 24-hour recall estimates of energy intake with total enerzy expenditure determined by the doubly labeled water method in young children. Jowrnal of the American Dietetic Asso. ciation, 96, 1140-1144.

Kim, S. A., Moore, L. V., Galuska, D., Wright, A. P., Harrik, D., Grummer-Strawn, L. M. et al. (2014). Vital signs: Fruit and vegetable intake among children. Uniked States, 2003-2010. MMWR. Mar. bidity and Mortality Weekly Repart, 63(31), 671-676.

Kriska, A. M., Knowler, W. C., LaPorte, R. E., Drash, A. L., Wing, R. R., Blair, S. N., et al. (1990). Development of quxstionnair to examine relationship of physical activity and diabets $s$ in pima Indians. Diabetes Care, 13(4), 401-411.

Kuczmarski, R. J. (2000). CDC growth charts. Hyattsville: National Center for Health Statistics

Kumanyika, S., \& Grier, S. (2006). Targeting interventions for ethnic minority and low-inoume populations. The Future of Childrem, 16, 187-207. 
Matheson, E. M., King, D. E., \& Everett, C. J. (2012). Heal thy lifestyk habits and mortality in overweight and obese individuals. The Journal of the American Bourd of Family Medicine, 25(1), 9-15.

MeGuire, S. (2011). US department of agriculture and US department of health and human services, dietary guidelines far americans, 2010. Washington, DC: US government printing office

Miqueles, J. H., Cadenas-Sanchez, C., Ekelund, U., Nystrüm, C. D., Mora-Gonzalez, J., Löf, M., et al. (2017). Acoe leromeler data collection and processing criteria to assess physical activity and other cuteomes: A systematie review and pnactical considerations. Sports Medicine, 47(9), 1821-1845.

Mink, M., Evans, A., Moore, C. G., Calderon, K. S., \& Deger, S. (2010). Nutritional imbalanoe endonsed by televised food advertisements. Journal of the American DieteficA ssociation, 110(6), 904-910.

Moort, L. L., Lombardi, D. A., White, M. J., Campbell, J. L., Oliveria, S. A., \& Ellison, R. C. (1991). Influxnce of parents' physical activity levels on activity lovels of young children. The Jotonal of Pediatrics, 118(2), 215-219.

Morland, K., Roux, A. V. D., \& Wing, S. (2006). Supermarkets, other food stores, and obesity: The atherowele rosis risk in communities study. Amer ican Jowmal of Preventive Medicine, 30(4), 333-339.

National Heart, Lung, Blood Institux, National Institute of Diabetes, Digestive, \& Kidney Diseases (US). (1998). Clinical guidelines on the identification, evaluation, and treatment of overweight and obesity in adults: the evidenoe report (No. 98). National Heart. Lung, and B lood Instituk.

Ogden, C. L., Carroll, M. D., Kit, B. K., \& Flegal, K. M. (2014). Provalenoe of childhood and adult obesity in the United States. 2011-2012. The Joumal of the A merican Medical Assoicat ion, $311(8), 806-814$.

Ptreira, M. A., FitzerClerald, S. J., Gregg, E. W, Joswiak, M. L., Ryan, W. J., Suminski, R. R , et al. (1997). A collection of physical activity questionnaires for bealth-related research. Medicine and Science in Sports and Exercise, 29(6 Suppl), S1-205.

Powell, L. M., Auld, M. C., Chaloupka, F. J., O'Malley, P. M., \& Johnston, L. D. (2007). Associations between access to frod stores and adolesor nt body mass index. A merican Joumal of Preventive Medicine, 33(4), S301-S307.

Ruiz, R., Gesell, S. B., Buchowski, M. S., Lambert, W. \& Barkin, S. L. (2011). The relationship between Hispanic parents and their preschool-aged children's physical activity. Pediatrics, $127(5)$, 888-895.
State of the Plate: 2010 Study un America's Consumption of Fruits and Vegetables, 2010. Produce for Better Health Foundation. Web. http//www. pbhfisundation.sorg.

Troiano, R. P., Berrigan, D., Dodd, K. W., Masse, L. C., Tilert, T., \& MeDowell, M. (2008). Physical activity in the United States measured by acoekrometer. Medicine and Science in Sports and Exencise, 4O(1), 181.

USDepartment of Health and Human Servioes. (2008). 2008 physical activty guidelines for Americans: Be artive, healthy, and happy! Washington, DC: US Department of Health and Human Servias. http//www.health.gow/paguidelines.

US Department of Health and Hurnan Services. (2010). Heath hy pecople 2020. Washington, DC: US Department of Health and Human Services. http: Ifwww.edc.gov/nchs/heulthy_people.

Vereecken, C., Revner, A, \& Maes, L. (2010). Associations of parenting styles, parental feeding practices and child characteristics with young children's fruit and ve getable consumption. Apped t̀e, 55(3), 589-596.

Wardle, J. Carnell, S., \& Cooke, L. (2005). Parental control over Eeding and children's fruit and vegetable intaks: How are they related? Journal of the Academy of Nutrition and Diefetics. $105(2), 227-232$.

Whitaker, R., Wright, J., Pepe, M., Seidk1, K., \& Diets, W. (1997).Predicting obesity in young adulthood from childhood and parental obesity. New England Journal of Medicine, 337, 869-873. htips //doi.cory/10.1056/NEJM199709253371301.

Wrotniak, B. H., Epstein, L. H., Paluch, R. A. \& Roemmich, J. N. (2004). Parent weight change as a predictor of child weight change in family-based behavioral obesity troatment. Archives of Pediat. rics \& Adolescent Medicine, 158(4), 342-347.

Wyse, R., Wolfenden, L., Campbell, E., Campbell, K., Brennan, L. Fletcher, A, et al. (2011). A pilot study of a telephone-based parental intervention to increase fruit and vegetable consumption in 3-5-year-old children. Public Heat̀ h Nutrition, 14(12), $2245-2253$.

Publisher's Note Springer Natuse remains neutral with og gand to jurisdictional claims in published maps and institutional affiliations. 
Associations Between Disruptive Behavior Problems, Parenting Factors and Sleep Problems Among Young Children

This manuscript has been published in The Journal of Developmental and Behavioral Pediatrics

Coto, J., Garcia, A., Hart, K., \& Graziano, P. (2018). Associations Between Disruptive Behavior Problems, Parenting Factors and Sleep Problems Among Young Children. Journal of Developmental and Behavioral Pediatrics, 39(8), 610-620. 


\title{
Associations Between Disruptive Behavior Problems, Parenting Factors, and Sleep Problems Among Young Children
}

\author{
Jennifer Coto, MS, Alexis Garcia, MS, Katie C. Hart, PhD, Paulo A. Graziano, PhD
}

\begin{abstract}
Objective: To examine within an at-risk/clinical sample of preschool-aged children with externalizing problems: (1) which disruptive behavior and attention disorder symptoms (i.e., inattention, hyperactivity/impulsivity, and oppositionality/aggression) and (2) what aspects of parenting (e.g. discipline practices or stress) are related to children's sleep problems (e.g., sleep habit and night waking problems). Method: The sample consisted of 148 children (mean ${ }_{\text {age }}=\mathbf{5 . 0 6}$ years, $82 \%$ male) with at-risk/clinically elevated levels of externalizing behavior problems and their primary caregiver. As part of a larger study, parents reported on their stress and parenting practices and their children's behavioral and sleep functioning. Positive and negative parenting behaviors "'do" and "don't" skills, respectively) were also observed during a 15-minute parent-child interaction during play. Results: Oppositionality/aggression was the only disruptive behavior and attention disorder symptom associated with more sleep habit problems. Higher levels of inconsistent discipline and "don't" skills were also associated with more sleep habit problems. Within a combined model, an interaction emerged such that the association between "don' $t$ " skills and elevated sleep habit problems was only evident at low levels of inconsistent discipline. In terms of night waking problems, there was only an association with parenting stress, whereas the other parenting factors and disruptive behavior and attention disorder symptoms were unrelated. Conclusion: Although the directionality of our associations cannot be ascertained because of the cross-sectional nature of our study, these findings, nevertheless, highlight the importance of parenting factors (e.g. inconsistent discipline and parenting stress) when considering sleep difficulties in young children with disruptive behavior and attention disorders.
\end{abstract}

U Dev Behav Pediatr 39:610-620, 2018) Index terms: disruptive behavior disorders, atterfion-deficit hypenctivity disorder, appostional defiant disarder, sleep, parenting.

D isnuptive behavior and attention disorders are com mon among young children, with prevalence rates ranging from $1 \%$ to $16 \%$ for oppositional defiant disorder (ODD), $1 \%$ to $9 \%$ for conduct disorder, and $6.8 \%$ to $10.2 \%$ for attention-deficit hyperactivity disorder (ADHD). ADHD and ODD, in particular, tend to co-occur, with comorbidity rates ranging from $25 \%$ to $50 \%$. ${ }^{1}$ Symptom of disnuptive behavior and attention disorders include aggression, defiance of authority, attention problems, impulsivity, and antisocial behavions, all of which can have a negative impact on young chikdren's functioning. For example, preschoolaged children diagnosed with disnuptive behavior and attention disorders have significantly greater levels of social dysfunction compared with typically developing children. ${ }^{2}$ Similarly, preschool children with disnuptive behavior and attention disorders are more likely to have academic difficulties and perform

From the Department of Prychology and Center for Gildren and Familiex, Flonida Intern rional Universiny Mtami, F-

Recelved November 2017; accepted April 2018

Disclosure: The authors declure no conflict of interest.

Address far reprints: Jennifer Coto, MS, Department of Aychology and Center for Chaldren and Fandlies, 11200 SW 8th St, AHC1 123, Miami, FL, 33199; email: hernajen ithu edu.

Copyaght 92018 wolters Kluwer Hed th, Inc. All rights reserved.

610 | www.jdbp.org poorly in neurocognitive tasks. ${ }^{1}$ Although the psychoso cial and neurocognitive impairments found among children with disruptive behavior and attention disorders are well estabished, less attention has been paid to comorbid health problems affecting young chikdren with disnuptive behavior and attention disorders. This study focuses on young children with or at risk for disruptive behavior and attention disorders with a particular focus on the link between parenting factors (i.e., parental stress and dis cipline strategies) and sleep functioning.

Sleep is a restorative period that is necessary for healthy development and optimal daytime functioning. ${ }^{3}$ During the preschool period, children spend approximately half of their time sleeping. ${ }^{3}$ Sleep disturbances in children are common, with $20 \%$ to $25 \%$ of children experiencing some type of sleep disturbance, including disordered breathing, insomnia, bedtime resistance, daytime sleepiness, and sleep terrors. ${ }^{4}$ Young children with disnupted sleep have poorer behavioral adjustment in preschool and worse cognitive functioning. ${ }^{5}$ Neurocognitive deficits are also implicated in the development of children's disruptive behavior and attention disorders. In fact, emerging work has suggested the important role of sleep functioning toward understanding phenotypical expression of disruptive behavior and attention disorder symptoms. ${ }^{6}$

Journal of Developmental \& Behavioral Pediatrics 


\section{DISRUPTIVE BEHAVIOR DISORDES AND SLEEP PROBLEMS}

Epidemiological studies have shown that general levels of extemalizing behavior problems are associated with poorer sleep. ${ }^{7}$ Children with disruptive behavior and attention disorders are also more susceptible than children without disruptive behavior and attention disorders to skep-related impairments, including sleepdisordered breathing. ${ }^{8,9}$ Sleep problems are especially concerning among children with attention-deficit hyperactivity disorder (ADHD), and it is estimated that up to $50 \%$ of children with ADHD have sleep difficulties. ${ }^{10}$ Specifically, children with ADHD have shorter sleep duration, more disturbed sleep, more bedtime struggles, and more night wakings compared with typically developing children. ${ }^{11,12}$ Additionally, previous research has found a bidirectional association between oppositional defiant disorder (ODD) and sleep problems. ${ }^{13}$

Comorbidity further elevates the risk for sleep problems, and previous studies have documented that children with both ODD/conduct disorder (CD) and ADHD sleep significantly less than typically developing children and children with $\mathrm{ODD} / \mathrm{CD}$ abne. ${ }^{8}$ Additionally, Corkum et al. ${ }^{14}$ found higher resistance to waking up in the morning and going to bed at night in children with comorbid ADHD and ODD compared with children with ADHD alone. Thus, although it is clear that children with comorbid disruptive behavior and attention disorders experience significantly greater kevels of skep problems, limited research has focused on comparing the specific symptoms of disruptive behavior and attention disorders (e.g, oppositionality/aggression vs hyperactivity) that may be more closely linked to sleep problems.

Research suggests that conduct problems are associated with bedtime resistance, whereas hyperactivity is associated with tossing, turning during sleep, and sleepwalking. ${ }^{15}$ Additionally, within an elementaryaged sample, insomnia symptoms and lower sleep duration were associated with inattention, clinically elevated externalizing problems, limit-setting, and rule-breaking behaviors. ${ }^{16}$ In contrast, Mayes et al. ${ }^{6}$ found that children with ADHDinattentive subtype did not differ from typically developing children in terms of nighttime sleep problems, although these children slept more and had higher daytime sleepiness. Children with ADHD-combined type had more nighttime skeep problems than typically developing children. ${ }^{6}$ Taken together, it seems that the hyperactivity dimension is more dosely tied to sleep problems compared with the inattention dimension. However, the only study ${ }^{6}$ that compared inattention to hyperactivity was with older children and faiked to include ODD symptoms. Moreover, the skep literature in children with ODD specifically is limited. Examining which symptoms of disruptive behavior and attention disorders relate to sleep problems among preschool-aged children is particularly important given the stability of both sleep ${ }^{17}$ and behavioral problems upon school entry. ${ }^{18}$

\section{PARENTING AND SLEEP PROBLEMS}

Examining the role of parenting as it relates to young children with disruptive behavior and attention disorders' sleep functioning is also important given the role of parenting in the maintenance and treatment of disruptive behavior and attention disorders. ${ }^{19}$ Parenting is a multifaceted construct, with the current study focusing on parental involvement and both positive and negative discipline strategies. From a theoretical perspective, parents' ability to implement positive discipline strategies (e.g., praise and reward) and limit negative ones (e.g., inconsistent discipline and corporal punishment) is central toward promoting positive parent-child interactions. Extending this theoretical framework to the sleep domain, parenting strategies likely also play a vital role in promoting healthy sleep habits. For example, good sleep hygiene is evidenced by a consistent bedtime and routine as well as skeping independently. ${ }^{20}$ Furthermore, Bell and Belsky ${ }^{19}$ found that children's sleep worsens over time when their mothers engage in less sensitive parenting and have more conflict in the parentchild relationship. Thus, despite the extensive literature on parenting strategies as it relates to parent-child interactions and behavior problems, positive and negative parenting strategies have not been examined independently in their associations with children's sleep problems.

Another parental factor that plays a role in parents' ability to promote their children's sleep is parenting stress. Parenting stress is the negative reaction to the demands of the role of parenting. Higher levels of parenting stress are associated with greater sleep problems among children. ${ }^{21}$ For example, in a study examining sleep problems in children aged 3 to 14 years, Meltzer and Mindell ${ }^{22}$ found that mothers of children with sleep disruptions reported higher parenting stress. Similarly, in a longitudinal sample of toddlers, shorter child sleep consolidation was associated with higher parenting stress. ${ }^{23}$ Sadeh et al. ${ }^{24}$ obtained similar findings in parents of children aged 7 to 11 years, in which increased familial stress was associated with poorer sleep quality. In terms of potential mechanisms linking parenting stress and children's sleep problems, neurobiological work has highlighted how stress activates the hypothalamic-pituitary-adrenal (HPA) axis and the secretion of glucocorticoids (e.g., cortisol), which then causes sleep disruptions and vice versa. ${ }^{25}$ Given the high heritability of children's HPA axis, ${ }^{26}$ such a link between stress and children's sleep problems could be due to this shared vulnerability.

Although parenting discipline strategies and stress have been linked to both disruptive behavior and attention disorders and sleep problems, ${ }^{19,22,23}$ to our knowledge, no study to date has examined the extent to which such parenting factors and disruptive behavior and attention disorder symptoms are uniquely related to sleep problems. Moreover, it may be especially valuable to 
elucidate which dimensions of parenting (e.g., stress or strategies) are related to children's sleep problems, because it may inform intervention targets. Finally, an interaction among parenting factors and disruptive behavior and attention disorders may better explain the associations with children's sleep problems. For example, a positive parent-child interaction style may buffer some of the negative effects of either stress or negative discipline strategies on sleep problems. Additionally, children with higher symptoms of oppositionality/ag gression may be more sensitive to negative discipline strategies and consequently experience more sleep difficulties. Finally, higher levels of stress could negatively impact a parent's ability to implement a daily sleep routine with their children, especially among children who may be more difficult to manage such as those with higher levels of hyperactivity or oppositionality/aggression.

\section{CURRENT STUDY}

Given the aforementioned gaps in the literature, the purpose of this study was to examine within a sample of preschoolaged children with or at risk for disnuptive behavior and attention disorders: (1) which disruptive behavior and attention disorder symptoms (i.e., inattention, hyperactivity/impukivity, and oppositionality/ aggression) and (2) what aspects of parenting (e.g., discipline practices or stress) are related to children's sleep problems (e.g, sleep habit and night waking problems). A unique aspect of this study is the use of a large Hispanic/latino sample, which has historically been unexamined in terms of the link between disnuptive behavior and attention disorders, parenting, and sleep functioning. It is particularly important to examine Hispanic/Latino families given that their parenting style when having a child with disruptive behavior and attention disorder differs from that of white families. ${ }^{27}$ In accordance with previous research, ${ }^{15,22}$ we expected that oppositionality/aggression would be more strongly associated with elevated sleep problems compared with attention-deficit hyperactivity disorder symptoms. Within the parenting domain, we expected higher kvels of parenting stress and poorer discipline strategies to be associated with elevated sleep problems.

\section{METHODS}

\section{Participants and Recruitment}

Children and their primary caregivers were recruited as part of a larger study targeting school readiness, the Summer Treatment Program for Pre-Kindergarteners ${ }^{28}$ during the 2014 to 2016 summer cohorts. Recruitment was conducted at local preschools and mental health agencies in a large urban southeastern city in the United States through brochures, parent workshops, and radio and newspaper advertisements. Interested parents called the study center and spoke with study staff who described the study and scheduled them for a screening

612 Disruptive Behavior Problems, Parenting and Slep appointment to determine eligibility. Children were eligible if they (1) had an estimated IQ of 70 or higher on the Wechsler Preschool and Primary Scale of Intelligence-Fourth Edition; (2) had at-risk or clinically elevated levels of externalizing behavior problems (t-score above 60) according to the Behavior Assessment System for Children, Second Edition, Parent or Teacher Report; (3) were previously enrolled in preschool; (4) had no parent-reported history of autism or psychotic disorder; and (5) were able to participate in an 8-week summer camp.

The final sample consisted of 148 preschool-aged children $\left(\operatorname{mean}_{\text {age }}=5.06\right.$ years, $82 \%$ male, $84.9 \%$ Hispanic/Latino) and their primary caregiver $\left(\operatorname{mean}_{\mathrm{age}}=\right.$ 35.94 years, $80.7 \%$ female, $85.5 \% \mathrm{Hispanic/Latino)} \mathrm{who}$ provided informed consent to participate in this study. The average Hollingshead SES score was in the low- to middle-class range (mean $=44.25, \mathrm{SD}=12.25$ ). During the pretreatment assessment, a diagnostic evaluation was conducted with all children through the administration of the disruptive disorders module of the Diagnostic Interview Schedule for Children, computerized version IV (C-DISC-IV) ${ }^{29}$ or from the KiddieDisruptive Behavior Disorder Schedule (K-DBDS). ${ }^{30}$ Of note, $87 \%$ of our sample met diagnostic criteria for attention-deficit hyperactivity disorder (ADHD), oppositional defiant disorder (ODD), or a combination. See Table 1 for detailed rates of diagnoses and sample demographics.

Table 1. Participart Demographic Variables

\begin{tabular}{|c|c|}
\hline & $\begin{array}{c}\text { Total Sample } \\
(\mathrm{n}=148)\end{array}$ \\
\hline \multicolumn{2}{|l|}{ Demographic variables } \\
\hline Child's sex (\% male) & 82 \\
\hline Child's age, years, mean (range) & $5.06(3.78-6.05)$ \\
\hline Mean Hollingshead SES (SD) & $44.39(12.06)$ \\
\hline \multicolumn{2}{|l|}{ Child's race (\%) } \\
\hline Hispanic/Latino & 84.9 \\
\hline Non-Hispanic/Latino white & 15.1 \\
\hline African-American & 7.5 \\
\hline Mean caregiver age (range) & $35.94(23-52)$ \\
\hline Medication status ( $\%$ on medication) & 6.8 \\
\hline \multicolumn{2}{|l|}{ Screening measures } \\
\hline $\begin{array}{l}\text { Externalizing } t \text {-score- } \\
\text { parent-BASC-2 (SD) }\end{array}$ & $64.25(11.06)$ \\
\hline $\begin{array}{l}\text { \% ADHD-only diagnosis- } \\
\text { C-DISC or K-DBDS }\end{array}$ & 22.3 \\
\hline $\begin{array}{l}\text { \% ODD-only diagnosis- } \\
\text { C-DISC or K-DBDS }\end{array}$ & 18.2 \\
\hline $\begin{array}{l}\text { \% ADHD + ODD diagnosis- } \\
\text { C-DISC or K-DBDS }\end{array}$ & 46.6 \\
\hline
\end{tabular}

Journal of Developmental \& Behavioral Pediatrics 


\section{Measures}

Disruptive Behavior Disorders

Assessment of children's ADHD and ODD symptoms was obtained through the Disruptive Behavior Disorders Rating Scale, Parent Version (DBRS-PV). ${ }^{31}$ The DBRS-PV is a widely used 45 -item measure that asks parents to rate Diagnostic and Statistical Manual of Mental Disorders (DSM) symptoms on a 4-point Likert scake ( $0=$ not at all to 3 = very much). Items were updated to reflect DSM-5 criteria and qualifiers. Reliability and validity are well established for the DBRS-PV with moderate to high internal consistency for the 3 factor scales of, inattention, hyperactivity/impulsivity, and oppositionality/aggression $(0.67-0.81))^{32}$ For the current study, raw symptom scores were averaged to provide a mean score for each dimension: inattention ( $\alpha=0.89$ ), hyperactivity/impulsivity ( $\alpha=0.84)$, and oppositionality/aggression $(\alpha=0.84)$.

\section{Children's Sleep Problems}

The child's sleep problems were assessed through parent report with an abbreviated version of the Children's Sleep Habits Questionnaire (CSHQ) modified for use in the National Institute of Child Health and Development-Study of Early Child Care and Youth Development. ${ }^{33}$ This measure is a reliable and clinically useful screening instrument for young children. ${ }^{3}$ The abbreviated and modified CSHQ assesses children's sleep problems through 22 items on a 5-point Likert scale (1 = never to 5 = always) and consists of a total score along with 4 subscales: sleep habit problems, night wakings, parasomnias, and daytime skepiness. This study examined only sleep habit problems $(\alpha=0.73)$ and night wakings ( $\alpha=0.68$ ) because the other subscales had poor internal consistency $(\alpha<0.60$ ). The sleep habit problems subscale consists of 5 questions (e.g., the child falls asleep in parents' or siblings' bed and the child goes to bed at the same time at night), and the night waking subscale consists of 3 questions (e.g., the child moves to someone else's bed during the night and the child wakes up more than once during the night).

\section{Parenting Strategies}

The Alabama Parenting Questionnaire (APQ) ${ }^{34}$ meas ures 5 dimensions of parenting: involvement, positive parenting, poor monitoring/supervision, inconsistent discipline, and corporal punishment through 42 items. Items use a 5-point Likert scake (1 = never to $5=\mathrm{al}$ ways). The APQ has been found to have good internal consistency across the positive parenting ( $\alpha=0.80$ ) and involvement ( $\alpha=0.80$ ) scales and good criterion validity in differentiating clinical and nonclinical groups. ${ }^{34}$ The current study examined the inconsistent discipline subscale $(\alpha=0.74)$ and a positive parenting factor $(\alpha=$ 0.81 ) consisting of the positive parenting practices and parental involvement subscales.

\section{Observed Parenting}

The Dyadic Parent-Child Interaction Coding System (DPICS) is a reliable and valid behavional coding system for parent-child interactions. ${ }^{35}$ Because the DPICS was originally developed as part of a Parent-Child Interaction Therapy (PCrT) protocol, it classifies positive and negative parenting behaviors (which are targeted in PCIT) as "Do" and "Don't" skills, respectively. "Do" skills consist of behavior descriptions (descriptive statements that describe the child's observable behavior), reflections (a declarative phrase or statement that has the same meaning as a child's verbalization), and praises (a positive evaluation of the child's behavior, activity, or products). "Don't" skills consist of questions (verbal inquiries that have a rising inflection at the end or have the sentence structure of a question), command (an order or direction for a behavior to be performed by the child), and negative talk (verbal expression of disapproval of the child or child's attributes, activities, products, or choices). "Do" and "Don't" skills were assessed during a 15 -minute observation of child-directed play, parent-directed play, and a cleanup situation. The proportion of "Do" skills and "Don't" skills was defined by the number of skills, respectively, divided by the number of parent's vocalizations. Undergraduate students completed coding and were trained to $80 \%$ agreement with a criterion tape. Twenty percent of observations were coded a second time for reliability. Reliability for the "Do" and "Don't" skills was excellent ( $r$ 's range from 0.98 to 0.99 ).

Parenting Stress

Parents completed the Parenting Stress Index (PSI)/ Short Form ${ }^{36}$ to assess the source and degree of parenting stress. The PSI contains 36 items rated on a 6-point Likert scake ( $1=$ strongly disagree to $5=$ strongly agree $)$ and subscales assessing parental distress, stress related to parent-child interactions, stress related to the child's behavior, and a total score. This measure demonstrates good test-retest reliability (0.68-0.85), intemal consistency $(0.85-0.91)$, and concurrent validity. ${ }^{36}$ For the present study, we used the total stress raw score ( $\alpha=$ 0.92 ) as the measure of parenting stress, in which higher scores indicated increased parenting stress.

\section{Procedure}

This study was approved by the university's in stitutional review board. As part of the pretreatment as sessment, consenting caregivers completed several questionnaires and completed 1 of 2 structured diagnostic interviews (i.e., C-DISC or K-DBDS). ${ }^{20,30}$ In instances of parental bilingualism, parents were asked whether they were more comfortable reading in English or Spanish, and parents' report forms/parent interview were provided in the language of choice. There were no significant differences in any variables reported between English- and Spanish-spealing parents, nor were there any differences in the rates of diagnoses among children whose parents were interviewed with the C-DISC $(n=67)$ versus the K-DBDS $(\mathrm{n}=81)$.

\section{Data Analysis Plan}

All analyses were conducted using Statistical Package for Social Sciences, version 22 (SPSS, 2013; IBM, 
Armonk, NY). Seven families had missing data on at least 1 variable. According to Little's MCAR test, data were missing completely at random $\left(\chi^{2}=11.57 ; p>0.05\right)$. Preliminary analyses were conducted between demographic variables and all outcome variables to identify any associations. Regression analyses were conducted to examine the unique associations between disruptive behavior and attention disorder symptoms (i.e., inattention, hyperactivity/impulsivity, or oppositionality/ aggression) and parenting factors (i.e., "Do/Don't" skills, inconsistent discipline, parenting stress, and a positive parenting factor [consisting of positive parenting and involvement subscales]) on children's sleep problems (sleep habit and night waking problems). All predictors were mean centered, and significant interactions were probed accordingly.

\section{RESULTS}

\section{Preliminary Analyses: Demographic Variables}

Preliminary analyses between demographic variables and study outcome variables revealed an association between children's age and parenting stress ( $r=-0.19$; $p<0.05$ ). Specifically, parents of older children reported lower parenting stress. Therefore, all analyses controlled for the child's age. Descriptive statistics for study variables are displayed in Table 2 .

\section{Regression Analyses: Associations Between Disnuptive Behavior and Attention Disorder Symptoms, Parenting, and Sleep Habit Problems}

Model 1: Only Parenting Questionnaires

A regression analysis was conducted to examine the unique association between parenting factors (i.e., inconsistent discipline, positive parenting factor, and parenting stress) and children's sleep habit problems $\left(F(4,136)=4.56 ; p<0.01\right.$, total $\left.\mathrm{R}^{2}=0.12\right)$. Inconsistent discipline was the only parenting factor that was associated with sleep problems $(\beta=0.27 ; p<0.01)$, which indicates that parents who reported more inconsistent discipline had children who were having more sleep habit problems (Table 3 ).

Model 2: Only Parenting Observations

A similar regression analysis was conducted with observed parenting (i.e., "Do" and "Don't" skills) and sleep habit problems. Although the overall model using observation measures was not significant $(\mathrm{F}(3,110)=1.43$; $p=0.24)$, "Don't" skills was marginally significant $(\beta=$ $0.21 ; p<0.08$ ); parents who reported higher levels of "Don't" skills had children who were having more sleep habit problems (Table 3).

Model 3: Only Disruptive Behavior and Attention Disorder Symptoms

Next, a regression analysis was conducted to examine the unique associations between disnuptive behavior and attention disorder symptoms (i.e., inattention, hyperactivity/impulsivity, or oppositionatity/aggression) and children's sleep habit problems $(F(4,136)=2.47 ; p<$

614 Disruptive Behavior Problems, Parenting, and Slep
0.05 , total $\mathrm{R}^{2}=0.07$ ). As seen in Table 3, oppositionality/aggression was the only symptom of disruptive behavior and attention disorders that was significantly associated with sleep problems $(\beta=0.22 ; p<0.05)$, which suggests that children reported as being more oppositional by their parents were also having more sleep habit problems.

\section{Model 4: Combined Model}

The final regression model included all significant main effects and tested for potential interactions. As shown in Table 3, step 1 of model $4(F(4,109)=5.94$; $p<0.001$, total $\mathbf{R}^{2}=0.18$ ), the significant main effects of inconsistent discipline and "Don't" skills on sleep habit problems remained $(\beta=0.30 ; p<0.001$, and $\beta=$ $0.18 ; p<0.05$, respectively). In contrast, oppositionality/aggression no longer had a significant effect on sleep habit problems. Additionally, step 2 indicated a significant interaction between "Don't" skills and inconsistent disciptine in predicting sleep habit problems $(\beta=-0.25 ; p<0.01)$. Probing of the interaction revealed that "Don't" skills were only predictive of sleep habit problems for parents with low levels of inconsistent discipline $(t=2.78 ; b=14.48 ; p=0.01$; Fig. 1). Conversely, "Don't" skills had no significant effect on sleep habit problems for parents with high levels of inconsistent discipline $(t=-0.72 ; b=-4.08 ; p=0.47$ ).

\section{Regression Analyses: Associations Between Disruptive Behavior and Attention Disorder Symptoms, Parenting and Night Waking Problems}

Model 1: Only Parenting Questionnaires

Although the overall model using observation measures was not significant $(F(4,137)=1.54 ; p=0.20)$, regression analyses for model 1 indicated that parenting stress was the only parenting factor uniquely associated with night waking problems $(\beta=-0.22 ; p<0.05)$, and higher levels of parenting stress were associated with more night waking problems (Table 4).

Model 2: Only Parenting Observations

The overall model $(F(3,111)=1.22 ; p=0.31)$ and main effects using observation measures were not significant (Table 4).

Model 3: Only Disruptive Behavior and Attention Disorder Symptoms

The overall model $(F(4,137)=1.33 ; p=0.26)$ and main effects using disnuptive behavior and attention dis order symptoms were not significant (Table 4).

\section{DISCUSSION}

This study examined within an at-risk/clinical sample of preschoolaged children which disruptive behavior and attention disorder symptoms (i.e., inattention, hyperactivity/impulsivity, oppositionality/aggression) and what aspects of parenting (e.g., discipline practices or stress) are related to children's sleep problems (e.g., sleep habit and night waking problems). Results of our study indicated that oppositionality/aggression was the only disruptive behavior and attention disorder symptom

Journal of Developmental \& Behavioral Pediatrics 


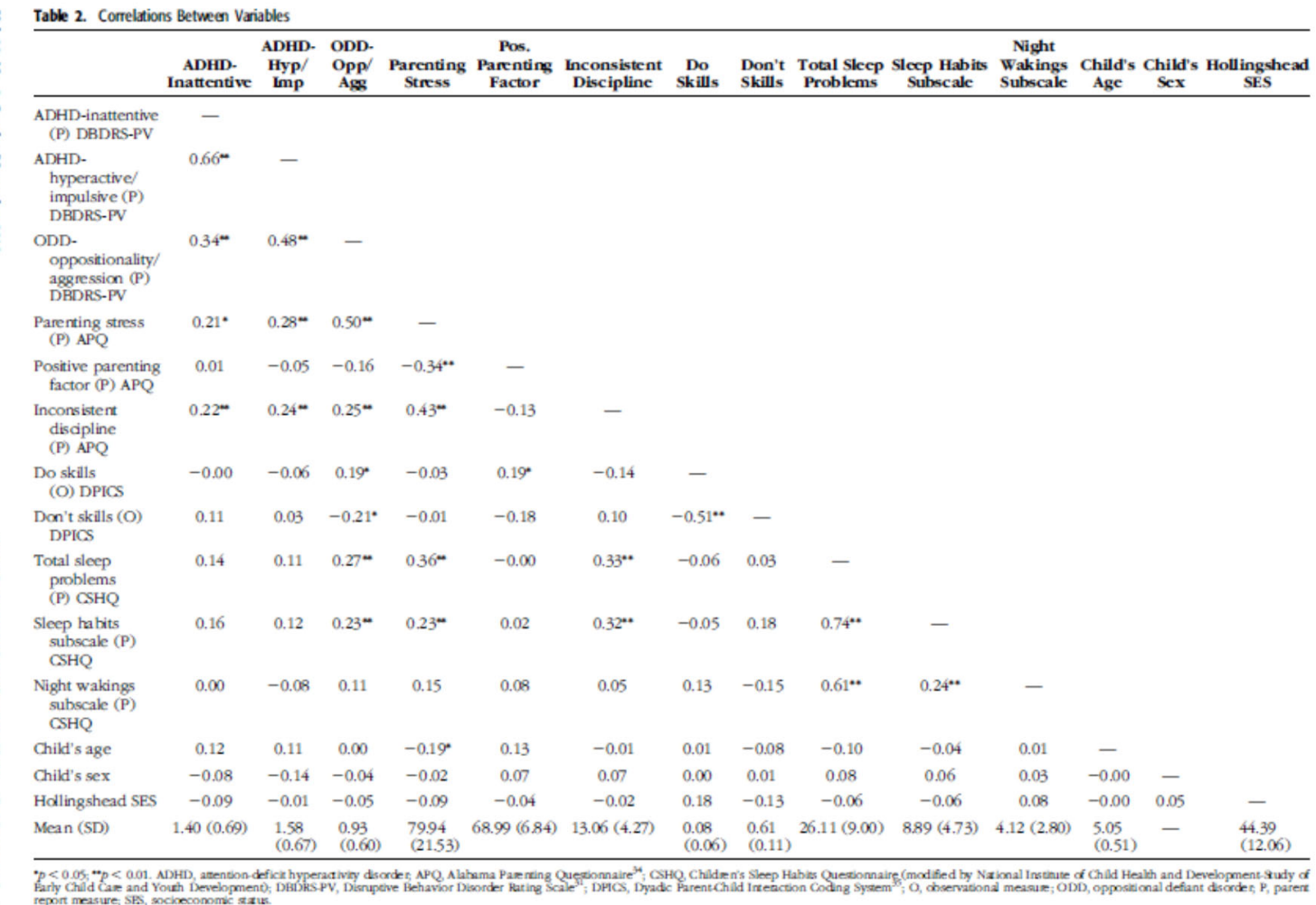


Table 3. Model for Predicting Sleep Habit Problems

\begin{tabular}{|c|c|c|c|c|c|}
\hline & $\beta$ & B (SE b) & $95 \% \alpha$ & Model $\mathbf{R}^{2}$ & F Test Statistic \\
\hline \multicolumn{6}{|l|}{ Model 1: parenting questionnaires } \\
\hline Child's age & -0.01 & $-0.11(0.77)$ & -1.64 to 1.41 & 0.12 & $4.56^{\circ}$ \\
\hline Parenting stress-PSI & 0.14 & $0.03(0.02)$ & -0.01 to 0.07 & - & - \\
\hline Inconsistent discipline-APQ & $0.27^{* *}$ & $0.30(0.10)$ & 0.10 to 0.50 & - & - \\
\hline Positive parenting factor-APQ & 0.10 & $0.07(0.06)$ & -0.05 to 0.19 & - & - \\
\hline \multicolumn{6}{|l|}{ Model 2: parenting observation } \\
\hline Child's age & -0.05 & $-0.49(0.93)$ & -2.33 to 1.34 & 0.04 & 1.43 \\
\hline Do skills-DPICS & 0.06 & $5.45(9.72)$ & -13.82 to 24.72 & - & - \\
\hline Don't skills-DPICS & $0.21 \dagger$ & $8.86(4.77)$ & -0.60 to 18.31 & - & - \\
\hline \multicolumn{6}{|l|}{ Model 3: dimensions of DBDs } \\
\hline Child's age & -0.04 & $-0.40(0.78)$ & -1.94 to 1.15 & 0.07 & $2.47^{\circ}$ \\
\hline Inattention-DBDRS-PV & 0.14 & $0.99(0.77)$ & -0.52 to 2.51 & - & - \\
\hline Hyperactivity/impulsivity—DBDRS-PV & -0.08 & $-0.53(0.83)$ & -2.17 to 1.12 & - & - \\
\hline Oppositionality/a ggression-DBDRS-PV & $0.22^{*}$ & $1.74(0.74)$ & 0.28 to 3.20 & - & - \\
\hline \multicolumn{6}{|l|}{ Model 4: combined model } \\
\hline Step 1: child's age & -0.04 & $-0.39(0.86)$ & -2.10 to 1.31 & 0.18 & $5.94^{* *}$ \\
\hline Inconsistent discipline- APQ & $0.30^{* *}$ & $0.33(0.10)$ & 0.13 to 0.53 & - & \\
\hline Don't skils-DPICS & $0.19^{*}$ & $7.73(3.88)$ & 0.04 to 15.43 & - & \\
\hline Oppositionality/aggression—DBDRS-PV & 0.17 & $1.28(0.71)$ & -0.13 to 2.69 & - & \\
\hline Step 2: don't skills $\times$ inconsistent discipline & $-0.25^{*}$ & $-2.67(0.93)$ & -4.50 to -0.83 & 0.25 & $4.99 m$ \\
\hline Don't skills $\times$ oppositionality/aggression & -0.08 & $-4.80(5.33)$ & -15.38 to 5.77 & - & - \\
\hline Inconsistent discipline $\times$ oppositionality/aggression & -0.42 & $-0.19(0.16)$ & -0.50 to 0.12 & - & - \\
\hline
\end{tabular}

associated with more sleep habit problems. Higher kvels of inconsistent discipline and "Don't" skills were also associated with more skep habit problems; however, this finding was qualified by an interaction such that the association between "Don't" skills and elevated sleep habit problems was only evident at low levels of

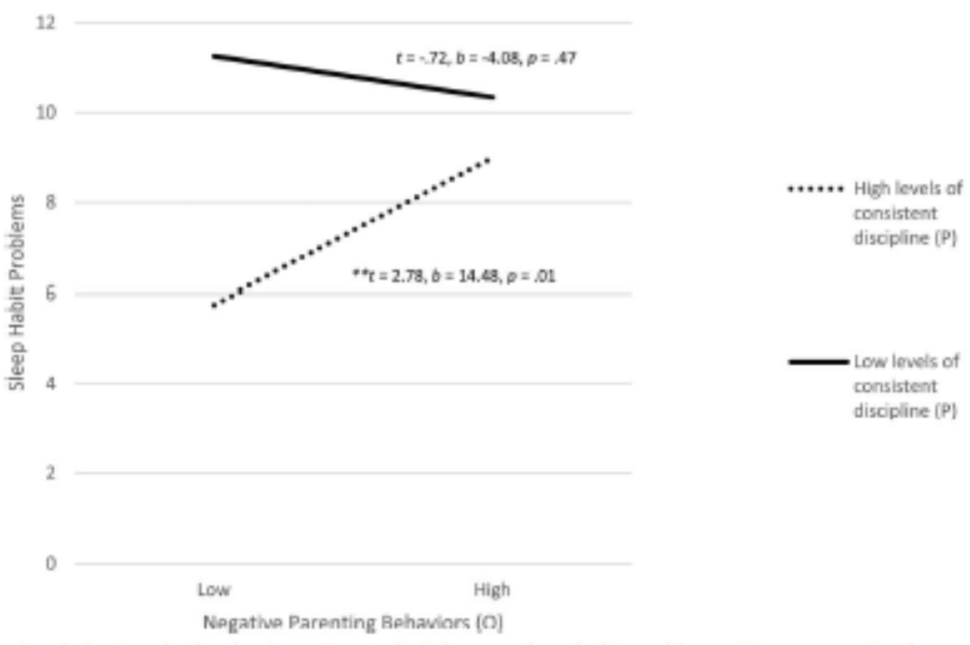

Figure 1. Negafive parenting behaviors by leveds $d$ consistent discipline on sleep habit problems. ${ }^{* *} p<0.01 .0$, observational measure; $P$, parent report measure High leves of consistert discipline are indicative of a low score on the inconsistent discipline subscale of the Alabama Parenting Questionnaire $\left(A P Q^{34}\right)$. Negative parenting behaviors are reflective of the number of "Don't" skills measured through the Dyadic Parent-Child Interaction Coding System (DPICS ${ }^{\text {T5 }}$ ). 
Table 4. Model for Predicting Night Waking Problems

\begin{tabular}{|c|c|c|c|c|c|}
\hline & $\beta$ & B (SE b) & $95 \%$ CI & Model $\mathbf{R}^{2}$ & F Test Statistic \\
\hline \multicolumn{6}{|l|}{ Model 1: parenting questionnaires } \\
\hline Child's age & 0.03 & $0.15(0.47)$ & -0.77 to 1.08 & 0.04 & 1.54 \\
\hline Parenting stress-PSI & $0.22^{*}$ & $0.03(0.01)$ & 0.00 to 0.05 & - & - \\
\hline Inconsistent discipline—APQ & -0.02 & $-0.02(0.06)$ & -0.14 to 0.11 & - & - \\
\hline Positive parenting factor-APQ & 0.14 & $0.06(0.04)$ & -0.01 to 0.13 & - & - \\
\hline \multicolumn{6}{|l|}{ Model 2: parenting observation } \\
\hline Child's age & 0.08 & $0.43(0.52)$ & -0.60 to 1.47 & 0.03 & 1.22 \\
\hline Do skills-DPICS & 0.07 & $3.79(5.61)$ & -7.32 to 14.89 & - & - \\
\hline Don't skills-DPICS & -0.11 & $-2.58(2.72)$ & -7.98 to 2.81 & - & - \\
\hline \multicolumn{6}{|l|}{ Model 3: dimensions of DBDs } \\
\hline Child's age & 0.02 & $0.12(0.46)$ & -0.80 to 1.03 & 0.04 & 1.33 \\
\hline Inattention-DBDRS-PV & 0.08 & $0.33(0.46)$ & -0.58 to 1.24 & - & - \\
\hline Hyperactivity/impulsivity—DBDRS-PV & -0.22 & $-0.92(0.50)$ & -1.91 to 0.07 & - & - \\
\hline Oppositionality/a ggress ion-DBDRS-PV & 0.19 & $0.87(0.44)$ & -0.01 to 1.74 & - & - \\
\hline
\end{tabular}

inconsistent discipline. In terms of night waking problems, there was only an association with parenting stress, whereas the other parenting factors and disruptive behavior and attention disorder symptoms were unrelated. These findings are further discussed below.

Consistent with our hypothesis, we found that oppositionality/aggression but not attention-deficit hyperactivity disorder (ADHD) symptoms were associated with more sleep habit problems but not with night waking problems. Our results are in agreement with previous work demonstrating that conduct problems are associated with global reports of sleep problems, particularly bedtime resistance. ${ }^{15}$ Conversely, Smedje et al. ${ }^{15}$ found hyperactivity to be associated with tossing and turning during sleep and sleepwalking. Potential reasons for the discrepancy between our findings and those of Smedjet et al. ${ }^{15}$ are the differences in study samples. The sample in the study by Smedje et al. ${ }^{15}$ consisted of children aged 6 to 8 years, whereas our study used a younger sample (mean age, 5 years). Additionally, Smedje et al. ${ }^{15}$ used a community sample in which $8 \%$ to $9.8 \%$ of children met the criteria for disruptive behavior disorders, whereas $87 \%$ of our at-risk/ clinical sample met the criteria for ADHD, oppositional defiant disorder [ODD], or a combination. In fact, $46.6 \%$ of our sample met the diagnostic criteria for ADHD and ODD. Given the significant comorbidity in our sample, children with a comorbid ADHD and ODD presentation may be the ones that are experiencing greater sleep problems than those with a more pure ADHD or ODD presentation. This is consistent with the study by Aronen et al., ${ }^{8}$ who found that nonmedicated children with ODD and ADHD skept less (measured by actigraphy) than children without comorbid ADHD and matched controls.

Vol. 39, No. 8, October/November 2018
Consistent with previous work, ${ }^{21}$ we found that greater levels of inconsistent discipline practices and "Don't" skills, respectively, were associated with more sleep habit problems. Our findings extend such literature by being the first to show these associations in a sample of preschool-aged children with at-risk or clinical elevations of externalizing symptoms. Inconsistent discipline may be particularly important among preschoolaged children with disruptive behavior and attention disorders given that early conduct problems remain stable into school-age. ${ }^{18}$ Parents who engage in inconsistent discipline practices may have a difficult time implementing appropriate sleep hygiene and therefore have children with more sleep problems. It is important to note that these parenting factors did not rekte to children's night waking problems. Therefore, it may be plausible that environmental factors, such as discipline strategies, play a larger role before sleep onset, whereas factors more closely related to biological processes (i.e., stress and cortisol) are more related to disruptions during sleep (i.e., night wakings).

Consistent with the aforementioned theory and previous work, ${ }^{24}$ we found that greater levels of parenting stress were associated with night waking problems. These findings extend the work of Yürümez and Kulıç, ${ }^{12}$ who found that children with ADHD had more night wakings than children without ADHD. Parenting stress is particularly relevant among young children with disruptive behavior and attention disorders because parental perception of their child being behaviorally difficult can increase parental stress. ${ }^{37} \mathrm{~A}$ possible explanation for why parenting stress may directly increase children's night waking problems relates to the shared vulnerability of the stress response because it relates to skep functioning ${ }^{26}$ For example, significant work has documented 
the role of cortisol in modulating sleep. ${ }^{38}$ Adults with higher levels of sleep disruptions exhibit increased cortisol levels. ${ }^{25}$ Similarly, El-Sheikh et al. ${ }^{39}$ found that children with sleep disturbances had significantly increased waking cortisol compared with children without sleep difficulties. When viewed in conjunction with studies documenting the heritability of the stress response and hypothalamic-pituitary-adrenal (HPA) axis reactivity, ${ }^{26}$ it may be the case that parents who are stressed have children who are stressed and consequently have more night waking problems. Future studies should measure cortisol reactivity in children with disruptive behavior and attention disorders and their parents to better examine the relationship between parenting stress and children's sleep functioning.

Furthermore, there was an interaction between "Don't" skills and inconsistent discipline in predicting sleep habit problems; parents who engage in less inconsistent discipline and higher usage of "Don't" skills have children with more sleep habit problems. The findings of this study contribute to and extend the literature by showing the importance of discipline strategies in combination with parent-child interactions. Specifically, the benefits of being a consistent parent seem to be partially nullified by engaging in negative parent-child interactions because it relates to sleep habits. However, our findings show that at high levels of inconsistent discipline, such parent-child interactions do not seem to have an impact on sleep habit problems. This theoretical sleep model is consistent with behavioral parental training interventions such as parent-child interaction therapy (PCIT), which focus on improving inconsistent discipline and parent-child interactions to reduce externalizing behavior problems. However, reduction of sleep problems through the use of PCIT has not been examined. Future work should examine whether improving parent-child interactions has an effect on children's sleep functioning.

\section{Study Limitations}

Limitations of this study should be noted. First, this study used a crossectional design, which limits the directionality of our findings. For example, given the bidirectional nature of parent-child interactions and inconsistent discipline as well as sleep problems and parent-child interactions, it is plausible to have a model in which chikdren's sleep problems lead to more negative parent-child interactions, which in turn contributes to greater inconsistent discipline or vice versa. Thus, future work needs to implement a longitudinal design to test these crosslagged associations between inconsistent discipline, parent-child interactions, and children's sleep habit problems to determine whether parent-child interactions mediate the association between inconsistent discipline and sleep problems. Second, we used an atrisk/clinical sample, and it remains unclear whether our findings would generalize to a community sample. Parenting stress may be a more important mechanism

618 Disruptive Behavior Problems, Parenting, and Slesp among an at-risk/clinical sample in which stress levels tend to be elevated compared with a typically developing sample. ${ }^{40}$ Third, this sample is primarily Hispanic and low income, which may also affect the generalizability of the findings. However, this may also be viewed as a strength because the literature on minorities and dis ruptive behavior and attention disorders, sleep, and parenting is limited. Finally, our measure of children's sleep problems was a questionnaire completed by the child's parent, and therefore, children's sleep problems might be inaccurately reported. However, previous research has found that the CSHQ is clinically useful in screening for sleep problems. ${ }^{5}$ Future studies should include objective sleep measures such as actigraphy or polysomnography. Similarly, to avoid potential positive rater bias, future work shoukd include observed parenting stress measures such as cortisol kevels.

\section{Clinical Implications}

In terms of the clinical implications of our findings, first, mental health providers should be aware of not only the welldocumented comorbidity between ADHD and children's sleep problems ${ }^{10}$ but perhaps be as equally aware of the relationship between ODD symptoms and sleep habits in young children. Second, if sleep problems are present and impaining, behavioral sleep interventions (e.g., extinction, positive routines, and parent education) should be provided. Third, within the parenting domain, our findings highlight the potential role of parenting stress, parent-child interactions, inconsistent discipline, and sleep functioning. Thus, when teaching healthy sleep habits, treatment may be more effective if parents are also addressing their own stress levels. Within the behavioral literature, Kazdin and Whitley ${ }^{41}$ did find that improving parental stress had a direct effect on improving children's behavioral outcomes. Similarly, within a preschool sample, the Triple P-Positive Parenting Program with the enhanced program that addressed stress resulted in a more reliable change in children's behaviors than did the standard program. ${ }^{42}$ Future work should examine whether providing an intervention that addresses parenting stress levels can directly improve children's sleep outcomes. Furthermore, parenting strategies should be considered when families present for sleep problems. Interventions that include improving discipline strategies and parent-child interactions should be recommended accordingly. In fact, sleep interventions that incorporate positive parent-child interactions (e.g., faded bedtime with response cost) have been found to improve sleep problems. ${ }^{43}$

\section{CONCLUSIONS}

Despite the aforementioned limitations, this study is the first to our knowledge to examine the associations between disruptive behavior and attention disorder symptoms, parenting factors, and chikdren's sleep problems within a sample of preschool-aged children with or

Journal of Developmental \& Behavioral Pediatrics 
at risk for disruptive behavior and attention disorders. Future research should include longitudinal analysis to confirm the directionality of our findings. Additionally, as children with disruptive behavior and attention disorders get older, treatment modalities often include medications, which on their own can also effect sleep functioning. Thus, it will be important to examine how parenting factors may either attenuate or enhance children with disruptive behavior and attention disorders medication-related sleep problems. Nevertheless, our study points to the significant clinical implications of parents jointly addressing parenting factors, sleep, and behavior problems among preschool-aged children.

\section{REFERENCES}

1. Barkley RA. Attentiondefic Hypenactitity Disorder: A Handbook for Dragnosis and Theatment. New York, NY: Guilfort Publications; 2014

2. Ros R, Graxiano P. Social dysfunction among children with ADHD a metasanalytic review. J CZ̈n Cbild Adolese Psycbol. 2017;1-23.

3. Goodlin-Jones BI, Sitnick SI, Tang K, et al. The Children's Sleep Habits Questionnaire in toddlers and preschool children. $J$ Dev Behav Pediatr. 2008,29:82-88.

4. Archbold KH, Pituch KJ, Panah P, et al. Symptoms of sicep disturbances among children at two general pediatric clinics $J$ Pediatr. 2002;110:97-102.

5. Touchette É, Petit D, Séguin JR, et al. Associations between Seep duration patterns and behavioral/cognitive functioning at school entry. \$lepp. 2007;30:1213-1219.

6. Mayes SD, Calhoun SL, Bixler EO, et al. ADHD subtypes and comorbid anxiety, depression, and oppositionaldefunt disorder. differences in sleep problems, J Pediatr Psychol. 2008;31:328-337.

7. Lavigne JV, Arend R, Rosenbaum D, et al. Sleep and behavior problems among preschoolers. J Dev Bebav Pediatr. 1999;20. 164169.

8. Aronen ET, Lampenius T, Fontell T, et al. Sleep in children with disruptive behavional disorders. Behav Sleep Med. 2014;12:3733888.

9. Constantin E, Low NC, Dugas E, et al. Association between childhood sleep-disordered breathing and disnuptive behavior disorders in childhood and adolescence. Behav Sleep Med. 2015; 13:462-65i.

10. Corkum P, Tannock R, Moldofsky H. Skep disturbances in children with attentiondeficit/hyperactivity disorder. J Am Acad Cbild Adolese Psjebiatry: 1998;37637-616.

11. Owens J, Nobile C, Spirito A. Prevalence and types of Seep disturbances in school-aged chililen: valibtion of a parental report, Children's Sleep Habits Questionnaire.J Sleep Res. 1998; 7(supp1 2):391.

12. Yürümez E, Kilaç BG. Rebationship between skeep problems and quality of tife in children with ADHD. JAften DXsont. 2016,20:34-40.

13. Shamahan L, Copeland WE, Angold A, et al. Sleep problems predic and are predicted by genenalized anxiety/depression and oppositional defiant disorder. JAm Acad Cbilk Adolese Pyycbiatry. 2014.53:550-558.

14. Corkum P, Moldofsky H, Hogg-Johnson S, et al. Sleep problems in children with attentiondeficit/hyperactivity disorder: impact of subtype, comorbidity, and stimubant medication. J Am Acad CDId Adolesc Pjuch katr. 1999;38:1285-1293.

15. Smedje H, Broman JE, Hetta J. Associations between disturbed sleep and behwioural difficulties in 635 children aged six to eight years a study based on parents' perceptions. Fur Cbild Adolese Psycbiatry. 2001;10:1-9.

16. Calhoun SL, Femandez-Mendora J, Vgontzas AN, et al. Behavional profiles associated with objective skeep duration in young children

Vol. 39, No. 8, October/November 2018 with insomnia symptoms. J Abnorm Obill Psycbol. 2017;45:357341.

17. Iglowstein I, Jenni OG, Molinari L, et al. Sleep duration from infancy to adolescence: reference values and generational trends. Pediatrics. 2003;111:302-307.

18. Campbell SB, Shaw DS, Gilliom M. Early extemalizing behavior problems: toddlers and preschookers at risk for later makdjustment. Dev Psycbopatbol. 2000;12:467-i888.

19. Bell BG, Belsky J. Parents, parenting, and children's seep problems: exploring reciprocal effects. If $J$ Dev Psychol. 2008,26: 579-593.

20. Mindell JA. Seeping Tbrougb tbe Nigbt: How Infants, Todalers, and Tberir Panents Can Get a Good Nigbrs Sleep (Reutsed). New York, NY: HarperCollins; 2005.

21. Thunstròm $M$. Severe sleep probiems among infants in a normal population in Sweden: prevalence, severity and correlates. Acsa Paediatr, 1999;88 1356-1363.

22. Meltzer I, Mindell JA. Rebationship between child seep disturbances and maternal skeep, mood, and parenting stress: a pilot study. $J$ Fam Psychol. 2007;21:67.

23. Bernier A, Bébnger MÉ, Bordeleau $S$, et al. Mothers, fathers, and toddlers parental poychosocial functioning as a context for young children's sleep. Dev Psychol. 2013;19:1375.

21. Sadeh A, Raviv A, Gruber R. Sleep patterns and sleep disruptions in schoolage children. Dev Psychol. 2000;36:291.

25. Buckley TM, Schaterg AF. Review: on the interactions of the hypothabamic pituitaryadrenal (HPA) axis and seep: nomal HPA axis activity and circadian thythm, exemplary seep disorilers. $J$ Gin Endocribol Metab. 2005;90:3106-3114.

26. Karlén J, Frostell A, Theodorson E, et al. Maternal influence on child HPA axis: a prospective studly of cortisol levels in hair Pediatrics. 2013;132×1333-e1340.

27. Jones HA, Epstein JN, Hinshuw SP, et al. Ethnicity as a moderator of treatment effects on parent: child interaction for children with ADHD. J Aten Drsord. 2010;13:592-600.

28. Graziano PA, Stevec J, Hart K, et al. Improving school readiness in preschoolers with behavior problems: results from a summer treatment program. J Paychopatbol Behav Asse'ss. 2014;36.555569 .

29. Shaffer D, Fisher P, Lucas CP, et al. NIMH Diagnostic Interview Schedule for Children Version IV (NIMH DISCIV): description, differences from previous version and reliability of some common diagnoses. J Am Acad Cbild Adolesc Psychiatry. 2000; 39:28-38.

30. Keenan K, Wakschug LS, Danis B, ct al. Furt her evidence of the reliability and validity of DSM-FV ODD and $C D$ in preschool children. J Am Acad Cild Adolese Psycbiatry. 2007;46:457468.

31. Pelham WE, Gragy EM, Greensbale KE, et al. Teacher ratings of DSM-IIIR symptoms for the disruptive behavior disorders. $J$ Am Acad Cikd Adolesc Psycbiatry. 1992;31:210-218.

32. Pillow DR, Pelham WE, Hora B, et al. Confirmatory factor analyses examining attention deficit hyperactivity disorder symptoms and other childhood disruptive behavions. J Abnorm Crill Psycbol. 1998;26:293-309.

33. NICHI SECCYD-Wisconsin Children's sleep habits questionnaire (abbreviated). Avaibible at: h tp $/ /$ njajap.org/wpcontent/uploadls/ 2016/01/ChildrensSlecpHabitsQuestionmaire.paf. Accessed April $15,2014$.

34. Shelton KK, Frick PJ, Wootton J. Assessment of parenting practices in families of elementary schoolage children. $J$ Gin Cbild Adolexe Psychol. 1996,25:317-329.

35. Eyberg S, Nelson M, Duke M, et al. Manual for the Dyadic ParentChild Interaction Coding System. 3rd ed. University of Florid: Parent-Child Interaction Therapy Web site; 2004. Avaibble at: htp $/ /$ www pcit.org. Accessed April 15, 2014.

36. Abidin R. Parenting Stress Index.Manual. 3ril ed. Odessa, FL: Psychological Assessment Resources; 1995.

Copyright $\oplus$ ans Wolters Wura Health, Inc. All rights resaved.

619 
37. MaSh E, Johnston C. Determinants of parenting stress: illustrations from families of hyperactive children and Emilies of physically abused children. $J$ Gin Crild Psycbol. 1990;19:313-328.

38. Steiger A. Sleep and the hypothabmopituitary-adrenocortical system. Sleep Med Ren 2002,6:125-138.

39. ElSheikh M, Buckhalt JA, Keller PS, et al. Children's objective and subjective sleep disruptions: links with aftemoon cortisol levels Health Psycbol. 2008;27:26-33

40. Podolski CI, Nigg JT. Parent stress and coping in relation to child ADHD severity and associated child disruptive behavior problems. J Clin Cbild Psychol. 2001;30:503-513.
41. Kazdin AE, Whitley MK. Treatment of parental stress to enhance therapeutic change among children referred for aggressive and antisocial behavior. $J$ Consult Clin Psjebol. 2003;71:504.

42. Sanders MR, Markie Dedds C, Tully LA, a al. The triple PPositive Parenting Programr a comparion of enhanced, sandard, and self directed behuvional family irrervention for perents of children with early onset conduct priblems, J Consult Cin Psychol. 2000,6862i-6io.

43. Mindell JA, Kuhn B, Lewin DS, et al. Behavioral treatment of bedtime problemsand night wakings in infants and young children. Skep. 2006;29:1263-1276. 
VITA

\section{JENNIER COTO}

EDUCATION

2003-2007

2007-2010

2015

2013 to present

2019 to present
B.A, Psychology

University of Miami,

Coral Gables, Florida

M.S.Ed., Mental Health Counseling

University of Miami,

Coral Gables, Florida

M.S., Psychology

Florida International University

Miami, Florida

Doctoral Candidate in Psychology

Florida International University

Miami, Florida

Predoctoral Clinical Child and Pediatric Psychology Intern University of Miami Miller School of Medicine Coral Gables, Florida

\section{PUBLICATIONS AND PRESENTATIONS}

Coto, J., Smith, N., Farias, A., \& Garcia, D. (2020). Post-Concussive Symptoms and Their Association with Follow-up Care in a Sample of Young Children with TBI. Poster presented at the Society of Pediatric Psychology Annual Conference, Dallas, TX: March 2020 .

Coto, J., Pulgaron, E.R., Graziano, P., Bagner, D.M., Villa, M., \& Delamater, A.M. (2018). Parents as role models: Associations between parent and young children's weight, dietary intake, and physical activity in a minority sample. Maternal and Child Health Journal, 23(7), 943-950.

Coto, J., Garcia, A., Hart, K., \& Graziano, P. (2018). The associations between disruptive behavior problems, parenting factors and sleep problems among young children. Journal of Developmental and Behavioral Pediatrics, 39(8), 610-620.

Coto, J., Garcia, A., Matthysse, A., Haddadian, P., Coccia, C., \& Graziano, P. (2018). Predicting child weight outcomes within a behavioral health intervention: The role of 
parental feeding practices. Poster presented at the Society of Pediatric Psychology Annual Conference, New Orleans, LA.

Graziano, P., Coto, J., Garcia, A., Matthysse, A., Haddadian, P., Dick, A., \& Coccia, C. (2018). Self-regulation of food intake in young children with and without attentiondeficit/hyperactivity disorder. Poster presented at the Society of Pediatric Psychology Annual Conference, New Orleans, LA.

Coto, J., Garcia, D., Kuluz, J., \& Bagner, D. M. (2016). Post-Injury symptoms and their association to behavior problems in a pediatric TBI sample. Presented at the Society for Research in Child Development Biennial Meeting, Austin, TX.

Coto, J., Pettit, J., Schmelzer, A., Wernovsky, G., \& Bagner, D. M. (2016). Mental health service seeking, referrals, and usage in parents of children with congenital heart defects. Presented at the National Conference in Clinical Child and Adolescent Psychology Meeting, Lawrence, KS.

Pulgaron, E.R., Hernandez, J., Dehaan, H., Patiño-Fernández, A., Carrillo, A., Sanchez, J., \& Delamater, A.M. (2015). Clinic attendance and health outcomes of youth with type 2 diabetes Mellitus. International Journal of Adolescent Medicine and Health, 27(3): 271-274. doi: 10.1515/ijamh-2014-0021

Patiño-Fernández, A., Hernandez, J., Villa, M., \& Delamater, A.M. (2013). School-based health promotion intervention: Parent and school staff perspectives. Journal of School Health, 83(11): 763-770. doi: 10.1111/josh.12092

Hernandez, J., Crumpton, M., \& Mitchell, M.J. (2012). New onset of overweight and obesity in a cohort of urban elementary school students. Presented at the American Psychological Association Annual Convention. Orlando, FL.

Daigre, A., Hernandez, J., Malik, J., Pulgaron, E.R., Patiño-Fernández, A., Sanchez, J., Wilson, D., \& Delamater, A. (2011). Physical activity and risk for metabolic syndrome in young minority children. Presented at the Society of Behavioral Medicine Annual Convention. New Orleans, LA.

Pulgaron, E. R., Hernandez, J., DiJohn, T., Fernandez, D., Villa, M., Patiño-Fernández, A., Sanchez, J., \& Delamater, A. (2009). A School-based intervention focused on obesity prevention for young hispanic students. Presented at the American Psychological Association Annual Convention. San Diego, CA. 